\title{
Isolated unilateral disk edema
}

This article was published in the following Dove Press journal:

Clinical Optometry

26 July 2011

Number of times this article has been viewed

\section{Paul Varner \\ John J Pershing VAMC Poplar Bluff, MO, USA}

Correspondence: Paul Varner I500 NWestwood Boulevard, Poplar Bluff, MO 6390I, USA

Fax + I 573778 4I64

Email paul.varner@va.gov
Abstract: Isolated unilateral disk edema is a familiar clinical presentation with myriad associations. Related, non-consensus terminology is a barrier to understanding a common pathogenesis. Mechanisms for the development of disk edema are reviewed, and a new framework for clinical differentiation of medical associations is presented.

Keywords: disk edema, axoplasmic flow, clinical multiplier, optic neuritis, ischemic optic neuropathy, papilledema

\section{Introduction}

The history of the study of acute optic neuropathies is a rich one that dates back to the mid-nineteenth century. Following the independent invention of the direct ophthalmoscope by Charles Babbage in $1847^{1}$ and Hermann von Helmholtz in 1851, ${ }^{2}$ observers were provided with the clinical means to directly view and to accurately differentiate pathological from the non-pathological optic nerve heads $(\mathrm{ONH})$ in vivo - apart from immersion of eye in water. ${ }^{3}$ A perusal of Sir Stewart Duke-Elder's extensive review of this and associated topics provides a sense of the depth of interest in the topic and the range of publications on the various disease presentations and associations up to the early 1970s. ${ }^{4}$ Electronic literature searches via PubMed show no gaps in clinical interest in the topic from the mid-1960s through the present time.

Neurological and ophthalmologic research during the past four decades has allowed for better discernment of underlying pathophysiology and greatly expanded knowledge on clinical associations in acute optic neuropathy. However, some presentations of unilateral disk edema remain ambiguous in their clinical presentations, and there has been no decision tree published to date which serves to aid clinicians in the differentiation of clinical associations of such cases. Terminology involving unilateral disk edema has served only to confound its description. It is the intention of this paper to streamline some of these issues.

\section{Limits of terminology}

It must be conceded that the highly varied terminology used in reference to unilateral disk edema was, and continues to be, a barrier in its study. This "confusion of nomenclature" was succinctly stated as early as $1950^{5}$ and has not been rectified to date - an unfortunate state given the relative commonality of this finding in clinical practice. ${ }^{6}$ In fact, until relatively recently, virtually all cases of disk edema were referred to as "optic neuritis." Because of these limits, reviews of the literature prove to be extremely 
challenging and have surely resulted in inadvertent omissions of important papers. Table 1 demonstrates the wide variety of terms related to optic disk edema.

Furthermore, literature searches for the various terms are complicated by the discovery that some of the same presentations are reported under different names. For example, postoperative disk edema following trabeculectomy can be found under searches for both "unilateral optic disc edema"7 and "unilateral papilledema." " Meanwhile disk edema related to sarcoidosis can be found under "unilateral papillitis," "optic neuropathy,"10,11 optic nerve granuloma, ${ }^{12}$ and optic glioma. ${ }^{13}$ Literature inconsistencies can also be demonstrated by a consideration of the use of the generic term "acute optic neuropathy." This phrase has been applied in cases of atrophic, ${ }^{14}$ compressive, ${ }^{15}$ inflammatory, ${ }^{16}$ and neoplastic ${ }^{17}$ optic diseases.

Two items become apparent during an initial review of Table 1. The first involves usage of "disc" and "disk." These represent two alternative spellings for the same, descriptive word, although without apparent consensus in the literature. In British English "disc" is the usual spelling, but American English favors "disk." PubMed usage tends to favor the British spelling with approximately $60 \%$ of the entries being "optic disc edema" and about 40\% spelled "optic disk edema." Between $30 \%$ and $40 \%$ of entries are redundant between the two spellings (unfortunately, there is not $100 \%$ redundancy). The same issue applies to alternative spellings of "ischaemic" and "papilloedema" (British) versus "ischemic" and "papilledema" (American). Literature searches omitting alternative spellings will unintentionally miss certain citations.

The second feature of note in Table 1 is the application of the term "amblyopia" to acute optic neuropathies. Fortunately, the use of this term seems to have fallen into disuse with modern terminology. Amblyopia is defined as "poor vision caused by abnormal development of visual areas of the brain in response to abnormal visual stimulation during early development." 18 Organic etiologies - such as from nutritional, tobacco, or toxic sources - when applied to acquired optic neuropathies, are inconsistent with current definitions of amblyopia and are, in fact, atrophic conditions. ${ }^{19,20}$ It is prudent to finally remove these terms from discussion of acute optic neuropathies.

This paper will focus solely on isolated unilateral optic disk edema. Many cases of bilateral disk edema have also been reported in the literature, and while there is some overlap of associated conditions between unilateral and bilateral disk edema, a decision tree has been published for consideration
Table I Optic nerve-related terms associated with disk edema

Acute optic neuropathy

Anterior ischaemic/ischemic optic neuropathy (AION)

Arteritic AION

Non-arteritic AION choked

Disc/disk

Diabetic papillopathy disc/disk

Edema disc/disk swelling

Ischaemic/ischemic optic neuropathy

Neuromyelitis optica (Devic's disease = autoimmune inflammation of spinal cord and optic nerve)

Neuroretinitis $=$ inflammation of optic nerve (primary) and retina

(secondary)

Nutritional optic neuropathy/amblyopia

Optic disc/disk edema

Optic disc/disk swelling

Optic disc/disk vasculitis

Optic nerve head swelling

Optic neuritis

Anterior optic neuritis $=$ papillitis

Posterior optic neuritis = retrobulbar optic neuritis (no special

designation)

Optic perineuritis = inflammation of the optic nerve sheath

(perioptic neuritis)

Papilledema/papilloedema

Papillitis

Papillopathy

Papillophlebitis (big blind spot syndrome)

Papilloretinitis = inflammation of the papilla (primary) and retina (secondary)

Perineuritis $=$ inflammation of the optic nerve sheath

Perioptic neuritis $=$ inflammation of the optic nerve sheath

Phlebitis of the optic disc/disk

Posterior ischemic/ischaemic optic neuropathy

Pseudopapilledema/pseudopapilloedema pseudopapillitis

Pseudopapillitis vascularis

Pseudo-optic neuritis

Retinopapillitis = inflammation of the retina (primary) and papilla

(secondary)

Swollen optic disc/disk

Tobacco optic neuropathy/amblyopia

Toxic optic neuropathy/amblyopia

Note: *The three most commonly used terms appear in boldface.

of bilateral disk edema ${ }^{21}$ and that presentation will not be considered here. Occasionally an ostensibly bilateral case will manifest as a unilateral case and these special cases ("unilateral papilledema") will be discussed in turn.

Additionally, part of the differentiation among the various acute optic neuropathies depends on associated ocular findings (such as retinitis, vasculitis, orbital findings). These conditions will not be considered for this review. Thus having removed bilateral and compound ocular findings from discernment of this clinical picture, the three most commonly used terms in the medical literature of acute optic neuropathies are anterior ischemic optic neuropathy (AION), optic neuritis, 
and papilledema (these terms appear in boldface in Table 1).

Until the early twentieth century, all cases of optic nerve head swelling were termed "optic neuritis," using the suffix "-itis" in its classic characterization of "swelling" (ie, inflammation). It was only in 1908 that the term papilledema was introduced by Sir John Parsons to indicate that the disk swelling resulted etiologically from increased intracranial pressure. ${ }^{4}$ Although etymologically the term "papilledema" would be strictly defined as edema of the papilla or optic nerve head - in other words of ONE optic nerve - this convention was not followed. Use of the term became linked to increased intracranial pressure and bilaterality from that time forward.

Thus the confusion began a century ago with the definition of papilledema taking on inherent bilaterality - and understandably so. By virtue of the anatomical continuation of both optic nerve sheaths to the brain meninges, increases in intracranial pressure (ICP) would be expected to manifest as bilateral disk edema. Therefore the term "papilledema" was linked to bilateral findings early in its study. Because it does so often affect both eyes and is clinically found to be bilateral, the term "bilateral" is often dropped from its discussion - apparently assumed by authors to be an unnecessary redundancy. "Unilateral papilledema" seems to be consistently and fully specified as needed in the literature, although exceptions still remain.

By consensus, papilledema continues to be defined as swelling of the optic nerve head related to increased ICP. ${ }^{22}$ Unfortunately, this usage has not been universally applied across time, geography, or medical disciplines. The term "bilateral papilledema" was frequently used both in the past $^{4,23,24}$ and is still used today, ${ }^{25-32}$ although probably more often than not "bilateral papilledema" is referred to as just "papilledema." So widespread is this usage of "papilledema" by itself that hearing "bilateral papilledema" almost sounds like redundant terminology.

The diagnostic dilemma that the terminology of "papilledema" presents was succinctly pointed out as early as $1939 .{ }^{33}$ To further confound this issue, there are numerous cases of "unilateral papilledema" cited in the literature, $8,34-42$ as well as additional cases of true unilateral papilledema which are reported under other names: "optic disc edema," "unilateral swollen disc," 43 "unilateral disk edema,"44 and "unilateral optic disk swelling," 45 even though these latter cases were, in fact, all related to increased ICP.

It is generally felt that the majority of unilateral papilledema cases represent asymmetric, bilateral papilledema, ${ }^{46}$ with most of these cases related to idiopathic intracranial hypertension, space-occupying lesions, and hemorrhages. ${ }^{47}$ In the absence of predisposing factors like Foster Kennedy syndrome or a space-occupying lesion physically located closer to one optic nerve than the other, the occurrence of unilateral papilledema is most likely due to anatomical variations between the two eyes that lead to asymmetric presentations. Asymmetric variations in glial tissue at the optic nerve heads ${ }^{4}$ dissimilar optic nerve sheaths, ${ }^{48,49}$ anatomic collagen or elasticity variations, ${ }^{49}$ and/ or the effects of asymmetric ICP at the optic nerve heads ${ }^{50}$ may all play a part in this paradoxical process of a unilateral presentation from a systemic - and what should intuitively be a bilateral - condition. Congenital anomalies, compression, and adhesion of the optic nerve sheath have also been suggested as being contributory to this finding. ${ }^{39}$

So, a view of unilateral disk edema does not rule out increased ICP, although papilledema with such a finding would essentially become a diagnosis of exclusion due to its rarity, and it should be accompanied by systemic symptoms. ${ }^{51}$ It has been reported that $<2 \%$ of neurosurgical patients manifested unilateral papilledema; ${ }^{52}$ it would seem likely to be an even rarer finding in the general ophthalmic clinical population.

In recent decades the definition of optic neuritis has changed slightly from "involvement of the optic nerve resulting from any inflammation, demyelination or degeneration" 53 to "an inflammatory, demyelinating disease of the optic nerve." ${ }^{54}$ This subtle shift appears to indicate that optic neuritis is no longer considered a degenerative process. Interestingly enough - and to add further confusion - optic neuritis seems to be applied to several specific cases of acute disk edema: those associated with multiple sclerosis, those involving "parainfectious" sources, cases of "paraneoplastic" disk swelling, and most cases involving children, although there are still widespread variations in terminology, even within those groups. And while demyelination can be confirmed pathologically, that determination in a clinical setting is difficult.

To further confuse research on this topic, many case reports refer only to "optic neuritis," and may omit further important anatomical differentiation between anterior or retrobulbar forms - Duke-Elder's text is a prime example. ${ }^{4}$ The addition of "unilateral" and "bilateral" descriptors would further help to eliminate confusion about the exact specification of the examination findings in these cases.

By the time that Duke-Elder conducted his final, major review of optic neuropathies in 1971, "papilledema" and "optic neuritis" ("inflammation of the optic nerve") were 
long considered to be two separate entities, but the term ischemic optic neuropathy was new, being coined only in the $1960 s,{ }^{55}$ with the "anterior" descriptor added by Hayreh in $1974 .{ }^{56}$ Thus the past 35 years have seen the addition of the third, common term applied to presentations of acute disk edema.

Strictly speaking, specific diagnoses of AION or optic neuritis cannot always be made in the absence of thorough understanding of the patient's medical history or without the results of ancillary testing. At an initial presentation, the most accurate description may simply be "unilateral disk edema." By corollary no new diagnosis of papilledema could be made with the patient sitting in the examination chair on the initial visit, without knowledge of intracranial processes. At an initial visit in the clinical setting, "bilateral optic disk swelling" 57,58 or "bilateral disk edema" 59 would be the more clinically accurate descriptors until the results of ancillary testing become known. But this demonstrates continued lack of consensus on use of these terms and suggests the need for uniform nomenclature in this clinical area.

At this point, the only way to resolve this terminology conflict would be to merely refer to swollen optic nerves as either "unilateral or bilateral disk edema related to ..." (if known). A "meshing" framework works well for the complexities of uveitis ${ }^{60}$ and would likely serve well in this clinical domain as well.

While much attention has been paid to the nosology of disk edema, it is extremely important to realize that each of these conditions is actually the result of a single, pathophysiological pathway.

\section{Pathophysiology of disk edema}

Autoregulatory processes tightly control blood supply to the eye within the blood-ocular barrier. ${ }^{61,62}$ Disruption in autoregulation leads to an unstable $\mathrm{O}_{2}$ supply for the $\mathrm{ONH},{ }^{63}$ and inadequate $\mathrm{O}_{2}$ perfusion of the $\mathrm{ONH}$ results in a localized, relative ischemia. Although localized ischemia can give rise to inflammation, ${ }^{64-66}$ inflammation has also been discovered to cause ischemia, ${ }^{67,68}$ so this is not a unidirectional biological process. ${ }^{69}$ This tandem process of ischemia/inflammation is further compounded by the normal aging processes of (1) decreased alveolar function in the lungs and (2) senescent arteriosclerosis of arteries. So it does not seem surprising that ischemic events at the optic nerve increase in frequency with age.

Anatomically speaking, the optic nerve is not actually a single "nerve," but rather a central nervous system (CNS) tract. ${ }^{4,70}$ Approximately 1-1.5 million myelinated ganglion cell axons converge on each optic nerve head (papilla). ${ }^{71-74,}$ These first-order neurons become demyelinated after passing through the lamina cribrosa and extend posteriorly from the globe to form the "optic nerve." It is at the lamina cribrosa that ganglion cell axons are most vulnerable to pathological insult ${ }^{75}$ due to the rigidity of Bruch's membrane surrounding its prelaminar portion. ${ }^{76}$ It is at this "choke point" that the physiological integrity is most susceptible to damage because a modest amount of edema is more likely to result in a significant amount of morbidity.

After physiological damage, retinal ganglion cells (RGC) within the optic nerve - like neurons elsewhere in the $\mathrm{CNS}^{77,78}$ - die by the process of apoptosis, a programmed cell death. ${ }^{79}$ Although RGC death may not occur immediately after the pathological insult, ${ }^{80}$ eventually, apoptosis appears to be a final common pathway for all optic neuropathies. ${ }^{81}$ After axonal injury, spontaneous regeneration of neurons is quite limited in humans. ${ }^{82,83}$ Endogenous repair of damaged CNS tissue is incomplete and typically does not restore function. ${ }^{84,85}$ Exogenous repair via gene therapy is only in its earliest stages at this time ${ }^{86}$ and the concept of neuroprotection has not yet been successfully demonstrated in neurological or ophthalmic disease. ${ }^{87,88}$

So, if RGC injury is considered irreversible at this time, then why do some patients (eg, those with "optic neuritis") typically recover function while others do not (eg, those with "AION")? It may be conjectured that those ONHs that recover functional vision must not have been pushed past the biological "apoptotic point of no return." Perhaps given the general observation that younger patients fare better than older ones with disk edema (discussed below), there may be another age-related phenomenon at play because the same underlying process accounts for the appearance of disk edema in patients of all ages.

Against this background, a look at the basic pathophysiology of disk edema is warranted. Regardless of terminology (eg, AION, optic neuropathy, papilledema, papillitis, papillopathy), the appearance of disk edema is the result of a single pathophysiological process. ${ }^{76,89,90}$ Namely, it is the interruption of axoplasmic flow along the optic nerve. ${ }^{91}$ Contributing components of this process include toxic calcium channel overload, ${ }^{92}$ inhibition of cytochrome oxidase, ${ }^{93}$ mitochondrial impairment, ${ }^{19,94}$ and vascular non-perfusion. ${ }^{56}$ Despite various terminologies, any edematous disk is the result of this final common pathway. It is a nonspecific response $^{95}$ to just a few stimuli (to be discussed further on), but which has many reported associations. In this sense, disk edema is analogous to choroidal neovascularization 
or conjunctival hyperemia - a secondary effect rather than a primary cause.

Axoplasmic transport involves the physical movement of various neuron microcomponents (such as proteins, mitochondria, lipids, waste products) between neuron cell bodies and axons in two directions. ${ }^{96}$ Movement occurs within axon microtubules in both kinesin-mediated anterograde (toward the brain) and dynein-mediated retrograde (toward the eye) directions, and involves fast and slow transport mechanisms. ${ }^{97}$ Microtubules are part of the axon cytoskeleton and integral to vesicular transport among other biological functions. ${ }^{98}$ This is a vital physiological function in neurons because axons can be orders of magnitude larger in length than the cell bodies and obviously depend on the physiological integrity of the microtubule system to transport vital cellular components across those relative distances. Also, microtubule transport is critical for axon physiology, as proteins are not synthesized in those parts of the cell. The impaired movement of mitochondria (ATP [cellular energy] producers) from either genetic predispositions (such as Leber's ${ }^{99}$ ) or acquired factors (inflammation) further degrades axonal transport in a negative feedback loop. ${ }^{94}$ Ischemia/reperfusion insults also contribute to vascular sources of degradation in axoplasmic transport. ${ }^{100}$

Because of the anatomical constraints mentioned above, axoplasmic flow is most constricted at the level of the lamina cribrosa. As the accumulation of mitochondria in axons is more common in unmyelinated than in myelinated axons in the optic nerve, ${ }^{101}$ mitochondrial dysfunction may play a critical role in the disruption of axoplasmic flow as well. The end result of all these factors is axoplasmic flow stasis, which results in axonal edema. ${ }^{76}$ The cumulative effect of axonal edema is observed clinically as disk edema. It is important to bear in mind that this clinical presentation appears regardless of associated conditions.

\section{Clinical associations}

After substantial literature review of the topic, it became apparent that attempts to revise optic disk edema associations by pathological classifications would be unsuccessful. Historical classification of disease has always been arbitrary, with difficulties classifying conditions with mixed mechanisms further limited by current understanding of pathogenesis and the limits of terminology: such as genetic versus metabolic, inflammatory versus autoimmune. In light of complex pathophysiological processes, single-factor hypotheses require compelling evidence, and are largely lacking for this clinical entity.
The list of ocular and systemic conditions associated with isolated unilateral disk edema (UDE) is rather lengthy, especially given the hundreds - if not thousands - of case reports that have accumulated during the past century and a half. Schemes of differential diagnosis for disk edema have typically been along classic nosologies in both neurological ${ }^{102}$ and ophthalmologic ${ }^{103,104}$ literatures. However, in the pregenomic era these groupings did not rely on pathophysiological bases for disease. Because of sheer numbers, it also seems likely that some reported associations between disk edema and systemic conditions are purely coincidental.

Classic examples of confounding associations with disk edema surrounded reproductive matters. Use of oral contraceptives, pregnancy, lactation, and postpartum recovery were all linked to disk edema at one time. However, each has been largely discounted as associative. Oral contraceptives were not shown to cause ocular abnormalities when prospectively studied in Great Britain. ${ }^{105}$ Cases of disk edema during pregnancy were found to be related to underlying diabetes, ${ }^{106,107}$ pre-eclampsia ("toxemia of pregnancy" in older literature), ${ }^{108}$ idiopathic intracranial hypertension or cerebral venous thrombosis. ${ }^{109}$ Cases observed during lactation were discovered to occur in women who ultimately developed demyelinating disorders, ${ }^{110,111}$ and peri/postpartum cases were ultimately related to cerebral venous thrombosis ${ }^{112}$ or undiagnosed demyelinating disease. ${ }^{113}$ In retrospect, these cases demonstrate the power of coincidence in patients with genetic predispositions. ${ }^{109}$ The lesson learned is that a mechanism underlying the association must be feasible, be biologically tenable, and be both repeatable and demonstrable to establish causation.

Another example of a confounder is provided by an association of UDE with spinocerebellar degeneration. Although bilateral optic atrophy has been associated with this condition ${ }^{114}$ - and this makes biological sense: a neurological, retrograde, atrophic process being observed directly in the eyes - the one case associated with disk edema in the literature ${ }^{115}$ would seem to be more coincidental than directly related to this condition. The pathophysiology of the process (genetic overexpression of SCA1 leading to neurotoxic production of ataxin- ${ }^{116}$ ) lends biological credence to a metabolic/toxic mechanism of inflammation, but the dearth of cases of UDE would seem to support such a presentation as being coincidental versus an expected part of the natural pathophysiological process.

Ultimately, progress in genetic sequencing will likely allow for more accurate pathological associations to be made. With the completion of the sequencing of DNA by the Human 
Genome Project in 2003, it became apparent that human disease could be classified based on gene networks. ${ }^{117}$ Underlying molecular pathophysiologies could be identified and used to replace classic delineation of diseases based on observational analysis of symptoms and ancillary testing. In essence, diseases can now be classified by pathophenotypes in networks based on underlying genetic proximity. All areas of medicine are sure to benefit from future research in these areas.

To date, a "single gene defect" related to acute optic neuropathy has been identified only for Leber's hereditary optic neuropathy (LHON), although various OPA genes have been linked to other inherited forms of optic neuropathies without acute presentations. ${ }^{86}$ Meanwhile, PAX genes are also recognized for their involvement in visual system development, ${ }^{118}$ and polymorphism of the endothelial nitric oxide synthase gene has been studied in context of AION. ${ }^{119}$ Research into genetic links for other acute optic neuropathies remains in its early stages, but may become telling as new evidence emerges. It should be pointed out that pathological loci represent susceptibility only (nature) and not necessarily that the appropriate environmental trigger will be present to elicit the disease state (nurture). Both these factors must be present for a disease to manifest itself. Whether a single locus for susceptibility to disk edema exists is yet to be determined.

Based on the concept of the final common pathway, the review of multitudinous case reports involving disk edema suggests that a new framework for classifying these cases is warranted. From the standpoint of a mechanistic approach, it would appear that there are just a few broad sources for the interruption of axoplasmic flow. Rather than grouping by disease category, classifying cases of optic disk edema by pathophysiology seemed to simplify this topic and also to suggest a useful mechanism for clinical work-up of patients who present with ambiguous forms of this condition.

\section{Sources of axoplasmic flow stasis in unilateral disk edema}

The three mechanisms for the interruption of axoplasmic flow that emerged from this review are: (1) inflammation, (2) mass effects, and (3) alterations in the pressure gradient across the lamina cribrosa. These are schematically depicted in Figure 1. All involve interference with normal microtubule physiological functioning and eventually the appearance of disk edema. As with any classification scheme, there will continue to be instances of mixed mechanisms and even alternative mechanisms for the same source, but it is intended that this framework will serve as a point of departure for future investigations into this topic. It must also be recognized that cases of UDE which cannot be explained in terms of pathophysiology of axoplasmic flow need further, careful consideration before direct associations can be made.

Causality is agreed to exist on the macro level when a final outcome depends on the occurrence of a primary event, that the primary event precedes the final outcome, and that contiguity links the two events. ${ }^{120}$ To suggest that a certain condition "causes" disk edema is a premature assumption at this time. (Note: posterior ciliary artery [PCA] infarction may be said to "cause" AION, but what causes PCA infarction?) Rather, various "risk factors" for the development of disk edema have been reported. It may be more useful to think of conditions associated with disk edema as being "clinical multipliers" of the underlying pathophysiological process, ie, those things that exacerbate the disruption of axoplasmic flow, rather than determinants of causality. At this stage of understanding, it seems unlikely that disk edema (effect) is the result of a single antecedent (cause). In this context a multiplier can thus be considered any pathologic stressor to homeostasis.

Within this framework, multipliers can be aligned within the three mechanisms as enumerated above. The focus is on pathophysiology, if known, or deduced if unknown or not reported. Again, the relative rarity of many of these processes may in fact suggest coincidence rather than another multiplier - rare events being extremely difficult to study systematically. And some multipliers may even be excluded from further association with UDE.

Papilledema (unilateral or bilateral disk edema related to increased ICP) is an exception to the discussion of multipliers. Causality for papilledema relates to the increase in ICP inside the optic nerve sheath ${ }^{121}$ with a secondary mechanical compression $^{93,122}$ on the ONH that results in axoplasmic flow stasis and ultimately disk edema. Further discussions of papilledema per se remain beyond the scope of this paper.

As illustrated in Figure 1, normal physiological integrity of $\mathrm{ONH}$ axoplasmic flow can be interrupted by three pathological mechanisms. In inflammation, axonal swelling or impingement on axons from surrounding extracellular fluid (ECF) can interrupt microtubule transport. Both endogenous and exogenous sources can cause inflammation, ${ }^{123}$ and both processes occur within the optic nerve. Mass effects can involve either infiltrative or compressive lesions, which result in a mechanical increase in axon density; the net result 


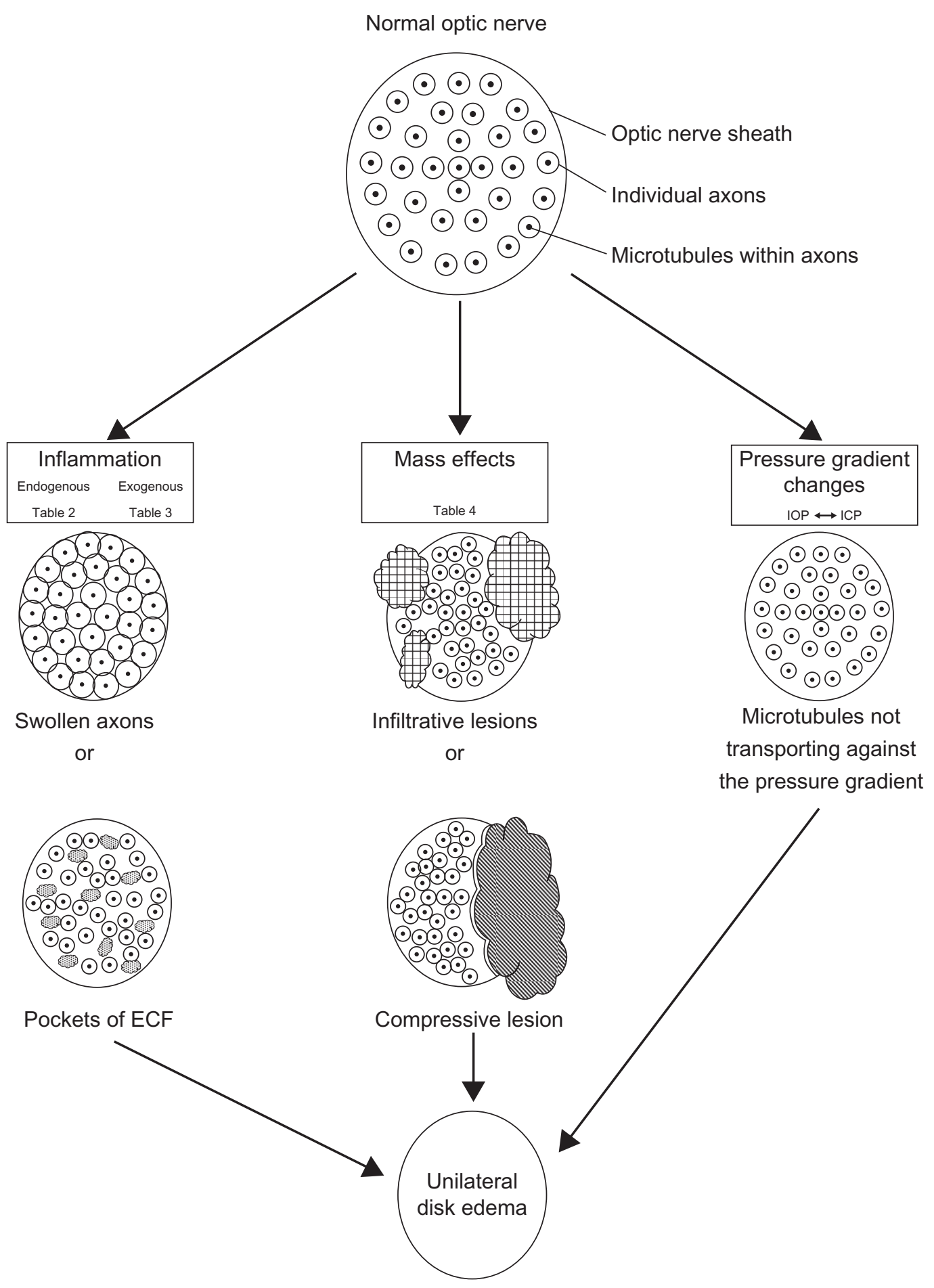

Figure I Schematic representations of pathophysiological sources for unilateral disk edema. Views are stylized cross-sectional views of the optic nerve. Abbreviations: ECF, extracellular fluid; ICP, intracranial pressure; IOP, intraocular pressure.

of which is impingement of microtubules. Changes in the intraocular pressure/intracranial pressure gradient across the ONH can result in disk edema when intraocular pressure (IOP) -related and unilateral papilledema when ICP-related. Figure 1 further delineates these sources of UDE.

\section{Inflammation}

By far the most common source of disruption of axoplasmic flow - inflammatory stimuli ("inducers") - can be from either endogenous (internally derived) or exogenous (externally derived) sources. 


\section{Endogenous}

Endogenous sources of inflammation can be the result of nonvascular and vascular (more common) antecedents.

\section{Nonvascular}

Nonvascular sources include those genetic defects in which mutations disallow normal biochemistry or metabolism to occur within the neurons of the optic nerve. The clearest example from this group is $\mathrm{LHON}$ in which point mutations in mitochondrial DNA complex I genes lead to defective oxidative phosphorylation and increased activity of reactive oxygen species (ROS). ROS are highly reactive and can readily damage biological molecules, ${ }^{124}$ leading to axonal swelling and mechanical blockage of axoplasmic flow, ONH edema, eventual apoptosis of retinal ganglion cells, and ultimately atrophy of the optic nerve (references in Table 2).

"Metabolic" (ie, relating to metabolism, the whole range of biochemical processes that occur within a living organism ${ }^{132}$ ) associations are harder to define due to overlapping pathophysiological processes. However, as growing evidence from different disciplines seems to point toward an inflammatory component for metabolic stresses, ${ }^{133-142}$ these associations will be considered in the context of inflammation.

\section{Vascular}

Vascular sources represent the largest grouping within inflammatory multipliers for axoplasmic stasis. These can be further subdivided into hematological, hemodynamic, and tissue-based factors.

Hematological Hematological changes are those changes directly involving alterations in blood composition and include alterations in oxygen saturation of the blood (from either decreased $\mathrm{O}_{2}$ availability in the blood or decreased $\mathrm{O}_{2}$ carrying capacity of the blood). Increases in blood viscosity can also lead to vascular-mediated inflammation as a source of disk edema. Osmotic and $\mathrm{pH}$ changes in blood composition will also be considered.

\section{Changes in $\mathbf{O}_{2}$ saturation}

Low $\mathrm{O}_{2}$ availability

Hypoventilation in pulmonary disease

The association of bilateral papilledema with respiratory failure was first reported in $1933 .{ }^{143}$ The prevalence of papilledema with respiratory diseases - and obstructive sleep apnea in particular - has been noted to be low, ${ }^{144}$ and the association with acute optic neuropathies has been
Table 2 Cases of unilateral disk edema (UDE) related to endogenous sources of inflammation

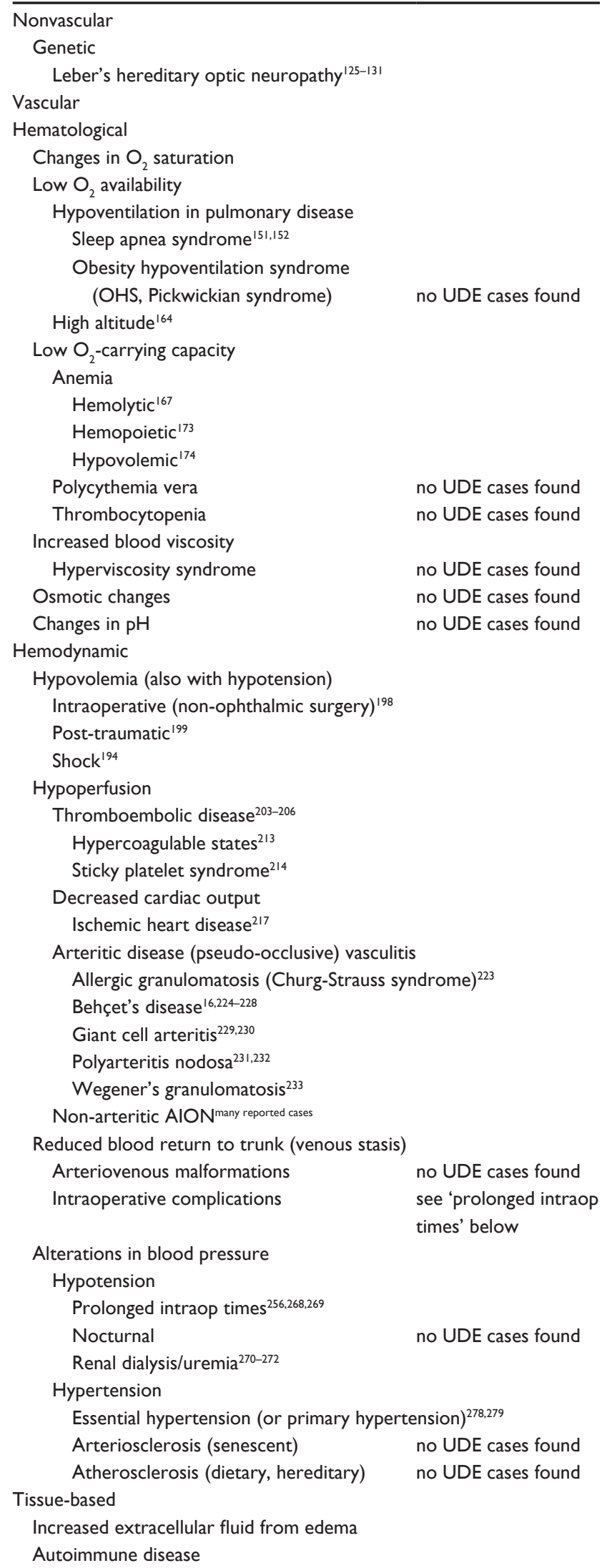

(Continued) 
Table 2 (Continued)

\begin{tabular}{|c|}
\hline Neonatal onset multisystem inflammatory disease (NOMID) ${ }^{294,295}$ \\
\hline Relapsing polychondritis ${ }^{296}$ \\
\hline Systemic lupus erythematosus ${ }^{297,298}$ \\
\hline Local vasculitides \\
\hline Optic disk edema with macular star (ODEMS) ${ }^{299,301}$ \\
\hline Optic disk vasculitis (ODV) $)^{302,304}$ \\
\hline Sarcoidosis (no optic nerve head granulomas) \\
\hline Other biochemical alterations in cells \\
\hline Decreased nitric oxide concentration \\
\hline Hypercholesterolemia ${ }^{242}$ \\
\hline Glucose exchange dysfunction \\
\hline Diabetes mellitus $318-321$ \\
\hline Damage from reactive oxygen species (demyelinating diseases) \\
\hline $\begin{array}{l}\text { Acute inflammatory demyelinating polyradiculoneuropathy } \\
\text { (AIDP, Guillain-Barre syndrome) })^{326}\end{array}$ \\
\hline Multiple sclerosis ${ }^{54}$ \\
\hline Neuromyelitis optica (of Devic) (,327,328 $^{4}$ \\
\hline
\end{tabular}

summarized previously. ${ }^{145,146}$ As it relates to the ONHs, the end result of sleep apnea is decreased oxygen saturation and promotion of ROS with end organ hypoxia. ${ }^{147}$ The prevalence of sleep apnea in AION has been reported to be in the $70 \%-80 \%$ range. ${ }^{148,149}$

As with any systemic antecedent, bilateral disk edema would be expected as it relates to pulmonary disease, and is reported as such for both adults ${ }^{150}$ and children. ${ }^{31}$ However, rare cases of UDE related to sleep apnea syndrome have been reported (Table 2), thus suggesting hypoventilation as a multiplier for UDE.

Obesity hypoventilation syndrome (OHS, Pickwickian syndrome) is the combination of obesity with hypoxia during sleep and hypercapnia during waking hours, and is often found with sleep disorders. ${ }^{153,154}$ The associated changes in blood chemistry result in respiratory acidosis, and combined with the ischemic state of the $\mathrm{ONH}$, apparently lead to disk edema that is unrelated to changes in ICP. Several cases of bilateral disk edema have been reported in OHS, ${ }^{155-158}$ but no unilateral cases of UDE related to OHS were uncovered during this review.

Long-term hypercapnia in and of itself has also been reported as another likely contributor to the development of disk edema, ${ }^{159}$ and may in fact, be an overlooked and underreported multiplier.

Although obesity has not been directly associated with UDE, it might be expected to be a cardiovascular morbidity multiplier due to its pathophysiological relationship to diabetes, dyslipidemia, hypertension, atherosclerosis and secondary hypoxia. ${ }^{160}$ The excess secretion of adipokines associated with obesity has been implicated in the apoptotic process, ${ }^{161}$ however, and would seem to be a biological contributor to any vascular component of optic neuropathies. Its relationship to OHS would also seem to support this supposition.

Hypobaric states

Interestingly enough, disk edema has been reported in highaltitude climbers returning from hypobaric atmospheric conditions. At depressed barometric pressures, the resultant low peripheral $\mathrm{O}_{2}$ saturation creates decreased perfusion pressure at the $\mathrm{ONH}$ and hypoxic-induced increases in brain volume resulting in increased ICP, which are the presumed sources for this finding. ${ }^{162,163}$ Again, due to the nature of this environmentally induced, systemic physiological change, it would be expected to be a bilateral finding, although one case of UDE in isolation has been reported (Table 2). In general, this should be considered an extremely rare, multiplying factor.

\section{Low 02 carrying capacity}

\section{Anemia}

Anemia is the most common hematologic disorder and results in end organ hypoxia. The broad origins of anemia are from hypovolemia (volume loss), hemolysis (excess blood cell destruction), and ineffective hematopoiesis (red blood cell [RBC] production). Disk edema related to hypovolemic anemia following surgery ${ }^{165}$ and gastrointestinal bleeding ${ }^{166}$ have been reported. UDE in hemolytic anemia associated with interferon treatment has also been noted. ${ }^{167}$ Acute optic neuropathies linked with hematopoietic forms of anemia have been described for iron-deficiency anemia, ${ }^{168}$ sickle cell disease, ${ }^{169}$ and aplastic anemia. ${ }^{170-172}$ However, nearly all of these cases have been bilateral cases - as would be expected in a systemic vascular disorder - and typically with concurrent retinal findings. Rare cases of UDE associated with anemia are referenced in Table 2, although their report indicates that low $\mathrm{O}_{2}$ carrying capacity may be viewed as a UDE multiplier. These cases also demonstrate the potential for mixed mechanisms leading to the disruption of axoplasmic flow and subsequent development of disk edema.

Polycythemia vera

Polycythemia vera (elevated RBCs/hematocrit) creates a milieu of increased blood viscosity and hypervolemia, which decreases blood flow and tissue perfusion, creating a relative ischemia of end organs. ${ }^{175}$ Associated bilateral disk edema has been reported with the condition,,$^{30,176,177}$ but no cases of UDE were discovered for this review.

Thrombocytopenia

Thrombocytopenia (low platelets) has been linked to bilateral disk edema ${ }^{178}$ and disk edema in conjunction with other 
ophthalmic findings. ${ }^{179}$ However, no UDE cases associated with thrombocytopenia have been reported to date.

\section{Increased blood viscosity}

Hyperviscosity syndromes also limit oxygenation of blood and have been associated with bilateral disk edema, ${ }^{180,181}$ but not yet UDE. The intriguing finding of high blood viscosity in patients with $\mathrm{AION}^{182,183}$ coupled with the suggestion that the disk edema can be improved with plasmapheresis ${ }^{184}$ or hemodilution therapy ${ }^{185}$ suggest interesting avenues for further exploration of this potential multiplier of acute optic neuropathies.

\section{Osmotic changes}

Osmotic changes in blood have been linked to simian models of disk edema; ${ }^{186}$ however this mechanism is via pressure gradient changes across the lamina cribrosa (to be discussed) and is unrelated to hematological alterations. This osmotic phenomenon has not been associated with disk edema in humans at the time of writing.

\section{Changes in $\mathbf{p H}$}

Blood acidosis leads to arteriolar vasoconstriction, which causes decreased perfusion of end tissue and ultimately leads to relative ischemia. It might be predicted that lower blood $\mathrm{pH}$ would create another multiplier for the development of disk edema. While oxygenation of the $\mathrm{ONH}$ does seem to be more regulated by carbon dioxide concentrations, ${ }^{187}$ oxygen levels at the $\mathrm{ONH}$ remain relatively unaffected by changes in $\mathrm{pH} .{ }^{188}$ So it does not seem likely that the $\mathrm{pH}$ change in and of itself can cause optic disk edema, but may be another multiplier - similar to the acidosis that develops in cases of methanol toxicity ${ }^{93}$ or $\mathrm{pH}$ change associated with profound trauma. ${ }^{189} \mathrm{In}$ sum, the $\mathrm{pH}$ of arterial blood does not seem to be a factor in the development of disk edema.

Hemodynamic Hemodynamic events leading to disk edema include hypovolemia (loss of blood volume leading to decreased ONH perfusion), hypoperfusion (decreased blood supply to ONH from macro- or microvascular causes), decreased blood return to the trunk, and changes in systemic blood pressure: hypotension (causing decreased $\mathrm{ONH}$ perfusion) and hypertension (related to increased peripheral resistance to available blood supply).

\section{Hypovolemia}

Hypovolemia is a vascular disorder in which there is a decrease in the volume of circulating blood and is the result of several different processes. Intraoperative non-ophthalmic surgical settings, ${ }^{190,191}$ post-traumatic, ${ }^{189,192,193}$ and shock- induced forms of hypovolemia ${ }^{194-196}$ have been linked to the development of acute optic neuropathy, although again, due to the systemic nature of hypovolemia, the majority of these cases are bilateral.

Ischemic forms of optic neuropathy are the most common cause of visual compromise following non-ophthalmic surgery. ${ }^{197}$ (The mechanism for the development of disk edema in ophthalmic surgical settings differs from systemic procedures and will be discussed in turn). Those few cases of UDE related to hypovolemia from various causes are listed in Table 2. It should also be noted that hypovolemia is often associated with hypotension ${ }^{200,201}$ and anemia, ${ }^{194}$ so several multipliers for the reduction of perfusion pressure at the $\mathrm{ONH}^{192,202}$ and subsequent development of UDE are likely at play.

\section{Hypoperfusion}

Hypoperfusion of the $\mathrm{ONH}$ can occur with thromboembolic disease, decreased cardiac output, and arteritic (vasculitis) and non-arteritic diseases.

\section{Thromboembolic disease}

The association of embolic disease with the development of disk edema is one fraught with contradictions. The association of UDE with an embolism has been occasionally reported in the medical literature (references in Table 2); however, this would seem to be an exceedingly rare clinical finding ${ }^{207,208}$ and may be more within the realm of coincidence. Screening of non-arteritic AION patients for prothrombotic/ thrombophilic factors has also proved inconclusive, with different authors both recommending ${ }^{209,210}$ and discounting ${ }^{211,212}$ this practice.

The reports of hypercoagulable states ${ }^{213}$ and sticky platelet syndrome ${ }^{214}$ with cases of UDE suggest that rarer forms of thromboembolic disease may be more likely to be associated with disk edema. However, these remain rarely reported clinical findings and merit further ophthalmic study on the generalizability of these potential multipliers to other cases of UDE.

As an interesting footnote to ocular hypoperfusion, although not occurring as UDE in isolation, ischemia of the $\mathrm{ONH}$ is thought to be the source of disk edema in central retinal artery occlusion (CRAO, most often an embolic disease of the eye) and is observed in about $20 \%$ of those cases. $^{215}$

\section{Decreased cardiac output}

Decreased cardiac output has been suggested as a contributor to the pathogenesis of the non-arteritic AION form of disk edema. ${ }^{216}$ As congestive heart failure has also been linked to 
the development of AION, ${ }^{217}$ these findings suggest that decreased cardiac output and the secondary effect on the ischemic milieu of the $\mathrm{ONH}$ may be another multiplying factor for the development of UDE in addition to the other, recognized hemodynamic factors.

Indirect evidence for the contribution of decreased cardiac output may be found in the context of the definitive treatment for ischemic heart disease: cardiopulmonary bypass surgery. With an incidence of one AION per 1100 cases of cardiopulmonary bypass surgery ${ }^{218}$ versus an estimated incidence of one per 2000 cases of postcataract extraction $\mathrm{AION},{ }^{219}$ the inference is that the physiological circumstances for developing AION are more common in patients undergoing bypass surgery than for those undergoing cataract extraction. This observation, coupled with other clinical reports of disk edema following coronary artery bypass surgery, ${ }^{220,221}$ suggest that this multiplier may also be more common than previously believed.

Arteritic disease (vasculitis)

Systemic vasculidites are widely known to have ocular findings ${ }^{222}$ and are considered "pseudo-occlusive" due to the inflammatory nature of the occlusions. In pseudo-occlusive diseases, active inflammation in the form of vasculitis effectively reduces the lumen of the affected artery and can result in complete occlusion. ${ }^{4}$ Inflammatory occlusion of the posterior ciliary arteries ensures axoplasmic flow stasis through space-occupying, ischemic and/or inflammatory mechanisms. This "arteritic" form of AION has been observed in allergic granulomatosis (Churg-Strauss syndrome), Behçet's disease, giant cell arteritis (GCA), polyarteritis nodosa, and Wegener's granulomatosis (references in Table 2). The important relationship between GCA and arteritic AION has been discussed extensively elsewhere. ${ }^{234-239}$ Work-up of patients with UDE to address GCA will be addressed later in this paper.

Non-arteritic disease

Non-arteritic AION (NAION) has been comprehensively reported in the ophthalmic literature. It is the most common cause of acute optic neuropathy in older patients, ${ }^{240}$ although it is not uncommon in patients younger than $50 .{ }^{241}$ This term was introduced in 1960s, ${ }^{55}$ and was refined in the $1974,{ }^{56}$ although this condition may have been recognized and reported as early as 1924 by Uthoff. Briefly, NAION is an acute ischemic event involving the short posterior ciliary arteries (PCA) that nourish the optic nerve head. ${ }^{242,243}$ Specifically, "when perfusion pressure in PCA falls below intraocular pressure, infarction of the optic nerve head results." 244
Many associations of systemic diseases with this disk edema have been reported for NAION;241,245-249 however, it may be more useful to think of NAION as the pathological outcome of several concurrent, multiplying pathophysiologies. ${ }^{250,251}$

Regardless of association, it is the ischemic environment at the lamina cribrosa which leads to interruption of axoplasmic flow and eventual development of observable disk edema. It has also been suggested that NAION may be a form of compartment syndrome, in which increased pressure (presumably from local inflammation) within the confined anatomical space of the lamina impairs blood supply. ${ }^{252}$

\section{Reduced blood return to the trunk}

Venous stasis (reduced blood flow from the head to the trunk) has been noted intraoperatively for both prone and Trendelenburg positions and has been linked to acute optic neuropathies. ${ }^{253}$ Venous stasis with hypovolemia has also been linked to postsurgical optic neuropathies, ${ }^{190,254,255}$ although separating these antecedents from hypotension may not be possible. Intraoperative anemia is yet another confounder for acute optic neuropathies following surgical cases. ${ }^{256-258}$ In these cases it seems reasonable that several multipliers have converged to create the untoward physiological event in predisposed individuals.

Cavernous sinus dural arteriovenous malformations can create another environment for venous stasis in the head. Disk edema has been reported as a part of the exam findings for these rare conditions ${ }^{259,260}$ although UDE in isolation has not. Arteriovenous malformations, therefore, are most likely not multipliers for UDE.

\section{Alterations in systemic blood pressure}

Hypotension (decreased blood flow through arteries and veins)

Systemic hypotension leads to decreased ONH perfusion, and has been implicated in acute optic neuropathies in nocturnal states, ${ }^{261,262}$ postoperative settings, ${ }^{263,264}$ and cardiopulmonary arrest. ${ }^{244}$ Normal diurnal fluctuations in blood pressure may also contribute to ischemic events; ${ }^{265}$ however it also seems likely that systemic hypotension is a contributing multiplier of a mixed-mechanism event. ${ }^{266}$ Chronic hypoperfusion of arterioles supplying the ONH may predispose susceptible ONHs to acute ischemic optic neuropathies. ${ }^{267}$

Prolonged intraoperative times (in which blood pressure is iatrogenically lowered) have been associated with UDE (Table 2), although possibly combined with anemia or other 
vasculopathic risk factors ${ }^{263}$ in another mixed mechanism pathophysiology.

Hypotension during hemodialysis is common, ${ }^{270}$ and this association with AION has been reported (references in Table 2), although concurrent vascular pathologies - uremia, hypertension, atherosclerosis, anemia - are also often found in these patients. ${ }^{271,273} \mathrm{AION}$ has also been noted in cases of peritoneal dialysis with hypovolemia felt to be the source of the ocular complication. ${ }^{274}$ Intracranial venous hypertension leading to retrograde blood flow, and ultimately decreased cranial blood outflow, has also been implicated in these processes. ${ }^{275}$ It seems likely that axoplasmic flow stasis in these patients is multifactorial and also includes pressure gradient mechanisms (to be discussed), with hypotension serving as a multiplier for biological outcomes.

Hypertension (increased peripheral vascular resistance to blood supply)

The case for causation between primary (essential) hypertension and disk edema is not clear-cut. A connection between hypertension and UDE has been reported, ${ }^{276-279}$ but seems more likely related to a combination of hemodynamic factors than a single process. Increased peripheral vascular resistance within the $\mathrm{ONH}$ vasculature - which is exacerbated by atherosclerotic and arteriosclerotic changes - due to endothelial dysfunction and decreased nitric oxide production (thereby limiting local vasodilation) would lead to loss of ocular blood flow and decreased perfusion of the $\mathrm{ONH}$ and eye..$^{280-283}$ The ensuing localized, relative ischemia/inflammation could alter microtubule function via this theorized pathway.

Although arteriosclerosis and atherosclerosis have been considered risk factors in the development of AION, ${ }^{248}$ these contributors to decreased end-organ perfusion should remain just that: multipliers of effect, not instigators of causation. No cases of UDE have been associated solely with arteriosclerosis or atherosclerosis. As a final note, it has been concluded that atherosclerosis of the carotid artery is not involved in the pathogenesis of nonarteritic AION. ${ }^{284}$

Tissue-based factors Tissue-based factors of vascular-based inflammation are those events which prevent the target tissue $(\mathrm{ONH})$ from using a normal and available $\mathrm{O}_{2}$ supply (ie, decreased $\mathrm{O}_{2}$ absorption).

\section{Increased ECF from edema}

Autoimmune disease

Autoimmune disease occurs when the body's immune system responds to self-antigens. ${ }^{285}$ Many diseases are considered to be autoimmune processes, however a definitive list of these diseases remains elusive, and separating some disease processes - for example autoimmune and demyelinating mechanisms - may be entirely arbitrary. The common cause hypothesis suggests that many of these conditions might ultimately be found to have a single cause: a yet-unspecified defect in the immune system. ${ }^{286} \mathrm{~A}$ similar theory has also been applied to the class of white spot syndromes of the retina. ${ }^{287}$ Allergic, infectious, toxic, and other conditions once classified separately may in fact prove to be immunological in origin. Future genetic studies may provide greater insight into the potential of this interesting theory.

The pathophysiology of the disruption of axoplasmic flow and the development of disk edema seems to be related to the local immune reaction in the optic nerve that disrupts extracellular fluid dynamics. The accumulation of inflammatory extracellular fluid in the limited space of the ONH ultimately impinges on the microtubules and leads to axonal edema - another compartment syndrome.

From an ophthalmic standpoint, there are myriad associations with autoimmune diseases. Specific antibodies have been reported with various optic neuropathies, including antinuclear antibodies ${ }^{288}$ and anticardiolipin antibody. ${ }^{289-291}$ However, in some cases, an underlying disease is not specifically determined and the acute optic neuropathy has been termed simply "autoimmune optic neuropathy." 292,293 After reviewing the literature, there appear to be very few instances of isolated UDE associated with autoimmune diseases. Those cases discovered for this review involve neonatal onset multisystem inflammatory disease, relapsing polychondritis, and systemic lupus erythematosus (Table 2). Again, due to the nature of systemic pathology, the expectation would be for bilateral ophthalmic involvement when it does occur. As with other cases of unilaterality, it must be conjectured that there are specific anatomical variations "protecting" the fellow nerve from simultaneous involvement.

\section{Local vasculitis}

Optic disk edema with macular star (ODEMS) and optic disk vasculitis (ODV) are two special cases of local vasculitis within the ONH, but which can present as a UDE. The development of disk edema in these cases is also possibly the result of mixed mechanisms: increased ECF as a result of the inflammation and/or vascular wall inflammation impingement on $\mathrm{ONH}$ axons.

ODEMS is a rare, primary optic neuropathy ${ }^{299}$ that can present as a UDE due to the 1- to 2-week delay between the development of disk edema and the involvement of the macula. ${ }^{300}$ Although often considered an idiopathic finding, 
this condition has also been associated with several infectious causes. ${ }^{301}$

ODV is another rare, primary optic neuropathy that appears clinically the same as other disk edemas. ${ }^{302-304}$ The differential diagnosis of ODEMS and ODV with other associations will be discussed in the second part of this series.

Sarcoidosis

Sarcoidosis is an idiopathic granulomatous multisystem disease involving hyperimmune responses to unknown agents. ${ }^{305,306}$ Disk edema can be related to one or more of three sources: increased ICP (papilledema), inflammation within the $\mathrm{ONH}$, or granulomatous infiltration of the $\mathrm{ONH} .{ }^{48}$ Unilaterality of findings would tend to suggest a more infiltrative process; however, this is not always the case. Variable outcomes after corticosteroid treatment ${ }^{307}$ would suggest alternative mechanisms other than direct inflammation when patients respond poorly to this mode of therapy.

Conversely, when sarcoidosis manifests primarily as a pulmonary disease, reduced lung function can result in low $\mathrm{O}_{2}$ availability. However, hypoventilation would seem to be more a multiplier than a primary cause in these cases of optic neuropathy. Optic nerve disease has been estimated to occur in $5 \%$ of sarcoid patients ${ }^{308}$ and can be observed clinically either as disk edema, optic atrophy (presumably the end result of disk edema), or ONH granuloma. ${ }^{309,310}$ Within the context of sarcoidosis, the development of UDE is probably related to mixed mechanisms. Reports of UDE associated sarcoidosis (without granulomas) are given in Table 2.

\section{Biochemical alterations at the cellular level}

Decreased nitric oxide concentration

UDE has been reported against a background of hypercholesterolemia. ${ }^{242}$ The mechanism for the development of disk edema in this instance is suggested to be related to endothelial vasodilator impairment in the short posterior arteries. Endothelial compromise interferes with the nitric oxide function, ${ }^{313}$ a vasodilator whose biological effect culminates in increased tissue perfusion. The resultant ischemia and inflammation within the ONH can then compromise axoplasmic flow. This could be another common, yet overlooked clinical multiplier.

\section{Glucose exchange dysfunction}

UDE related to diabetes is also probably multifactorial. The hyperglycemic state in genetically predisposed individuals results in biochemical alterations of localized cellular metabolism. Impaired microcirculation within end organ tissues results in altered glycation metabolism, oxidative stress, and hypoxia. ${ }^{314-316}$ Although there was once controversy surrounding an association of diabetes and disk edema, ${ }^{317}$ this debate now seems largely resolved and "diabetic papillopathy" is now recognized as belonging to the list of associations with UDE. Reported cases of UDE related to diabetes are listed in Table 2. However, it remains important to emphasize that diabetes is a multiplier not a "cause" of disk edema.

Damage from ROS (demyelinating diseases).

Demyelinating diseases may be mediated by ROS, ${ }^{322}$ with inflammation involved in the demyelinating processes. ${ }^{323}$ Obviously, with ROS also being implicated in pathways associated with LHON and hypoventilation related to sleep apnea (both discussed above), then these biochemicals may be common multipliers for the pathophysiology of UDE and linked to other associations as well.

The association of "optic neuritis" with multiple sclerosis is well known, and the subject of the large-scale Optic Neuritis Treatment Trial (including both anterior and posterior forms). ${ }^{324,325}$ However, other, rarer demyelinating diseases have also been associated with acute optic neuropathies, such as acute disseminated encephalomyelitis and diffuse periaxial encephalitis (of Schiller). ${ }^{4}$ Acute inflammatory demyelinating polyradiculoneuropathy (AIDP, Guillain-Barre syndrome) and neuromyelitis optica (Devic's disease) have also been reported with UDE in isolation (references in Table 2). The exact relationship between demyelination and disk edema remains unknown.

Cases of perceived endogenous associations of UDE which are not substantiated in the medical literature are denoted "no UDE cases found" in Table 2. It seems unlikely that these conditions need longer be considered either multipliers or clinical associations for UDE.

\section{Exogenous}

Exogenous insults associated with acute optic neuropathies include those from infectious agents, either as primary, secondary, or even opportunistic effects of the infection, and those from noninfectious agents, such as nutritional, radiation-induced and toxic inducers. (So-called "tobacco" optic neuropathy is considered a "toxic" mechanism for the purposes of this review).

\section{Infectious agents}

Many bacterial, fungal, parasitic, and viral microbes have been associated with optic disk edema through the years. Such cases are frequently referred to as "parainfectious optic neuritis," are typically bilateral, and are most often found in 
children. ${ }^{329}$ However, a list of the various infectious agents associated with UDE can be found in Table 3. In these unilateral cases, it would be presumed that the inflammatory response to localized infection of the $\mathrm{ONH}$ would disrupt axoplasmic flow and lead to disk edema.

Table 3 Cases of unilateral disk edema related to exogenous sources of inflammation

\begin{tabular}{|c|c|c|}
\hline \multicolumn{3}{|c|}{ Infectious } \\
\hline \multicolumn{3}{|c|}{ Bacterial } \\
\hline \multicolumn{2}{|c|}{ Bartonella henselae } & Cat scratch disease ${ }^{330,331}$ \\
\hline \multicolumn{2}{|c|}{ Borrelia spp. } & Lyme disease $^{332,333}$ \\
\hline \multicolumn{2}{|c|}{ Leptospira spp. } & Leptospirosis $^{334}$ \\
\hline \multicolumn{2}{|c|}{ Mycobacterium tuberculosis } & $\mathrm{TB}^{335}$ \\
\hline \multicolumn{3}{|c|}{ Mycoplasma pneumoniae ${ }^{336}$} \\
\hline \multicolumn{3}{|c|}{ Propionibacterium acnes ${ }^{337}$} \\
\hline \multicolumn{2}{|c|}{ Treponema pallidum } & Syphilis ${ }^{338}$ \\
\hline \multicolumn{3}{|c|}{ Fungal } \\
\hline \multicolumn{2}{|c|}{ Aspergillus spp. } & Aspergillosis ${ }^{339}$ \\
\hline \multicolumn{2}{|c|}{ Histoplasmosis capsulatum } & Histoplasmosis ${ }^{340}$ \\
\hline \multicolumn{3}{|c|}{ Parasitic } \\
\hline \multicolumn{2}{|c|}{ Taenia solium (tapeworm) } & Cysticercosis ${ }^{341}$ \\
\hline \multicolumn{2}{|c|}{ Toxocara canis (helminth) } & Toxocariasis ${ }^{342-344}$ \\
\hline \multicolumn{2}{|c|}{ Toxoplasma gondii (protozoa) } & Toxoplasmosis ${ }^{345-347}$ \\
\hline \multicolumn{3}{|l|}{ Viral } \\
\hline \multirow[t]{8}{*}{ RNA } & Alphavirus Chikungunya & CHIKV 348,349 \\
\hline & Flavivirus spp. & Dengue fever ${ }^{350,351}$ \\
\hline & & West Nile virus ${ }^{352}$ \\
\hline & Hepacvirus & Hepatitis $C^{353}$ \\
\hline & Lentivirus & $\mathrm{HIV}^{354}$ \\
\hline & Morbillivirus & Rubeola/measles ${ }^{355}$ \\
\hline & Orthohepadnavirus & Hepatitis B ${ }^{356}$ \\
\hline & Rubulavirus & Mumps $^{357}$ \\
\hline \multirow[t]{4}{*}{ DNA } & Cytomegalovirus & Human herpes virus type $5, \mathrm{CMV}^{358}$ \\
\hline & Lymphocryptovirus & Human herpes virus type 4, Epstein- \\
\hline & & Barr, infectious mononucleosis ${ }^{359}$ \\
\hline & Varicellovirus & Varicella, $\mathrm{HZV}^{360-362}$ \\
\hline \multicolumn{3}{|c|}{ Non-infectious } \\
\hline \multicolumn{3}{|c|}{ Nutritional } \\
\hline \multicolumn{3}{|c|}{ Folic acid deficiency ${ }^{364}$} \\
\hline \multicolumn{3}{|c|}{ Radiation-Induced exposures } \\
\hline Ultr & aviolet wavelength ${ }^{365}$ & \\
\hline loni & zing Particles & \\
\hline & achytherapy ${ }^{366}$ & \\
\hline & kternal beam ${ }^{367}$ & \\
\hline Toxic & & \\
\hline Che & mical & No UDE cases found \\
\hline Phar & maceutical & \\
\hline & miodarone $e^{368,369}$ & \\
\hline & terferon ${ }^{167}$ & \\
\hline & Idenafi $^{370-372}$ & \\
\hline Post & vaccination for: & \\
\hline & epatitis $B^{373}$ & \\
\hline & easles/rubella ${ }^{374}$ & \\
\hline & vine $f_{l} u^{375}$ & \\
\hline Ven & omous & \\
\hline & ee sting 376,377 & \\
\hline & asp sting ${ }^{37}$ & \\
\hline
\end{tabular}

\section{Noninfectious agents}

Exogenous, noninfectious sources of disk edema include radiation-induced sequelae, malnutrition, and toxic effects. Both ultraviolet wavelength and ionizing particle radiation therapies have been linked to the development of UDE (references in Table 3); however, these are relatively rare instances and should be easily discerned when case histories are obtained for these patients. Nutritional sources of UDE appear to be exceptionally rare with only one associated case discovered, ${ }^{363}$ and this case was possibly confounded by the resultant associated anemia. Some nutritional cases of optic neuropathy also share a clinical profile with toxic sources.

Most toxic associations with optic neuropathy are bilateral, symmetrical, atrophic processes $^{364}$ and, therefore, would not present as UDE. However, rare cases of UDE in isolation have been reported in the context of pharmaceutical agents, vaccinations, and venomous reactions. Those noninfectious sources of UDE are listed in Table 3, and - if truly associative - manifest monocularly due to the anatomical reasons previously mentioned.

Incidentally, secondary toxic-mediated inflammation by neither endotoxins (eg, from Salmonella enterica serovar Typhi in typhoid fever) nor exotoxins (eg, botulin toxin from Clostridium botulinum or the scarlet fever antecedent from Streptococcus pyogenes) seems to be associated with UDE. Graft-versus-host disease (a toxic versus inflammatory response) has been associated with bilateral optic disk edema $^{379}$ via an inflammatory mechanism, but has not been reported in conjunction with a case of UDE.

Indeed, the presence of any one of the nutritional or toxic factors (chemical, tobacco, or toxin) in an acute case of UDE would appear to be suspect, ${ }^{4,46}$ given the atrophic nature of these bilateral conditions. ${ }^{19}$ Literature searches for cases of a commonly cited source of nutritional optic neuropathy that derived from vitamin B12 deficiency - uncovered no reports of acute presentations of UDE. It seems probable that most cases of nutritional optic neuropathies are nonacute, bilateral, and restricted to developing countries. ${ }^{363}$

"Tobacco amblyopia," in particular, does not appear acutely as disk edema, ${ }^{380}$ is bilateral, ${ }^{381}$ and may not even be an optic neuropathy at all. ${ }^{382}$ While hyperemic disk edema is more often seen in cases of acute ethanol intoxication, ${ }^{46}$ again, these cases are expected to be bilateral in presentation. It is unclear that ethanol in isolation has been linked to disk edema historically ${ }^{4}$ or via more recent literature searches in the preparation of this review. Methanol has been long associated with disk edema with the first case series reported in $1904,{ }^{383}$ although even in the period when these cases were 
more commonly observed, Duke-Elder considered them to be "always bilateral."

Although, tobacco, ethanol, nutritional, and toxic optic neuropathies are often considered in the same discussion - and indeed with considerable overlap in some cases - here, "toxic" is strictly applied in the sense of being related to a chemical toxin or a poison, and comprising chemicals (including tobacco and ethanol), pharmaceutical agents, vaccinations, and venoms. "Toxic amblyopias" are also considered to be bilateral conditions. ${ }^{384,385}$ All of these chronic optic neuropathies are probably multifactorial in development.

Vitamin B12 deficiency and "tobacco amblyopia" may be mutually exclusive multipliers: is the tobacco the source of the optic neuropathy, or is it because tobacco abusers are more likely to have poorer diets and be vitamin-deficient? To further complicate this clinical picture, toxicity related to cyanide - a known by-product of tobacco combustion - is a known confounder for "tobacco amblyopia." 386

Within the discussion of toxic optic neuropathies, singlefactor causality remains difficult to establish and coincidence must be strongly considered, as in the case of retrobulbar optic neuritis once associated with styrene toxicity. ${ }^{387}$ This review uncovered no other specific chemical, nonpharmaceutical agents linked to UDE.

Many pharmaceutical agents have been linked to various optic neuropathies, ${ }^{388}$ although very few have been associated with UDE (Table 3). Again, systemic circulation and absorption of the offending agent would be expected to produce bilateral optic neuropathies. Indeed, this is the case for well-known agents of optic neuropathy such as ethambutol $^{389}$ (although typically a retrobulbar form), linezolid, ${ }^{390}$ and amiodarone. ${ }^{391}$ It is interesting to point out that coincidence may be an important factor to consider in the purported association of UDE with amiodarone ${ }^{392}$ and even phosphodiesterase type 5 inhibitors, ${ }^{393}$ although these could be secondary immune responses, as has been conjectured for a case of retrobulbar optic neuritis related to interferon-beta administration. ${ }^{394}$

Toxic sources of acute optic neuropathies have been reported in regard to many different vaccinations, ${ }^{329,395}$ but are typically bilateral ${ }^{329}$ and overall are considered to be rare. ${ }^{396}$ However, a few cases of UDE related to contemporary vaccinations have been reported (Table 3). Again, it must be presumed that these few cases are the result of physiological variation with an ostensibly bilateral condition manifesting as a unilateral one.

Venomous sources of UDE have also been noted after both insect and snake bites, although the exact mechanism of this pathway is not clearly understood. Immune, toxic, allergic, or other pathways are possible. ${ }^{378}$ The few cases of disk edema related to snake bites since 1939 have been reported as being bilateral. ${ }^{397-399}$ This review was unable to find any cases of UDE related to this mechanism of injury. The rare cases of UDE related to Hymenoptera stings are reported in Table 3 .

Regardless of the exogenous source of inflammation in the $\mathrm{ONH}$, tissue swelling within the $\mathrm{ONH}$ results in the compression of the microtubules, which in turn leads to axoplasmic flow stasis and the visible manifestation of UDE. Due to limited reports associated with UDE, essentially all of the associations reported in Table 3 must be considered rare.

\section{Mass effects}

Mass effects represent the second pathophysiological grouping for UDE. Paraneoplastic disk edema has been used to describe $\mathrm{ONH}$ swelling related to neoplasms; however, cysts, hematomas, and orbital manifestations of thyroid disease can also create similar end effects on the optic nerves. Neuroimaging becomes critical in the identification and differential diagnosis of these various lesions.

In these cases it is quite possible that a single-cause hypothesis for the development of UDE is appropriate: it is a direct manifestation of mechanical pressure on the optic nerve. These direct mechanical stresses exert physical force on the ONH neurons, and can be the result of either compressive lesions that impinge on all layers surrounding the axon bundles themselves (ONH anatomic integrity intact) or infiltrative lesions within the vascular tunics or optic nerve sheaths (ONH anatomic integrity compromised). These mechanical forces are depicted schematically in Figure 1. Once either process of mechanical impingement reaches a certain, critical stage, there is perfunctory collapse of the microtubules, leading to loss of normal axoplasmic flow and finally to disk edema that is visible to the observer.

This particular mechanism is one in which a preponderance of unilateral cases might be expected; however this is not always the case, and many bilateral cases of disk edema related to mass effects have been reported in the literature. With respect to mass lesions, anatomical location is the important determinant for whether the disk edema is unilateral or bilateral. In all cases of mass effect, neuroimaging is required to aid in the differential diagnosis. Those conditions reported with UDE in isolation related to either compressive or infiltrative lesions are noted in Table 4. 
Table 4 Cases of unilateral disk edema resulting from mass effects

\begin{tabular}{l} 
Compressive \\
Neoplastic \\
Astrocytoma/glioma ${ }^{45,400,401}$ \\
Carcinoma \\
$\quad$ Lung $^{402}$ \\
$\quad$ Nasopharyngeal ${ }^{403}$ \\
Ectopic brain tissue \\
Hamartoma \\
$\quad$ Hemangioma ${ }^{405,406}$ \\
$\quad$ Lymphangiomas \\
Melanocytoma \\
Meningioma \\
Metastatic disease \\
Prostate cancer \\
Pineal tumors \\
Pituitary tumors \\
Sarcoma \\
Non-neoplastic \\
Cysts \\
Arachnoid \\
Cystercicosis, \\
Hematoma \\
Optic perineuritis \\
Thyroid disease \\
Infiltrative \\
Neoplastic \\
Leukemia/lymphoma \\
Non-neoplastic \\
Syphilis (granuloma) \\
Sarcoidosis (granulomatous infiltration) \\
Tuberculosis (TB granuloma) \\
\hline 4,437 \\
\hline
\end{tabular}

\section{Compressive neoplastic}

Many different tumors have been directly linked to the development of UDE. In some cases there is a visible neoplasm at the $\mathrm{ONH}$, although in the presence of retrobulbar tumors, patients may present with optic disk edema in isolation. ${ }^{438}$ It should also be further emphasized that disk edema may not necessarily be a presenting finding for some tumors, such as melanocytoma ${ }^{439}$ or malignant melanoma. ${ }^{440}$

Metastatic tumors to the $\mathrm{ONH}$ account for about $5 \%$ of all ophthalmic metastatic lesions ${ }^{441}$ and can rarely manifest with UDE as the initial finding. Although isolated metastases to the optic nerve are considered quite rare, ${ }^{442}$ bilateral cases have been noted for meningioma ${ }^{443}$ and carcinomas of the breast, ${ }^{442,444} \mathrm{CNS},{ }^{445}$ and lung. ${ }^{446}$ The development of UDE appears inconsistent with the underlying pathophysiology of these neoplastic conditions.

\section{Compressive non-neoplastic}

Non-neoplastic compressive sources of UDE can arise from various cysts, hematoma, optic nerve sheath inflammation (optic perineuritis), or from the effects of thyroid disease. While it might also be expected that UDE could occur with inflammatory orbital pseudotumor - and it can within a constellation of other ocular findings - no cases of UDE in isolation related to this process were retrieved.

Although once considered common, optic neuropathy related to orbital inflammation associated with nasal disease is actually "rare," while that associated with sinusitis is considered a "diagnosis of exclusion.",447

Optic perineuritis (also described as perioptic neuritis) is a special case of inflammation involving only the optic nerve sheath. ${ }^{425}$ In instances of optic perineuritis, the optic neuropathy is a secondary effect in which the inflammation of the optic nerve sheath impinges on the optic nerve tissue itself. The ultimate effect on the $\mathrm{ONH}$ is axoplasmic flow stasis and is sometimes visible clinically as a disk edema. Optic perineuritis has been reported in the context of sarcoid, ${ }^{448}$ tuberculosis, ${ }^{449}$ nonspecific orbital inflammation, ${ }^{450}$ and idiopathic settings. ${ }^{451}$

Optic nerve involvement in thyroid disease is due to compression of the optic nerve at the orbital apex, ${ }^{452,453}$ but accounts for $<5 \%$ of ophthalmic signs in thyroid eye disease, and is typically hidden among more salient congestive findings. ${ }^{454}$

While not presenting as a UDE in isolation, the disk edema associated with central retinal vein occlusion (CRVO) may be compressive in origin, as hemostasis in the CRV may create an environment in which accumulated blood physically compresses axons within the optic nerve. Obviously ischemic factors are also likely at play. The presence of UDE has been shown to be of no diagnostic value in $\mathrm{CRVO},{ }^{455}$ but is still a common finding in this ophthalmic vascular disease. ${ }^{456}$

\section{Infiltrative neoplastic}

Unilateral cases of optic nerve infiltration have been reported with respect to retinoblastoma ${ }^{457-460}$ and choroidal melanoma, ${ }^{461}$ but without UDE in isolation. The most common infiltrative lesion of the $\mathrm{ONH}$ that does present as UDE appears to be leukemic/lymphoma infiltration (references in Table 4), although there may also be instances of compressive leukemic lesions manifesting in the same manner.

\section{Infiltrative non-neoplastic}

Syphilis, sarcoidosis and granulomas related to tuberculosis appear to be the three main infiltrative non-neoplastic sources of UDE. Sarcoidosis is of special note as infiltration is just one of the three possible mechanisms for the development 
of disk edema (discussed previously). While granulomatous infiltration and pulmonary disease/hypoxia are less likely contributors than overt inflammation/ECF accumulation for UDE related to this association (and probably still with mixed mechanisms ${ }^{462}$ ), an infiltrative pathway can lead to UDE.

Disk edema from non-neoplastic infiltration of the optic nerves has been reported in POEMS (polyneuropathy, organomegaly, endocrinopathy, M-protein, skin changes) syndrome, ${ }^{463-466}$ but these were bilateral cases.

Infectious agents have also been associated with optic nerve infiltration: herpes viruses and $\mathrm{CMV},{ }^{104}$ as well as mycoses ${ }^{467,468}$ among others, but with variable concurrent monocular or binocular findings, and this review uncovered no such cases in which UDE in isolation was the presenting sign, the implication being that these are extremely rare cases, or - more likely - not part of the manifestations of these diseases.

\section{IOP/ICP pressure gradient factors}

The third and final source for axoplasmic flow stasis is based on biological fluid and pressure dynamics within the optic nerve. The pressure-gradient sources for disk edema may best be appreciated by schematic representation in Figure 2. The anatomic rigidity of Bruch's membrane at this site and the anatomical continuity of optic nerve sheaths with brain meninges ensure that the effects of pressure changes within this system occur across the lamina cribrosa. As mentioned previously, this "choke point" is critical in its role for the development of disk edema.

At the lamina, normal axoplasmic flow occurs in both anterograde and retrograde directions against a background

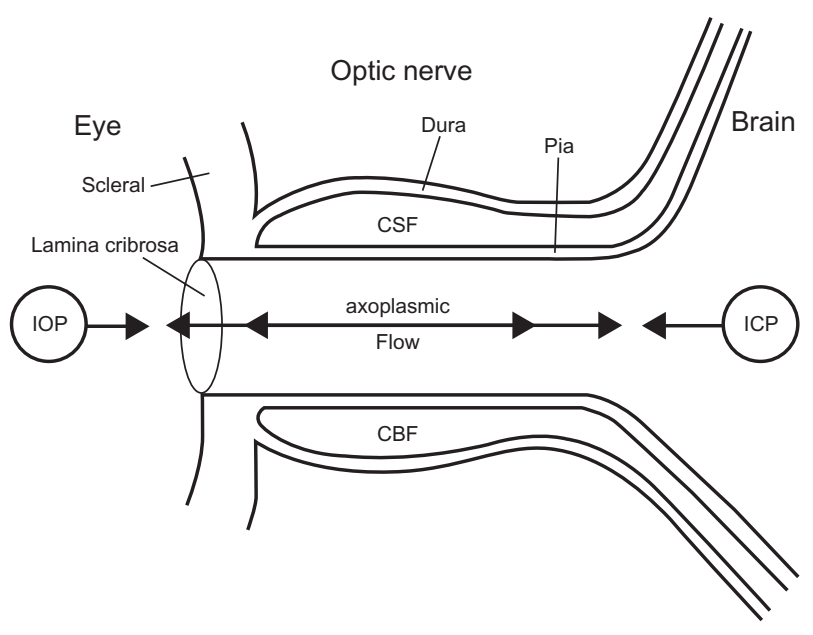

Figure 2 Pressure gradient across the lamina cribrosa.

Abbreviations: CSF, cerebrospinal fluid; ICP, intracranial pressure; IOP, intraocular pressure. of normal ONH perfusion hemodynamic (ie, ONH perfusion pressure $=$ arterial blood pressure $-\mathrm{IOP}^{469}$ ). Although typically in a steady-state system, the pressure gradient across the lamina cribrosa represents the fulcrum of pressure gradient changes between the eye and brain. ${ }^{37,470}$ The average normal IOP for humans is $16 \mathrm{mmHg}^{471}$ and normal resting ICP is $<15 \mathrm{mmHg}$; ${ }^{472}$ thus, on average there is a slight pressure gradient in an anterograde direction along the optic nerve.

Blood flow to the optic disk - and by consequence ONH perfusion pressure - has been noted to be compromised at IOP levels of $40-50 \mathrm{mmHg},{ }^{473,474}$ but has been reported as occurring at IOPs as low as $25 \mathrm{mmHg}^{475}$ in simian models. Also in these study eyes, axoplasmic stasis has been noted in environments of both increased and decreased IOP. ${ }^{476,477}$

What can disrupt the normal IOP/ICP gradient and compromise axoplasmic flow? Marked elevations or depressions in pressure on either side of this anatomical landmark can alter the pressure balance, thus creating axoplasmic flow stasis, eventually leading to the development of disk edema. ${ }^{8}$ Theoretically the IOP/ICP gradient could be affected by substantial elevations in either ICP or IOP. Possibly even large relative changes (ie, low-normal IOP in conjunction with high-normal ICP) could alter this balance enough to create an environment conducive to the development of disk edema. $^{7}$ This presumably occurs in predisposed nerves and may be influenced by multipliers as well.

\section{Elevated ICP}

As is well known, the relationship of bilateral disk edema with raised ICP (ie, papilledema) has long been recognized, with ICPs $>15 \mathrm{mmHg}$ also being associated with disk edema. ${ }^{478}$ Radiological studies of papilledema have suggested that it is the mechanical pressure on the $\mathrm{ONH}$ that leads to decreased perfusion, ischemia, axoplasmic flow stasis and, ultimately, neuronal atrophy. ${ }^{479}$

Underlying conditions resulting in increased ICP include intracranial masses, cerebral edema, increased cerebrospinal fluid production, decreased cerebrospinal fluid absorption, obstructive hydrocephalus, increased cerebral blood volume, venous outflow obstructions, craniosynostosis, and pseudotumor cerebri. ${ }^{102}$ The effects of trauma on the development of papilledema may also be multifactorial. ${ }^{480}$ Iron-deficiency anemia has been associated with elevated $\mathrm{ICP}^{481}$ and a contributor to the lowered $\mathrm{O}_{2}$-carrying capacity of the blood as previously mentioned.

The atypical finding of UDE related to ICP has been extensively reported in the literature ${ }^{8,34-45,49,482-486}$ but remains an atypical presentation. 


\section{Decreased ICP}

Normal resting ICP for upright body positions is $<10 \mathrm{mmHg}^{487}$ and $<15 \mathrm{mmHg}$ for supine positions. ${ }^{488}$ As a result, depressions in ICP would not be expected to manifest themselves clinically because, if pathological in nature, then the edema resulting from impaired retrograde axoplasmic flow would be expected to manifest itself farther from the globe (posterior in the nerve) and would not be visualized ophthalmoscopically. This does pose a possible mechanism for acute retrobulbar or "posterior" optic neuropathies, however, especially for bilateral cases.

To date, there have been no reported cases of low/zero ICP with respect to disk edema as might be expected with open head wounds or the after effects of surgical procedures. Again, for all cases of ICP-related disk edema, it would be expected that the optic neuropathies would be bilateral UDE related to ICP would occur only in rare anatomical circumstances.

\section{Elevated IOP}

While increased IOP has not been directly associated with the development of UDE (and specifically dismissed for $\mathrm{AION}^{489}$ ), elevated IOP is the corollary to decreased ICP with respect to the IOP/ICP pressure gradient. IOPs in the $30-60 \mathrm{mmHg}$ range have been noted to block retrograde axoplasmic transport ${ }^{490}$ and IOP at the $45-55 \mathrm{mmHg}$ level can impede autoregulation of blood flow at the $\mathrm{ONH},{ }^{491}$ thus creating the potential for a mechanical multiplier of ischemic sequelae.

As the development of perioperative UDE is not uncommon, a link to IOP elevations should be considered. Surgery with patients lying in the prone position has the potential to raise $\mathrm{IOP}^{263}$ and this circumstance may be associated with decreased ocular perfusion. ${ }^{492}$ Direct pressure on the periorbita can artificially raise IOP. ${ }^{493}$ Although $20 \mathrm{mmHg}$ elevations in IOPs have been noted in cases of gravity inversion ${ }^{494}$ and in players of high-resistance wind instruments, ${ }^{495}$ UDE cases have not been reported in these unusual circumstances, again suggesting that genetic susceptibility may play an important role for those patients who do develop disk edema related to IOP increases.

Elevations in IOP, however, have limits in the pathogenesis of acute optic neuropathies. Excessive ocular hypertension can cause a different ophthalmic problem: central retinal artery occlusion due to the collapse of the central retinal artery. ${ }^{496}$ Elevations of $40 \mathrm{mmHg}$ in simian models ${ }^{497}$ or an absolute IOP of $50 \mathrm{mmHg}$ in a human ${ }^{498}$ have been associated with CRAO. Both of these numbers fall within the range noted above for dysregulation of axoplasmic flow, so central retinal artery collapse could be a confounder if assigning the development of disk edema directly to factors of IOP.

UDE following both intracapsular ${ }^{499}$ and extracapsular ${ }^{500}$ procedures with postoperative IOP elevations have been associated with AION. Of special note is the case of NAION following cataract surgery. Disk edema following extracapsular cataract extraction without postoperative IOP elevation has been noted, ${ }^{501}$ and this occurrence seems unrelated to periocular injection. ${ }^{502}$ This casual relationship of NAION to postoperative status following cataract surgery remains unresolved, ${ }^{503}$ with reports both favoring ${ }^{504}$ and disfavoring ${ }^{505}$ the link. The hemodynamic milieu during surgeries - both ophthalmic and non-ophthalmic - certainly merits further study with the intent of discovering previously unknown UDE multipliers.

UDE has been associated with other conditions presenting with IOP elevations: Posner-Schlossman syndrome with IOPs in the $50-60 \mathrm{mmHg}$ range, ${ }^{506,507}$ anterior uveitis (IOP unspecified), ${ }^{508}$ and angle-closure with IOPs in the 40-50 mmHg range ${ }^{509-511}$ However, it should be remembered that these are not cases of UDE in isolation and carry different differential diagnoses. Other conditions associated with increases in IOP - ocular trauma/hyphema, pseudoexfoliation, pigmentary dispersion - have not been reported with respect to UDE to date.

Also, any procedure iatrogenically elevating IOP can be associated with the development of disk edema. The 10 seconds required for LASIK procedures may elevate IOP to the $80 \mathrm{mmHg}^{512}$ or even $150 \mathrm{mmHg}^{513}$ level. And in fact, post-LASIK AION has been documented. ${ }^{514}$

All subjects undergoing intraocular surgery necessarily have hypotony and an IOP of essentially zero with an IOP/ ICP pressure gradient that may favor ICP; however, very few of these patients develop optic disk edema. The important factor may be "predisposed" individuals: not all patients who undergo IOP elevations automatically develop UDE. The converse is also true, not all patients with UDE are found to have elevated IOP.

\section{Decreased IOP}

Reversal of the IOP/ICP gradient would be expected with significant decreases in IOP, especially in the presence of an open globe - either traumatic or surgical. Indeed, hypotony has been linked to the development of disk edema in cases of spontaneous scleral rupture, ${ }^{515}$ and postsurgical settings. ${ }^{516,517}$ Disk edema in hypotony has also been reported in closed globe settings: post-traumatic cyclodialysis ${ }^{518-520}$ 
and uveitis. ${ }^{521}$ Again, it should be noted that none of the above cases presented as UDE in isolation as all of these cases were noted to have at least choroidal folds as a result of the hypotony.

Hypotony has been associated with profound changes in the osmotic hematological state in monkeys, ${ }^{186}$ but it is unclear if this has any bearing on the development of UDE in humans. Ultimately, specific levels of hypotony have not been reported, but would be expected to become clinically significant at IOPs of $<5 \mathrm{mmHg} .{ }^{522}$ To date, no cases of UDE in isolation related to hypotony have been reported.

In sum, with regard to the IOP/ICP pressure gradient across the lamina cribrosa, it would appear that only elevated IOP or elevated ICP are related to UDE.

\section{Summary of associations}

The complex topic of disk edema is fraught with the perils of theoretical association versus biological causation. It seems likely that there are mixed mechanisms involved with multiplying factors, which intersect in predisposed individuals to create the clinical picture of disk edema. As a prime example, consider the report of a case that involved two separate ophthalmic presentations. ${ }^{523}$ The second event involved UDE in isolation. Given this patient's lung carcinoma and "paraneoplastic optic neuritis," it is conceivable that his disk edema was the result of combined infiltrative (secondary to lymphocytes), compressive (secondary to optic perineuritis), and inflammatory (secondary to demyelinating processes) mechanisms. It seems illogical that the development of disk edema in such a case would be due to a single factor. As in other sciences, biological evidence for causality should be equally compelling.

It may also be pointed out that this pathophysiological framework can be applied to bilateral disk edema cases (beyond the scope of this paper), although the work-up for those cases correspondingly varies.

\section{Medical associations and clinical differentiation Consideration of associations}

Much effort has been made to characterize the most common of the three presentations of disk edema-AION, optic neuritis, and papilledema - based on clinical features during the acute phase and found in both the neurological and ophthalmologic literature. ${ }^{103,524-526}$ Their clinical characteristics are summarized in Table 5. While differentiation has been suggested to be somewhat more characteristic during the chronic phase, ${ }^{527}$ there remain times when the acute clinical

Table 5 Clinical characteristics of anterior ischemic optic neuropathy (AION), optic neuritis, and papilledema

\begin{tabular}{|c|c|c|c|}
\hline & AION & Optic neuritis & Papilledema \\
\hline Age of patient (years) & $>50$ & $20-40$ & $\begin{array}{l}\text { Any depending on underlying } \\
\text { cause }\end{array}$ \\
\hline Gender of patient & $M=F$ & $F>M$ & $\begin{array}{l}\text { Variable, depending on } \\
\text { underlying cause }\end{array}$ \\
\hline \multicolumn{4}{|l|}{ Symptoms } \\
\hline Visual chronicity & Acute & Acute & Subtle, non-acute \\
\hline Deficits & Variable VA/VF & Often marked decrease & Often none \\
\hline Other & None & None & $\begin{array}{l}\text { Amaurosisfugax } \pm \\
\text { diplopia }\end{array}$ \\
\hline Systemic & $\begin{array}{l}\text { Arteritic - various } \\
\text { Non-arteritic - none }\end{array}$ & $\begin{array}{l}\text { Pain on EOM excursions } \\
\text { Possible neuromuscular symptoms }\end{array}$ & $\begin{array}{l}\text { Headache, nausea, } \\
\text { other focal neurological signs }\end{array}$ \\
\hline Acuity & Variable & Usually diminished & Usually normal \\
\hline FA characteristics & $\begin{array}{l}\text { Arteritic - non-filling of choroid } \\
\text { Delayed pre-laminar filling }\end{array}$ & No delays noted & \\
\hline Laterality & Unilateral & Unilateral & Bilateral \\
\hline Optic disk edema & $\begin{array}{l}\text { Often associated with hemorrhages } \\
\text { "Chalky" appearance in artertic forms }\end{array}$ & $\begin{array}{l}\text { Anterior: } \\
\text { rarely associated with hemorrhages } \\
\text { Retrobulbar: none }\end{array}$ & $\begin{array}{l}\text { Variable association } \\
\text { with hemorrhages }\end{array}$ \\
\hline Other & Disk at risk in fellow eye & & \\
\hline SVP present in fellow eye? & Yes & Yes & No \\
\hline Visual field & Variable & Variable & Minimal \\
\hline Prognosis & Poor & Good & Good \\
\hline Time to signs (of disk edema) & $2-3$ months & $2-4$ weeks & Variable \\
\hline
\end{tabular}

Abbreviations: EOM, extraocular muscle; FA, fluorescein angiography; SVP, spontaneous venous pulsation; VA, visual acuity; VF, visual field. 
presentation is ambiguous. ${ }^{381,528-530}$ Determining an underlying association is equally indistinct. ${ }^{531}$

While the disk edema itself is a self-limiting process, the clinical relevance is this: can a UDE be the presenting sign of a systemic disease? The answer is "yes," some cases of UDE are, therefore, clinically significant. UDE described as "optic neuritis" is often an indicator of impending multiple sclerosis and other morbidity associated with that disease; and UDE associated with arteritic anterior ischemic optic neuropathy (A-AION) in GCA is one of the very few, true ocular emergencies that carries with it a risk of mortality. The clinical importance of disk edema is in the determination of important, underlying associations.

Regardless, it is important to remember the basic, pathophysiological concept of disk edema: namely that, when considering the differential diagnosis of optic disk edema, the provider must keep in mind that this is not a consideration of its "etiology." The etiology of disk edema is known - it is due to axoplasmic flow stasis. Again, UDE is a nonspecific response to one of three antecedent sources that interrupt normal axoplasmic flow: inflammation, mass effects, or changes in the pressure gradient across the lamina cribrosa. Nor is the disk edema the result of "many" pathological processes. Bearing this in mind, the "differential diagnosis" of disk edema is most accurately understood to be a consideration of the associations with this ocular finding. Finally, it should always be borne in mind that other reported associations of UDE that occur so infrequently as to be singular events may be merely coincidental.

In general, self-reported ocular symptoms would be expected in cases of acute optic neuropathies: visual blur, visual field changes/scotomata, amaurosis fugax (indicative of transient ischemia of the $\mathrm{ONH}^{532}$ ), or pain on eye movements, ${ }^{54}$ although asymptomatic cases of UDE are well documented. ${ }^{462,533-535}$ Regarding visual symptoms, only pain on eye movement would seem to be a useful clinical indicator as to the underlying association as $>90 \%$ of "optic neuritis" patients report this at the initial presentation. ${ }^{54}$ Otherwise utilization of patient symptoms seems not to be a reliable indicator of disk edema association.

Optic disk edema that is not isolated in presentation is observed with many ocular conditions. The first step in the evaluation of any disk edema is to rule out concurrent ophthalmic findings in both the ipsilateral and contralateral eyes. Many case reports were not considered in this review because of the relative rarity of discovering isolated UDE occurring without other ocular findings in either eye.
This would seem to indicate that a UDE in isolation goes a long way in the differential diagnosis of associated conditions. Findings such as chorioretinal scars (suggestive of prior infectious processes ${ }^{536}$ ) or optic atrophy (suggestive of FosterKennedy syndrome: ipsilateral optic atrophy and contralateral disk edema ${ }^{4}$ ) in the fellow eye assist greatly in the assignment of clinical risk for the current disk edema in the eye of regard.

In addition to other conditions mentioned above (such as angle-closure, CRAO, CRVO, hypotony, ODEMS, uveitis), many ophthalmic conditions present with disk edema as merely one part of a constellation of findings. Choroidal neovascularization, ${ }^{537}$ diffuse unilateral subacute neuroretinitis (DUSN), ${ }^{538-540}$ various forms of neuroretinitis, ${ }^{541-543}$ optic nerve avulsion, ${ }^{544-546}$ orbital pseudotumors, ${ }^{547,548}$ papillophlebitis ("big blind spot syndrome"), ${ }^{549,550}$ and the "white spot syndromes" of the retina ${ }^{551,552}$ may present with a disk edema, but it is not an isolated ocular sign. Differential diagnosis of these conditions involves accurate history taking and consideration of concurrent ocular findings.

Once apparent isolated UDE has been confirmed, the second step in the differential diagnosis is to rule out those clinical entities that masquerade as disk edema, especially when the disk edema appears to be an incidental finding in an asymptomatic adult patient or in children. Often, the lack of accompanying acute signs (especially a relative afferent pupillary defect for unilateral cases) and patient symptoms can be used to help separate the physiological from the pathological. ${ }^{553}$ Pseudopapilledema is the term given to any $\mathrm{ONH}$ presentation that can be mistaken for true disk edema; 554 although due to the confusion surrounding terminology for this clinical topic, it might prevent misunderstandings to instead refer to these presentations as "disk edema masqueraders."

The most common source of disk edema masqueraders - approximately two-thirds of cases - is optic disk drusen, ${ }^{554}$ but several other congenital anomalies have been associated with confounding disk appearances: tilted ONH insertions, anatomical variations (small scleral canal, small optic cup, anomalous ONH appearance), congenitally "full" or "crowded" ONHs with normal but elevated disk tissue ("crowded" axons become "heaped up" as they enter the lamina and exit the eye), embryonic remnants (glial tissue, hyaloid remnants, unregressed myelination), and local gliosis. ${ }^{553,554,556}$ In these cases, both disk margins and cupping can appear indistinct and give the impression of an edematous ONH.

Optic disk findings in these cases are typically not accompanied by other intraocular findings (such as venous 
congestion, hemorrhages, retinal edema). Direct ocular examination (to determine characteristic features of optic disk drusen versus pathological findings associated with disk edema) and B-scan ultrasonography are the most sensitive clinical indicators for ruling out masqueraders of pathological disk edema. ${ }^{104,557}$ Initial B-scan is a crucial, initial test in cases of questionable disk edema in order to preclude further expensive ancillary testing in the presence of disk drusen. ${ }^{558}$

It is of clinical interest to note that the presence of disk drusen is not "protective" against the development of disk edema. In fact drusen are believed to form via alterations in axoplasmic transport, ${ }^{559,560}$ can show progression, ${ }^{561,562}$ and have been reported in conjunction with disk edema. ${ }^{563-566}$

Once isolated UDE with no other concurrent ocular findings has been confirmed, then the third step in the determination of clinical relevance is to consider the age of the patient. Since various associations for disk edema cannot always be differentially diagnosed by clinical findings (such as visual acuity [VA] involvement, ONH appearance, visual field [VF] defects, presence of disk hemorrhages, or spontaneous venous pulsations) or pathologically (identical pathological process for all manifestations) - especially in the early stages ${ }^{304,425,567}$ - a new decision tree would seem to be in order to facilitate this process. During the research for this paper, the author was unable to discover any previously published UDE flowcharts, decision trees, or discussions similar to that for stepwise evaluation of bilateral disk edema ${ }^{21}$ via consulted references, PubMed or even through unrefereed internet resources. Finally, the importance of the patient history in these cases should be re-emphasized as it may elicit unusual facts to sort through UDE associations, especially for unusual cases with rare associations: factors such as a family history of LHON, recent head/neck radiation treatment, possible toxic exposures, recent surgeries, and so on.

Following the clinical dictum that "common things happen commonly" (and its literary corollary: common things are reported commonly), the two most common terminologies for acute unilateral optic neuropathy (AION and optic neuritis) were reviewed and found to reveal agespecific incidences. In fine, there are just a handful of "common" acute unilateral optic neuropathies, and the frequency of other pathological associations drops off rapidly - sometimes to a single, isolated case.

A look at incidences for these two conditions gives an idea of just how "common" they really are. The annual incidence of non-arteritic AION is noted to be between about one and ten cases per 100,000 per year in patients older than
50 years. ${ }^{568-570}$ The average age for AION is reported to be in the 60 - to 70-year age range. ${ }^{277,568,571 ~ " O p t i c ~ n e u r i t i s " ~ i s ~ s t a t e d ~}$ to have an annual incidence between about one and five cases per 100,000 per annum, ${ }^{570,572-575}$ with an average of onset of 30-32 years of age ${ }^{54,573,575}$ Incidences for other forms of UDE have not been reported to date. Based on these available findings, it appears that UDE in general occurs more frequently with age - especially since the epidemiology of "optic neuritis" includes retrobulbar forms of optic neuropathy.

Again, it should be pointed out that nearly all cases of papilledema involve bilateral disk edema. Thus unilateral papilledema in any age group is quite unusual. In the rare cases of UDE related to increased intracranial pressure, those patients could be differentiated by concurrent systemic symptoms: headache, nausea, vomiting, diplopia, ataxia, altered consciousness, among others.

\section{Clinical differentiation for UDE}

Using incidences for the most common presentations of disk edema as a starting point, an age-matched flowchart for clinical application can be developed (Figure 3). Common presentations of UDE can largely be separated into three age groupings: $<20$ years, $20-40$ and $>40$ years. Obviously, patients with ages near these arbitrary cut-offs may share characteristics with both groups. It should be emphasized that inflammation is the most common underlying pathophysiology for UDE in all age groups (albeit with different mechanisms) and that UDE related to mass effects or pressure gradient changes are much less common.

In the youngest group, disk edema is most often bilateral, ${ }^{576-578}$ with about one-third of children presenting with UDE. ${ }^{576,577,579}$ In young patients the most common association is an antecedent viral syndrome, ${ }^{577,579}$ accounting for approximately two-thirds of cases. ${ }^{580}$ The next most common association for UDE in this age group is demyelinating disease (specifically, multiple sclerosis), representing about one-quarter of cases. ${ }^{577,579}$ Ischemic sources of acute optic neuropathy are considered rare in this age group. ${ }^{580,581}$ Percentages for associations are summarized in Figure 3. Thus, UDE in isolation in this age group should be considered an infectious - and most likely viral - event until proved otherwise.

For the 20- to 40-year age group, UDE is more common than bilateral involvement. In contrast to the younger age group, approximately two-thirds of disk edema cases found in patients of these ages are in one eye..$^{582}$

Disk edema associated with demyelination and multiple sclerosis is the most important and common association for 
1) Rule out other ocular findings in both eyes.

2) Rule out masqueraders via patient symptoms and/or B-scan

3) Consider the age of the patient.

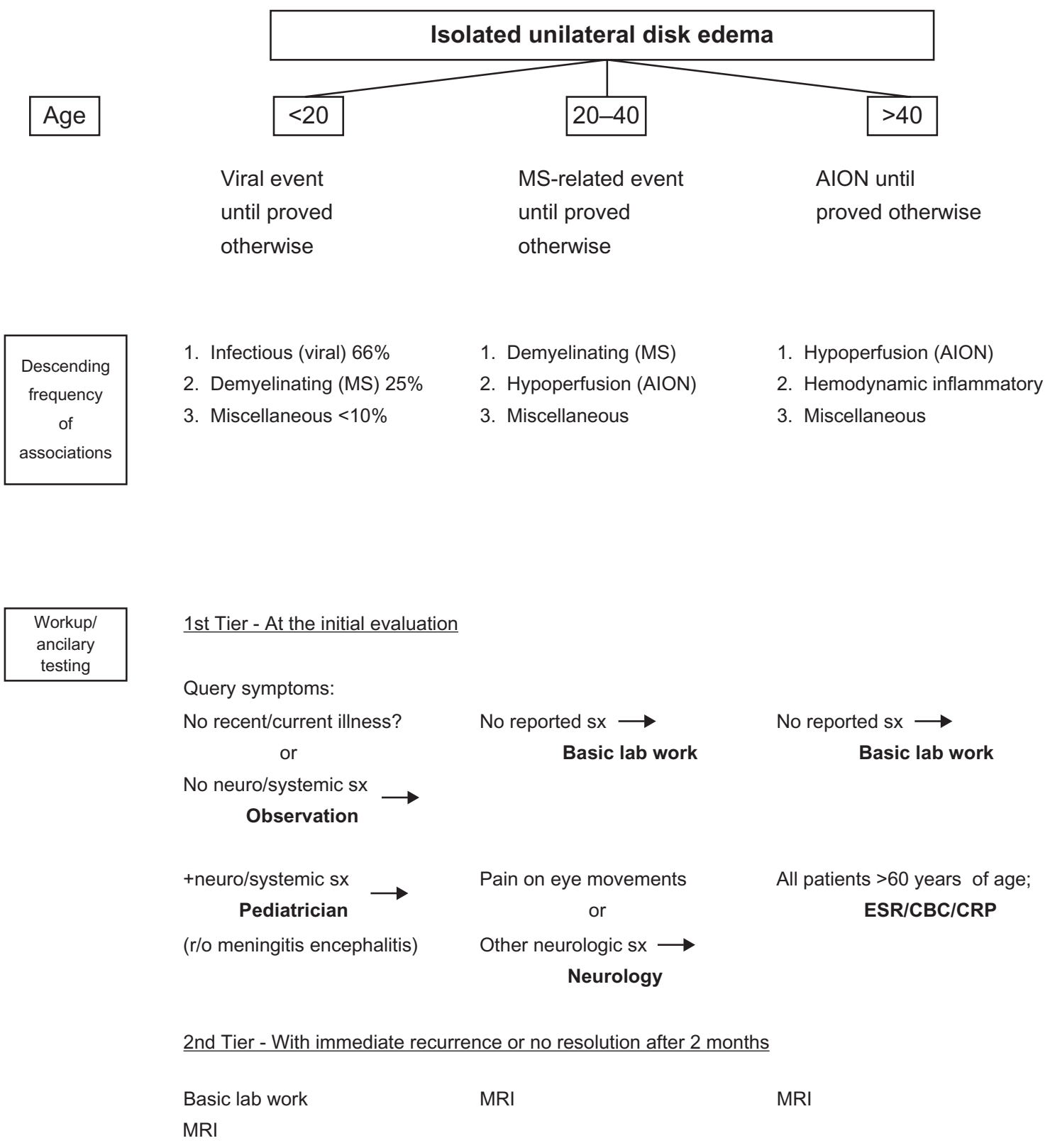

Figure 3 Age-stratified flowchart for isolated unilateral disk edema.

Abbreviations: AION, anterior ischemic optic neuropathy; MRI, magnetic resonance imaging; MS, multiple sclerosis; sx, symptoms; ESR/CBC/CRP, erythrocyte sedimentation rate/complete blood count/C-reactive protein.

this cluster of patients. ${ }^{583}$ Average age in the Optic Neuritis Treatment Trial (ONTT) was 31 years, and three-quarters of participants were female. ${ }^{54}$ Apparently because disk edema in this age group has been so widely associated with multiple sclerosis, there have been no systematic studies of disk edema in relation to frequency of other underlying associations in adults. Thus, at this point in time, it is not possible to conclude that $\mathrm{X} \%$ of patients in this age group have disk edema related to multiple sclerosis, whereas $\mathrm{Y} \%$ of these patients have disk edema related to ischemic events - similar to the percentages derived for the younger age group.

Of other associations with disk edema in this age group, AION is the most studied ${ }^{241,242}$ with a clinical profile similar to that of AION in older patients. ${ }^{584}$ It may be inferred then 
that vascular hypoperfusion (historically described as "ischemic") is probably the second most common source of UDE in this cohort. Other sources of disk edema in this age group - infectious, infiltrative, inflammatory ${ }^{320}$ - are considered rare. ${ }^{585} \mathrm{ODV}^{302}$ and $\mathrm{ODEMS}^{300}$ are rarer associations of disk edema in this younger age group of adults, as is LHON, which is more common in young males. ${ }^{586}$

Qualitatively then, it may be concluded that disk edema in this age group is a demyelinating, multiple sclerosis-related event until disproved. Hemodynamic, hypoperfusion events (ie, AION) probably account for the second - albeit distant most common association in this age group, followed by a miscellaneous collection of rarer associations. These are outlined in Figure 3.

Hemodynamic, hypoperfusion UDE predominates past the age of 40 years in the form of AION. Like the 20- to 40 -year age range, disk edema in this age group is also unilateral about two-thirds of the time. ${ }^{587}$ Series reports place the average for non-arteritic AION in the 55- to 67-year age range, ${ }^{277,588-593}$ although with standard deviations up to 13 years. ${ }^{591}$ Average age in the Ischemic Optic Neuropathy Decompression Trial was 66 years, but patients younger than 50 years were specifically excluded from this clinical study. 247

Arteritic AION typically affects slightly older patients. The average age for arteritic forms of AION have been reported to be in the 74- to 78-year age range $\mathrm{e}^{236,247,592,594,595}$ with arteritic AION being identified in patients as young as $57^{594}$ or 60 years. $^{236}$

AION is noted to be the most common acute optic neuropathy in older adults. ${ }^{568}$ Differentiation between "ischemic" and "inflammatory" forms of UDE cannot be made solely on clinical grounds, and it has been suggested that "inflammatory" forms may account for about $45 \%$ of UDE cases in this age group. ${ }^{587}$ However, secondary causes of UDE in this age group are widely variable and have not been systematically studied to date.

Associations with systemic vascular diseases seem to be more common than cerebrovascular ones in acute optic neuropathies in the 55- to 65-year age group ${ }^{596}$ and rare associations such as optic perineuritis may also be found in patients of this age. ${ }^{425}$ The primary concern for disk edema in anyone older than 60 years is its relationship to GCA, as up to $20 \%$ of GCA patients manifesting UDE have no associated systemic symptoms of the disease. ${ }^{594}$

Again using qualitative assessment in the absence of concrete data, it may be suggested that disk edema in patients over the age of 40 years is a vascular, hemodynamic, hypoperfusion event until proved otherwise. Other hemodynamic inflammatory sources are possibly the second most common association (although probably also a distant second), and include GCA, which must be ruled out for all patients over the age of 60 years. Miscellaneous associations would be grouped together into a final, smaller category. These proposed rankings are also summarized in Figure 3.

It will take rigorous, large-scale studies of consecutive UDE cases to further systematically differentiate clinical signs, standardize assignment of medical associations, and organize treatment protocols. However, based on existing, limited data currently available on frequencies of the most common associations with UDE, it becomes apparent that infectious associations are most common under the age of 20 years, demyelinating ones between the ages of 20 and 40 years, and vascular hypoperfusion associations predominate above the age of 40 years. For each age group it would seem prudent to consider a UDE to be related to the corresponding, most-prevalent association until disproved. This knowledge can be used as a clinical basis for assignment of clinical risk of the UDE and serves as a point of departure in the discussion on discreet ordering of ancillary testing.

\section{The role of technology in associations of UDE}

Many tests and other technologies have been used through the years to help differentiate associations of UDE. Unfortunately, there is no single, definitive modality that is currently used in acute optic neuropathies and large-scale studies in this domain to determine "gold standards" are lacking.

Alterations in color vision are almost universally associated with acute optic neuropathies; ${ }^{597-600}$ however use of this test to differentiate demyelinating from other forms has not been shown to be useful. ${ }^{601-603}$ The main usefulness of color vision testing may be when trying to determine the subtle presence of a previous optic neuropathy. ${ }^{104,603}$

Likewise, perimetry is useful to plot out the extent of initial visual field losses and possible recovery over time, but specific visual field defects are not pathognomonic for any single presentation..$^{54,582,587}$ Occasionally altitudinal defects (those respecting the horizontal meridian) are helpful in the identification of hypoperfusion associations (ie, AION).

B-scan ultrasonography is utilized to differentiate disk drusen from disk edema, ${ }^{605-610}$ and has also been suggested to be useful in the determination of optic neuritis versus AION. ${ }^{527}$ While its use is not quite as widespread, A-scan 
echography has been proposed to help in the differentiation between acute optic neuropathies as well. ${ }^{605,606,611}$

Fluorescein angiography (FA) has been applied in UDE in order to help identify associations of disk edema ${ }^{612} \mathrm{FA}$ appears to be most useful in cases of anterior ischemic optic neuropathy ${ }^{613}$ due to the filling delays noted for the choroid observed in arteritic forms, ${ }^{614}$ or the $\mathrm{ONH}$ in non-arteritic forms. ${ }^{615}$ Indocyanine green angiography has not been shown to be a better diagnostic instrument than standard FA. ${ }^{614}$

Other technologies used to assist in ONH evaluation for UDE have included orbital Doppler sonography, ${ }^{616}$ scanning laser ophthalmoscope,${ }^{617}$ optical coherence tomography,${ }^{589,618}$ scanning laser polarimetry, ${ }^{619}$ pattern electroretinogram, ${ }^{620}$ visual evoked potentials, ${ }^{600,621}$ neural network analysis, ${ }^{529}$ and fractal analysis. ${ }^{622}$ In general, however, more critical evaluation will be required to evaluate the benefits of these technologies for acute optic neuropathies. ${ }^{623}$ Scanning laser polarimetry may be of special note as retinal nerve fiber layer birefringence is thought to give a direct measure of microtubule integrity. ${ }^{624}$

The utility of immediate neuroimaging for isolated UDE is not established. While magnetic resonance imaging (MRI) is generally considered the radiological modality of choice for cortical pathological processes, ${ }^{62-627}$ imaging for orbital events is not as clear cut. Computerized tomography (CT) may be the screening examination of choice to rule out orbital disease, ${ }^{628}$ although MR scans may be better in cases of optic nerve pathology. ${ }^{629}$ Orbital neuroimaging (either CT or MRI) can be used in the case of suspected mass effects to rule out various space-occupying lesions, ${ }^{630-634}$ although for some presentations definitive diagnosis may still require tissue biopsy. ${ }^{635}$

$\mathrm{CT}$ and MRI have been studied specifically for optic neuropathies, ${ }^{70,636-638}$ MRI perhaps being the imaging of choice, except in the instance of calcific lesions. ${ }^{639}$ MRI has been extensively studied in "optic neuritis," 324 the ONTT representing an approximate midway point between studies focusing on predictive value for cortical plaques associated with the development of MS $^{640-643}$ and studies using MRI results in terms of visual prognosis and recurrence. ${ }^{577,644-648}$ MRI has also been used to help differentiate optic perineuritis from other forms of optic nerve swelling. ${ }^{649} \mathrm{Three}$-dimensional neuroimaging may yet to prove to be the most useful neuroimaging modality. ${ }^{650}$

Two final clinical caveats on neuroimaging: (1) the diagnostic value of MRI in cases of suspected "optic neuritis" in patients fitting the correct demographics and clinical presentation has not been demonstrated, ${ }^{651,652}$ although these scans continue to be ordered. This practice should be reconsidered. (2) Perhaps neuroimaging would be most useful not as an ancillary test to an initial clinical evaluation but for those cases in which persistence of the UDE is documented (to be discussed further).

In general, B-scan would be the procedure of choice in ruling out masqueraders (ie, optic disk drusen) and MRI for use in suspected orbital lesions or with persistent disk edema. Although commonly used, clinical usefulness of FA remains to be demonstrated. Again, large-scale clinical trials of consecutive UDE cases are required to help answer these important questions.

\section{Other issues surrounding UDE The "disk at risk"}

The majority of multipliers ("risk factors") associated with UDE are those systemic factors related to AION and which were reviewed in the classification framework proposed above. The sole ocular risk factor for the development of AION is the optic disk at risk, a phrase that first appeared in 1993. ${ }^{653}$ That AION was more frequently noted in patients with fellow eyes having small cup-to-disk (c/d) ratios has been conjectured to be related to anatomic crowding at the $\mathrm{ONH} .{ }^{654-657}$ Interestingly enough, up to $70 \%$ of the population manifested a c/d ratio of 0.3 or less ${ }^{658}$ so genetic predisposition must be an important consideration for the development of UDE.

The disk at risk is a physiological configuration of the ONH that consists of a small $\mathrm{c} / \mathrm{d}$ ratio or no cupping at all. With little or no cupping present, as disk edema develops swollen axons of the $\mathrm{ONH}$ are confined to the anatomic restrictions placed on them by the small optic cup. As axonal edema increases, cupping disappears with no more anatomical space in which the edematous axons can swell - and continued fluid accumulation mechanically collapses microtubules - then axoplasmic flow is stifled. However, when cupping is more pronounced, expansion of swollen axons within the potential space present noted for a large $\mathrm{c} / \mathrm{d}$ ratio is not restricted, and mechanical compression on the axons - and, therefore, disruption of axoplasmic flow - is avoided. ${ }^{76}$ In essence, UDE could - and surely does - occur in an $\mathrm{ONH}$ with a $0.7 \mathrm{c} / \mathrm{d}$ ratio, but without resultant morbidity. This anatomical configuration would not necessarily be immune from the possibility of posterior ciliary artery infarction (the etiology of AION); however, because $\mathrm{ONH}$ axons found in this arrangement could expand and then recover without significant disruption of axoplasmic flow, the effects of this process would remain subclinical and unnoticed by patients. 
The relationship to overall ONH size is probably more related to general physiological findings: smaller disks (and therefore smaller scleral tunnels) have smaller $\mathrm{c} / \mathrm{d}$ ratios. However it is the ratio of $\mathrm{ONH}$ cupping to the disk diameter and the potential space in which edematous axons can expand that is the key factor. This anatomical concept should also apply to other presentations of UDE (ie, disk swelling should be more common in "optic neuritis" or "papilledema" patients with small c/d ratios); however the disk at risk has not been reported in other associations for UDE.

\section{Is there such a thing as an "idiopathic" unilateral disk edema?}

If all disk edema is the result of axoplasmic flow stasis, then probably no disk edema case can truly be called idiopathic - by definition a disease of unknown cause. ${ }^{659}$ This descriptor seems unlikely in the sense that it is applied to idiopathic intracranial hypertension, where the cause of the hypertension remains ambiguous. In cases of UDE the etiology (cause - axoplasmic stasis) and pathophysiology (cellular-level events - microtubule dysfunction) are essentially known; however it is the pathogenesis (trigger) that eludes understanding. Perhaps this official-sounding synonym for "I am uncertain of the cause" should be avoided with this nomenclature.

Fortunately, the use of the term idiopathic in acute optic neuropathies has been quite limited. A review of the literature uncovered only two references to "idiopathic optic neuritis" 528,660 and one to "idiopathic unilateral disc edema." 550

Thus, it is the associations with UDE which often remain difficult to discern and undetermined. The current lack of rigorous clinical studies investigating a standardized work-up for these patients prevents more accurate assignment of associations. Again, it may be conjectured that once disease determination reaches the individual pathophenotype level that accurate assessment of clinical associations for UDE may be made. ${ }^{117}$

\section{"Treatment"}

Ideally, any treatment should directly target the pathophysiological mechanism underlying the disease process, halt it, effect a cure that restores normal physiological functioning without untoward side effects to the patients, and prevent recurrence. No specific treatment is currently available for optic disk edema (ie, that directly restores normal axoplasmic flow). Reduction of intracranial pressure has the secondary effect of removing the pressure gradient limiting axoplasmic transport and reversing papilledema. Corticosteroid treatment is effective in restoring physiologic optic nerve integrity in autoimmune-related acute optic neuropathy ${ }^{291}$ by removing the effect (secondary inflammation), but not the cause (primary insult).

"Ischemic" forms of disk edema remain untreatable. ${ }^{248,251,661}$ Although steroids will hasten resolution of the disk edema in ischemic forms of UDE, there is no restoration of visual function if lost. ${ }^{662}$

No large-scale randomized controlled clinical trials have specifically addressed treatment for UDE to date. The ONTT exclusively addressed "optic neuritis," but this study also included retrobulbar forms. ${ }^{324}$ In general, "optic neuritis" cases tend to resolve spontaneously ${ }^{663}$ or show minimal improvement despite treatment with corticosteroids. ${ }^{324,583,664}$ Since these forms do not respond to this treatment, it seems reasonable to suppose that they have little or no inflammatory component and that the disk edema is mediated by other processes.

Although treatment of disk edema lags behind diagnostic capability, subsequent medical work-up of patients who are found to have UDE is often indicated. This is done in order to determine possible systemic associations - many of which require medical treatment ${ }^{57}$ - and should be tailored to the individual cases. So in essence, current "treatment" in UDE is confined mainly to identification of associated conditions.

It should be pointed out that medical treatment of UDE associations has not always prevented recurrences for either "optic neuritis" 325 or "AION." 665 These empirical findings again demonstrate the challenges of assigning causality for disk edema.

Surgical options are really effective only for spaceoccupying lesions. ${ }^{666}$ Unfortunately, optic nerve defenestration was shown to be not only ineffective for ischemic forms of optic nerve swelling, but was actually detrimental to the outcome of the disease in the Ischemic Optic Nerve Decompression Trial. ${ }^{240,667}$

While aspirin was once felt to help reduce the risk of AION development in the fellow eye, ${ }^{668}$ subsequent studies have not confirmed this finding. ${ }^{669}$ Other reported therapies which require more study include: hyperbaric oxygen therapy, ${ }^{670}$ intravitreal bevacizumab $\left(\right.$ Avastin $\left.^{\circledR}\right),{ }^{671}$ intravitreal triamcinolone, ${ }^{672,673}$ and oral antihypertensive medications. ${ }^{674}$

In sum, disk edema itself remains untreatable. Steroids have not been demonstrated to be useful in restoring functional vision via widespread clinical trials, and anecdotal reports of improvements may be confounded by spontaneous recovery. No other medications are currently known to alter the course of UDE. Viable surgical options exist only for 
UDE related to mass effects. Lowering ICP is the only alteration in the IOP/ICP pressure gradient which can reduce papilledema, but this has been observed only as a secondary effect and not a primary intervention.

\section{Management}

\section{Ancillary testing}

Management of patients with UDE involves the determination of whether undiagnosed, systemic associations are present which may have exacerbated the development of the optic neuropathy. It would appear that such testing can be performed over a 2-month period in order to help prevent unnecessary testing. As with any ambiguous clinical presentation, ancillary testing must be judiciously ordered according to the individual presentation and "shotgun approaches" avoided. ${ }^{675,676}$

A two-tiered system of ancillary testing may be useful in managing UDE cases: a first group of tests to be weighed at the initial presentation, and a second group of tests to be considered with persistent disk edema. As most UDE resolves within 2 months, regardless of association, ${ }^{47,300,662}$ the second group of tests might be considered, as beyond this time frame the UDE would be considered "persistent." This appears to be a reasonable time interval given the slowly progressive nature of orbital mass lesions ${ }^{104}$ and occasional vagueness of initial findings. 677

For patients younger than 20 years, UDE in isolation should be considered a viral event until proved otherwise. In a young patient who presents with a recent history of URI and is found to have an isolated UDE but no other neurological symptoms, observation may be the most prudent course of action as the vast majority of these cases are viral syndromes and spontaneously resolve without remark. However, concurrent systemic symptoms could suggest meningitis or encephalitis, and would indicate pediatric referral. For cases of immediate recurrence or non-resolution of UDE after a 2-month time frame, MRI would be indicated to reveal effects of mass lesions or rare possibility of childhood multiple sclerosis. Basic lab work might also be considered at that time.

In the 20- to 40-year-old patient, UDE in isolation should be considered a multiple sclerosis-related event until disproved. No immediate ancillary testing is indicated if the patient reports pain on eye movements. The presence of this pain is nearly pathognomonic for "optic neuritis" and nonemergent referral to neurology is indicated (with MRI ordered only for cases where neurology service requires scanning prior to initial evaluation). In the absence of pain, perimetry could then be of use. If an altitudinal defect is demonstrated, then an ischemic process becomes more likely; however, the absence of an altitudinal defect does not rule out an ischemic event and basic blood panels would be considered in either case. As for the younger adult group, neuroimaging for isolated UDE would be most prudently reserved for persistent cases of disk edema. Although MRI is indicated regarding prognosis for development of MS - the realm of neurology it is not useful for ruling out non-MS related ophthalmic entities $^{652}$ at an initial visit. LHON, ODEMS, ODV, and space-occupying lesions would be associations considered much less frequently for this age group.

In patients older than 40, isolated UDE is most often a hypoperfusion (ischemic) event, and should be considered such until proved otherwise. Hemodynamic inflammatory sources would be the second most likely association in this age group. Initial testing for these patients would be basic hematological laboratory work only. In the absence of any other constitutional symptoms, immediate recurrence or persistence of UDE beyond 2 months would suggest the need for MRI at that time in order to rule out orbital spaceoccupying lesions or other potential sources for the edema. Mass effects and optic perineuritis are rare events to consider in this age group.

For those patients older than 60 years, while the most probable diagnosis remains an ischemic form of hypoperfusive UDE (ie, non-arteritic AION), arteritic forms must be ruled out via blood work (complete blood count [CBC]/erythrocyte sedimentation rate $[\mathrm{ESR}] / \mathrm{C}$-reactive protein [CRP]) for patients in this age range since approximately $20 \%$ of GCA patients with UDE may remain asymptomatic. ${ }^{236}$ It should be emphasized that ESR can be artificially elevated (and give a "false positive" result) by a variety of conditions, including diabetes and anemia. ${ }^{678}$ In such circumstances its result should be interpreted only in context of a concurrent CBC. Its singular use as a screening test should be avoided ${ }^{679}$ and highest specificity (97\%) for GCA is when combined with CRP. ${ }^{680}$

Typically, patients found to have isolated UDE and no known systemic diseases are initially recommended the following hematological laboratory testing: basic metabolic panel (including blood urea nitrogen, creatinine, electrolytes, and glucose), complete blood count with differential, clotting studies (prothrombin time/partial thromboplastin time), erythrocyte sedimentation rate, and serology testing for syphilis..$^{95,320,587}$ Beyond these tests opinion varies widely and may involve assays for autoimmune markers (such as angiotensin converting enzyme, antinuclear antibodies), 
various infectious agents (such as Borelli [Lyme], Bartonella [cat scratch]), and hypercholesterolemia among many others. Ideally, all ancillary testing would be tailored to the clinical findings of the case at hand.

A suggested two-tiered scheme for ancillary testing based on the age of the patient is presented in Figure 3.

\section{When is enough testing enough?}

Because there are overlapping associations, concurrent multipliers and mixed clinical profiles involved in some cases of UDE, when is enough ancillary testing "enough?" For example, if a 55-year-old obese male with UDE in isolation and no constitutional symptoms is found to have undiagnosed diabetes as a result of initial lab work, is that the end of the ancillary testing? There are no clear-cut answers to this clinical dilemma.

It might be suggested that the answer in the above scenario is "yes," with two caveats: (1) that the UDE entirely resolves within the 2-month period of expected resolution, and (2) that there are no immediate recurrences in the same eye or development of UDE in the fellow eye (possibly within 6-12 months of first event). Failure to satisfy those two circumstances probably changes the answer to "no," and further testing would be indicated as likelihood of events move toward rarer associations (ie, these "uncommon things happen uncommonly").

\section{Prognosis}

The overall prognosis for disk edema varies by age. It is better for younger patients (most often an "optic neuritis"), ${ }^{664,681}$ with visual recovery during the first $1-4$ weeks after the event. ${ }^{302,681}$

Spontaneous recovery of visual function is expected in the non-ischemic forms of UDE. ${ }^{585}$ Recurrence of "optic neuritis" occurs in about one-third of adult patients, ${ }^{325,682,683}$ but perhaps only $10 \%-20 \%$ of children. ${ }^{684,685}$ Bilateral involvement accounts for only about $16 \%$ of cases of optic neuritis in adults, ${ }^{682}$ but over half the cases in children. ${ }^{576}$

That intravenous steroids have had little impact on the long-term visual outcomes in cases of optic neuritis ${ }^{324,583}$ would suggest that this particular association is not strictly inflammatory and calls into question the use of the term "neuritis." Those cases that do not respond to steroid therapy should be reconsidered in terms of pathophysiology. For rarer cases, ODV appears to respond well to steroid therapy ${ }^{302,303}$ whereas ODEMS follows the course of the underlying - often infectious - disease. ${ }^{300}$

So, in general, young adult patients presenting with a UDE are more likely to have a recurrence than children, but less likely to develop bilateral disk edema. Prognosis remains good in both groups - both unilateral and bilateral - without treatment. $^{329,578}$

In older adult patients, the prognosis for disk edema most often an ischemic event - is not as positive. ${ }^{686}$ Permanent functional vision loss (ie, worse than 20/40: the cut-off for driver's licensing and ability to read newspaper print) is present over half the cases, ${ }^{249}$ with no significant change occurring in VA 6 months after the event. ${ }^{591,687}$ As mentioned above no treatment is currently available to alter the natural course of this disease.

The risk of a second disk edema event in same eye in older adults is rare, but not unprecedented, and when it does occur is usually associated with further loss of visual function. ${ }^{665}$ Recurrence in the same eye may be more common than expected, but would be difficult for patients with marked visual losses to perceive further subjective degradation in visual function; ${ }^{666}$ and as dead axons can no longer swell, ${ }^{104}$ it may be difficult for clinicians to appreciate. Resolved edema can lead to atrophy, but the reverse is not observed. For "retrospective" consideration of bilateral optic neuropathies (presumably the chronic result of acute events), such observed optic atrophy is more than twice as common as unilateral optic atrophy. ${ }^{688}$ The risk of AION developing in the second eye appears to be in the $40 \%$ range. $234,687,689,690$

Thus, the overall prognosis for isolated UDE remains good for younger patients and guarded for older ones.

\section{Variability in outcomes}

Final visual outcomes following an occurrence of disk edema seem to vary by the age of the patient: in general, younger patients frequently have recovery of visual function; older patients often do not. Variability in outcomes includes observations of both clinical signs (visual acuity losses, visual field defects, color vision desaturation, development of a relative afferent pupillary defect, and/or pallor of the $\mathrm{ONH}$ ) and reported patient symptoms.

Which leads to the inevitable question: if all disk edema is the result of the same biological mechanism, then why is there such variability in outcomes? Why do some cases of disk edema entirely resolve without remark (ie, "optic neuritis" in multiple sclerosis), but other cases result in marked loss of visual function (ie, "AION" with VF/VA loss)? There is no straightforward answer to this question at this time either.

It has been suggested that the development of visual loss depends on the cause, not presence of, axoplasmic flow stasis. ${ }^{93}$ Presumably, the difference is multifactorial and the 
following factors may be inter-related: the degree of axoplasmic flow disruption (how much at once), fast axonal "slowdown" versus complete blockade ${ }^{691}$ (selective transport disruption), longevity (how long the ischemia lasts), unknown physiological factors (are some causes of disk edema "more ischemic" than others?), anatomical variability ("disk at risk": do ONHs with larger c/d ratios have better prognosis?), and the presence of various, concurrent multipliers. All these factors must be considered against a background of genetic susceptibility. The fact that age seems to have some role in prognosis also suggests that aging axons may be more susceptible to the effects of disrupted axoplasmic flow and ischemia/reperfusion injury. Reperfusion injuries result in increased ROS (produced mainly in mitochondria), which can damage neuron structures ${ }^{62}$ and which are known to be more active in older individuals. ${ }^{692-695}$

It remains to be seen if these are indeed the causative mechanisms of variability and which of these factors can be effectively modified in order to favorably alter the course of disk edema.

\section{Future direction}

Challenges for research in the area of disk edema exist because of a lack of animal models for it. There are currently no primate versions of $\mathrm{AION}^{670}$ or even for studying the $\mathrm{ONH}$ region in general. ${ }^{696}$

Stemming axoplasmic flow disruption at the earliest stage would be ideal, but currently restorative therapy is on a distant horizon. Spinal cord research into neuronal repair may provide one avenue of applicability to optic neuropathy. ${ }^{697}$

By corollary, inquiries into cessation of the apoptotic process may also be viable. The role of apoptosis in mammalian CNS development is recognized, but not entirely understood at this time. ${ }^{698}$ Once better comprehended, then perhaps the triggers for apoptosis could be targeted and halted. ${ }^{699}$

Study of the axon microtubules may become a particularly interesting domain of research in this clinical arena. To date, experimental study of the microtubule alterations of optic nerve axons is not a broad one due to the difficulty of studying this physiology in vivo. Animal models suggest microtubules are sensitive to demyelinating, ${ }^{700}$ traumatic, ${ }^{701}$ and anterograde degenerative ${ }^{702}$ processes, but have not been examined to date in the context of optic disk edema. It could be surmised that microtubules collapse under the mechanical, inflammatory or pressure-gradient effects and that pharmacological means of maintaining microtubule integrity might present a future therapeutic option for acute optic neuropathies. Anticancer drugs with direct actions on microtubules exist, but have not been studied in the eye.

Finally, neuroprotective strategies, ${ }^{72,699}$ stem cells, ${ }^{703}$ regeneration and transplantation of optic nerve tissue, ${ }^{697}$ and gene therapy ${ }^{322,704-706}$ have all been suggested or made the subject of preliminary studies for the treatment of various optic neuropathies. However, none of these strategies are yet ready for human clinical trials. Ultimately, treatment involving combined strategies may be needed..$^{218}$

\section{Conclusion}

The recognition and associations of isolated UDE have been widely reported and studied during the past 150 years, but not in a systematic way. Clinicians should continue to realize that its appearance is the result of a final common pathway induced by three separate mechanisms: inflammation, mass effects, and pressure gradient changes across the lamina cribrosa. There is currently no effective treatment for UDE. Rather, management of the condition involves sorting through multitudinous associations to discover undiagnosed systemic diseases, and can be effectively approached by considering the age of the patient. Ancillary testing should be applied in a judicious manner for all cases. Prognosis is clearly better for younger patients than for older ones, with variable outcomes to be expected in the latter. Future research in the area of disk edema may provide more insight to this common clinical finding on the cellular level. It is hoped that this paper will provide a starting place for improved clinical understanding and a framework for future study of this common presentation.

\section{Method of literature search}

A literature review was conducted using the PubMed search engine for the MEDLINE database of the National Library of Medicine (http://www.ncbi.nlm.nih.gov). Multiple searches were performed to review reported cases of UDE and associated conditions from within the 1966-2010 time frame covered by this database. Specific search terms included: disc/ disk edema, optic disc/disk edema, optic neuritis, non-arteritic/ arteritic, anterior ischemic optic neuropathy, papilledema, and papillitis, in addition to the names of many other conditions related to these ophthalmic findings.

References from these articles were also reviewed to discover other relevant publications - including textbooks that were missed during initial searches. Heavy emphasis was placed on Duke-Elder's treatment of this subject in order to identify references prior to the 1966 MEDLINE cut-off. Abstracts from the non-English literature were surveyed for 
this review. Generic internet investigations via Ask, Google and Yahoo search engines were used as final means to locate other references. Due to the nature of this topic, many references are from case reports. Finally, due to the disparate terminology used in these topics and difficultly locating references by exact terminology, the author extends his apologies for probable omissions in this literature review these were entirely unintentional.

\section{Acknowledgment}

The author would like to thank Antonia Varner for her assistance in the preparation of the figures.

\section{Disclosure}

The views expressed in this article are those of the author and do not necessarily represent the positions of the Department of the Army or the Department of Defense. The author reports no proprietary or commercial conflict of interest for any product mentioned or concept discussed in this article.

\section{References}

1. Keeler CR. 150 years since Babbage's ophthalmoscope. Arch Ophthalmol. 1997;115:1456-1457.

2. Ravin JG. Sesquicentennial of the ophthalmoscope. Arch Ophthalmol. 1999;117:1634-1638.

3. Heitz RF. The earliest fundus visualization of living eyes. $\mathrm{Am} \mathrm{J}$ Ophthalmol. 2009;147:500.

4. Duke-Elder S. Neuro-ophthalmology, Vol XII. In: System of Ophthalmology. St Louis: The C.V. Mosby Company; 1971.

5. Graveson GS. Syphilitic optic neuritis. J Neurol Neurosurg Psychiatry. 1950;13:216-224.

6. Eggenberger ER. Inflammatory optic neuropathies. Ophthalmol Clin North Am. 2001;14:73-82.

7. Kawasaki A, Purvin V. Unilateral disc edema following trabeculectomy. J Neuroophthalmol. 1998;18:121-123.

8. Abegg M, Fleischhauer J, Landau K. [Unilateral papilledema after trabeculectomy in a patient with intracranial hypertension]. Klin Monstsbl Augenheikd. 2008;225:441-442. German.

9. Abenza-Abildua MJ, Ruiz-Ares G, Tallon-Barranco A, et al. Unilateral papillitis as the presenting symptom of neurosarcoidosis. Rev Neurol. 2008;46:599-601.

10. Galetta S, Schatz NJ, Glaser JS. Acute sarcoid optic neuropathy with spontaneous recovery. J Clin Neuroophthalmol. 1989;9:27-32.

11. Achiron LR, Strominger M, Witkin N, Primo S. Sarcoid optic neuropathy: a case report. J Am Optom Assn. 1995;66:646-651.

12. Castagna I, Salmeri G, Fama F, et al. Optic nerve granuloma as first sign of systemic sarcoidosis. Ophthalmologica. 1994;208:230-232.

13. Pollock JM, Greiner FG, Crowder JB, et al. Neurosarcoidosis mimicking a malignant optic glioma. J Neuroophthalmol. 2008;28:214-216.

14. Tsuchida H, Takagi M, Miki A, et al. A case of osteopetrosis with acute optic neuropathy. Jpn J Ophthalmol. 2008;52:72-74.

15. Yamaguchi K, Ohnuma I, Takahashi S, et al. Magnetic resonance imaging in acute optic neuropathy by sphenoidal mucocele. Int Ophthalmol. 1997;21:9-11.

16. Voros GM, Sandhu SS, Pandit R. Acute optic neuropathy in patients with Behcet's disease: report of two cases. Ophthalmologica. 2006; 220:400-405.
17. Lee AG, Lin DJ, Kaufman M, et al. Atypical features prompting neuroimaging in acute optic neuropathy in adults. Can J Ophthalmol. 2000;35:325-330.

18. Stedmans.com. Amblyopia, in Stedman's Online Medical Dictionary. http://www.stedmans.com/section.cfm/45. Accessed March 13, 2009.

19. Sadun A. Metabolic optic neuropathies. Semin Ophthalmol. 2002;17: 29-32.

20. Smiddy WE, Green WR. Nutritional amblyopia. A histopathologic study with retrospective clinical correlation. Graefes Arch Clin Exp Ophthalmol. 1987;225:321-324.

21. Sharma A, Crompton J, Selva D. Optic neuropathy: puls/minus. Surv Ophthalmol. 2004;49:429-435.

22. MedicineNet.com. Papilledema, in Webster's New World Medical Dictionary. http://www.medterms.com/script/main/art.asp?articlekey= 4757. Accessed March 15, 2009.

23. Friedman MW. Bilateral papilledema in otherwise well patients. Arch Ophthalmol. 1957;58:59-65.

24. Yaskin JC, Groff RA, Shenkin HA. Severe bilateral papilledema of indeterminate etiology with report of twelve cases. Confin Neurol. 1948/1949;9:108-128.

25. Deschamps R, Dehais C, Heran F, et al. Bilateral papilledema: prospective study of fifty patients. Rev Neurol (Paris). 2008;164:42-46. French.

26. Hauser D, Barzilai N, Zalish M, et al. Bilateral papilledema with retinal hemorrhages in association with cerebral venous sinus thrombosis and paroxysmal nocturnal hemoglobinuria. Am J Ophthalmol. 1996;122: $592-593$.

27. Kling F, Cochener B, Colin J. Bilateral papilledema in young women: two case reports of benign intracranial hypertension? J Fr Ophtalmol. 2002;25:835-839. French.

28. Maloca P, Arnold W, Job O, Schipper I. Bilateral papilledema from a massive intracranial epidermoid cyst. Am J Ophthalmol. 2000;130: 254-256.

29. Pandya VA, Sharma NS, Khong P, Males J. Severe bilateral papilloedema secondary to a large primary brain tumor. Med J Aust. 2008;189:413

30. Parija S, Mohapatra MM, Pattnaik BK. Polycythemia vera presenting with bilateral papilledema: a rare case report. Indian J Ophthalmol. 2008;56:327-329.

31. Quinn AG, Gouws P, Headland S, et al. Obstructive sleep apnea syndrome with bilateral papilledema and vision loss in a 3-year-old child. JAAPOS. 2008;12:197-199.

32. Saenz-Frances F, Calvo-Gonzalez C, Reche-Frutos, et al. Bilateral papilledema secondary to chronic lymphocytic leukaemia. Arch Soc Esp Oftalmol. 2007;82:303-306. Spanish.

33. Smith EG. Unilateral papilledema: its significance and pathologic physiology. Arch Ophthalmol. 1939;21:856-873.

34. Aguilera Perez A, Escamilla Sevilla F, Rodriguez Hurtado FJ. [Unilateral papilledema in pseudotumor cerebri]. Arch Soc Esp Oftalmol. 2001; 76:567-570. Spanish.

35. Chigusa K, Nakano T, Shicishima K, Kitahara K. [Unilateral papilledema in idiopathic intracranial hypertension. A case report]. Neuroophthalmol Japan. 1999;16:311-316. Japanese.

36. Cole A, George NDL. Unilateral papilloedema with transient visual obscurations. Eye. 2006;20:1095-1097.

37. Greenfield DS, Wanichwecharungruang B, Liebmann JM, Ritch R. Pseudotumor cerebri appearing with unilateral papilledema after trabeculectomy. Arch Ophthalmol. 1997;115:423-426.

38. Killer HE, Flammer J. Unilateral papilledema caused by a frontotemporo-parietal arachnoid cyst. Am J Ophthalmol. 2001;132: 589-591.

39. Saito J, Kami M, Taniguichi F, et al. Unilateral papilledema after bone marrow transplantation. Bone Marrow Transplant. 1999;23: 963-965.

40. Sher NA, Wirtschafter J, Shapiro SK, et al. Unilateral papilledema in 'benign' intracranial hypertension (pseudotumor cerebri). JAMA. 1983;250:2346-2347. 
41. Strominger MD, Weiss GB, Mehler MF. Asymptomatic unilateral papilledema in pseudotumor cerebri. J Clin Neuroophthalmol. 1992;12: 238-241.

42. Harada T, Sawamura Y, Ohashi T, et al. Severe optic disc edema without hydrocephalus in neurofibromatosis 2. Jpn J Ophthalmol. 1998;42: 381-384.

43. Huna-Baron R, Landau K, Rosenberg M, et al. Unilateral swollen disc due to increased intracranial pressure. Neurology. 2001;56: 1588-1590.

44. Moster ML, Slavin M, Wall M. Unilateral disk edema in a young woman. Surv Ophthalmol. 1995;39:409-416.

45. Sedwick LA, Burde RM. Unilateral and asymmetric optic disk swelling with intracranial abnormalities. Am J Ophthalmol. 1983;94: 484-487.

46. Chan JW. Optic Nerve Disorders: Diagnosis and management. New York: Springer; 2007.

47. Friedman DI. Papilledema. In: Miller NR, Newman NJ, editors. Walsh and Hoyt's clinical neuro-ophthalmology. Philadelphia, PA: Lippincott Williams \& Wilkins; 2004:237-292.

48. Katz JM, Bruno MK, Winterkorn JMS, Nealon N. The pathogenesis and treatment of optic disc swelling in neurosarcoidosis. Arch Neurol. 2003;60:426-430.

49. Lepore FE. Unilateral and highly asymmetric papilledema in pseudotumor cerebri. Neurology. 1992;42:676-678.

50. Wall M, White WN. Asymmetric papilledema in idiopathic intracranial hypertension: prospective interocular comparison of sensory visual function. Invest Ophthalmol Vis Sci. 1998;39:134-142.

51. Whiting AS, Johnson LN. Papilledema: clinical clues and differential diagnosis. Am Fam Physician. 1992;45:1125-1134.

52. Bruntse E. Unilateral papilloedema in neurosurgical patients. Acta Ophthalmol (Copenh). 1970;48:759-764.

53. Walsh FB, Hoyt WF. Clinical neuro-ophthalmology. Baltimore, MD: Williams \& Wilkins Co, 1969.

54. Optic Neuritis Study Group. The clinical profile of optic neuritis. Experience of the optic neuritis treatment trial. Arch Ophthalmol. 1991;109:1673-1678.

55. Miller GR, Smith JL. Ischemic optic neuropathy. Am J Ophthalmol. 1966;62:103-115.

56. Hayreh SS. Anterior ischaemic optic neuropathy. I. Terminology and pathogenesis. Br J Ophthalmol. 1974;58:955-963.

57. Ba-Abbad RA, Nowilaty SR. Bilateral optic disc swelling as the presenting sign of pheochromocytoma in a child. Medscape J Med. 2008;10:176.

58. Connell P, Brosnahan D, Dunlop A, Reardon W. Bilateral optic disk swelling in the 4q34 deletion syndrome. JAAPOS. 2007;11:516-518.

59. Gilbert ME, Vaphiades M. A woman with unilateral visual loss and bilateral disk edema. Surv Ophthalmol. 2008;53:85-89.

60. Smith RE, Nozik RA. Uveitis: a clinical approach to diagnosis and management. Philadelphia, PA: Lippincott Williams \& Wilkins; 2003.

61. Mackenzie PJ, Cioffi GA. Vascular anatomy of the optic nerve head. Can J Ophthalmol. 2008;43:308-312.

62. Flammer J, Mozaffarieh M. Autoregulation, a balancing act between supply and demand. Can J Ophthalmol. 2008;43:317-321.

63. Grieshaber MC, Mozaffarieh M, Flammer J. What is the link between vascular dysregulation and glaucoma? Surv Ophthalmol. 2007;52: S144-S154.

64. Daemen MARC, van't Veer C, Denecker G, et al. Inhibition of apoptosis induced by ischemia-reperfusion prevents inflammation. J Clin Invest. 1999; 104:541-549.

65. Jander S, Schroeter M, Saleh A. Imaging inflammation in acute brain ischemia. Stroke. 2007;38:642-645.

66. Thurman JM. Triggers of inflammation after renal ischemia/reperfusion. Clin Immunol. 2007;123:7-13.

67. Bartels DB, Dammann O. Inflammatory Perinatal Brain Damage: Observations, Experiments, Explanations. In: Fatemi HS, editor. Neuropsychiatric Disorders and infection. London, UK: Taylor and Francis; 2005:216-221.
68. Mehta JL, Li DY. Inflammation in ischemic heart disease: response to tissue injury or a pathogenetic villain? Cardiovasc Res. 1999;43:291-299.

69. Di Napoli M, Papa F. Response to letter to the editor. Stroke. 2002;33: 2146-2147.

70. Smith MM, Strottmann JM. Imaging of the optic nerve and visual pathways. Semin Ultrasound CT MR. 2001;22:473-487.

71. Forrester JV, Dick AD, McMenamin PG, Lee WR. The eye: basic sciences in practice. Philadelphia, PA: Elsevier Health Sciences; 2002: $1-98$.

72. Mikelberg FS. Assessment of the optic disc to measure neuroprotection. Can J Ophthalmol. 2007;42:421-424.

73. Oster SF, Deiner M, Birgbauer E, Sretavan DW. Ganglion cell axon pathfinding in the retina and optic nerve. Semin Cell Dev Biol. 2004;15: 125-136.

74. Wade N, Swanston M. Light and the Eye. In: Visual perception. London, UK: Taylor and Francis; 2001:85-142.

75. Morgan JE. Circulation and axonal transport in the optic nerve. Eye. 2004;18:1089-1095.

76. Hayreh SS. Reply to letter to the editor. Ophthalmology. 2002;109: 1202-1204.

77. Harvey AR. Combined therapies in the treatment of neurotrauma: polymers, bridges and gene therapy in visual system repair. Neurodegener Dis. 2007;4:300-305.

78. Marcic TS, Belyea DA, Katz B. Neuroprotection in glaucoma: a model for neuroprotection in optic neuropathies. Curr Opin Ophthalmol. 2003; 14:353-356.

79. Levin LA, Louhab A. Apoptosis of retinal ganglion cells in anterior ischemic optic neuropathy. Arch Ophthalmol. 1996;114:488-491.

80. Levin LA. Intrinsic survival mechanisms for retinal ganglion cells. Eur J Ophthalmol. 1999;9:S12-S16.

81. Levin LA. Mechanisms of optic neuropathy. Curr Opin Ophthalmol. 1997;8:9-15.

82. Chierzi S, Fawcett JW. Regeneration in the mammalian optic nerve. Restor Neurol Neuro sci. 2001;19:109-118.

83. Lebrun-Julien F, Di Polo A. Molecular and cell-based approaches for neuroprotection in glaucoma. Optom Vis Sci. 2008;85:417-424.

84. Benowitz LI, Yin Y. Combinatorial treatments for promoting axon regeneration in the CNS: strategies for overcoming inhibitory signals and activating neurons' intrinsic growth state. Dev Neurobiol. 2007;67: 1148-1165.

85. Oster SF, Sretavan DW. Connecting the eye to the brain: the molecular basis of ganglion cell axon guidance. Br J Ophthalmol. 2003;87: 639-645.

86. Martin KRG, Quigley HA. Gene therapy for optic nerve disease. Eye. 2004;18:1049-1055.

87. Levin LA. Axonal loss and neuroprotection in optic neuropathies. Can J Ophthalmol. 2007;42:403-408.

88. Whitcup SM. Clinical trials in neuroprotection. Prog Brain Res. 2008;173:323-335.

89. Tso MO, Hayreh SS. Optic disc edema in raised intracranial pressure. IV. Axoplasmic transport in experimental papilledema. Arch Ophthalmol. 1977;95:1458-1462.

90. Van Stavern GP. Optic disc edema. Semin Neurol. 2007;27:233-243.

91. McLeod D, Marshall JU, Kohner EM. Role of axoplasmic transport in the pathophysiology of ischaemic disc swelling. Br J Ophthalmol. 1980;64:247-261.

92. Fern R, Ransom BR. Ischemic injury of optic nerve axons: the nuts and bolts. Clin Neurosci. 1997;4:246-250.

93. Hayreh MS, Hayreh SS, Baumbach GL. Methyl alcohol poisoning: III. Ocular toxicity. Arch Ophthalmol. 1977;95:1851-1858.

94. Sadun A. Acquired mitochondrial impairment as a cause of optic nerve disease. Trans Am Ophthalmol Soc. 1998;96:881-923.

95. Wall M. Optic disk edema with cotton-wool spots. Surv Ophthalmol. 1995;39:502-508.

96. Pasquale LR. Low intracranial pressure: a tipping point in our understanding of primary open-angle glaucoma? Ophthalmology. 2008;115: 761-762. 
97. Oztas E. Neuronal tracing. Neuroanatomy. 2003;2:2-5.

98. Usui T, Nakazawa J, Osada H. Studies on inhibitory mechanism of microtubule inhibitors. Riken Rev. 2001;41:92-93.

99. Votruba M. Molecular genetic basis of primary inherited optic neuropathies. Eye. 2004;18:1126-1132.

100. Cioffi GA. Ischemic model of optic nerve injury. Trans Am Ophthalmol Soc. 2005;103:592-613.

101. Hollander H, Makaraov F, Stefani FH, Stone J. Evidence of constriction of optic nerve axons at the lamina cribrosa in the normotensive eye in humans and other mammals. Ophthalmic Res. 1995;27:296-309.

102. Schwartzman RJ. Cranial nerve II. In: Differential diagnosis in neurology. Amsterdam, the Netherlands: IOS Press; 2006:264-283.

103. Glaser JS. Topical diagnosis: prechiasmal visual pathway. Part II. The optic nerve. In: Neuro-ophthalmology. Philadelphia, PA: Lippincott Williams \& Wilkins; 1999:118-198.

104. Miller NR, Newman NJ, editors. Walsh and Hoyt's clinical neuroophthalmology: the essentials. Philadelphia, PA: Lippincott Williams \& Wilkins; 1999.

105. Davidson SI. Reported adverse effects of oral contraceptives on the eye. Trans Ophthalmol Soc UK. 1971;91:561-574.

106. Cillino S, Lodato G, Scimemi M. Diabetic papillopathy and pregnancy. Clinical contribution and pathogenetic considerations. J Fr Ophtalmol. 1985;8:459-466. French.

107. Ward SC, Woods DR, Gilstrap LC 3rd, Hauth JC. Pregnancy and acute optic disc edema of juvenile-onset diabetes. Obstet Gynecol. 1984;64:816-818.

108. Beck RW, Gamel JW, Willcourt RJ, Berman G. Acute ischemic optic neuropathy in severe preeclampsia. Am J Ophthalmol. 1980;90 342-346.

109. Schiffman JS, Scherokman B, Tang RA, et al. Evaluation and treatment of papilledema in pregnancy. Comp Ophthalmol Update. 2006; 7 : 187-202.

110. Erkkila H, Raitta C, Iivanainen M, et al. Optic neuritis during lactation. Graefes Arch Clin Exp Ophthalmol. 1985;222:134-138.

111. Retzloff MG, Kobylarz EJ, Eaton C. Optic neuritis with transient total blindness during lactation (1). Obstet Gynecol. 2001;98:902-904.

112. Sanchetee PC, Dhamija RM, Roy AK, Venkataraman S. Peripartum cerebral venous thrombosis. J Assoc Physicians India. 1992;40: 664-666.

113. Leiba H, Glaser JS, Schatz NJ, Siatkowski RM. Postpartum optic neuritis: etiologic and pathophysiologic considerations. J Neuroophthalmol. 2000;20:85-88.

114. Abe T, Abe K, Aoki M, et al. Ocular changes in patients with spinocerebellar degeneration and repeated trinucleotide expansion of spinocerebellar ataxia type 1 gene. Arch Ophthalmol. 1997;115: 231-236.

115. Nakazawa T, Abe T, Hasegawa T, Tamai M. Optic disc edema associated with spinocerebellar degeneration. Ophthalmologica. 1998;212: 281-283.

116. Tsuda H, Jafar-Nejad H, Patel AJ, et al. The AXH domain of ataxin-1 mediates neurodegeneration through its interaction with Gfi-1/ senseless proteins. Cell. 122:633-644.

117. Loscalzo J, Kohane I, Barabasi A-L. Human disease classification in the postgenomic era: a complex systems approach to human pathobiology. Mol Syst Biol. 2007;3:124.

118. Ziman MR, Rodger J, Chen P, et al. Pax genes in development and maturation of the vertebrate visual system: implications for optic nerve regeneration. Histol Histopathol. 2001;16:239-249.

119. Sakai T, Shikishima K, Matsushima M, Kitahara K. Endothelial nitric oxide synthase gene polymorphisms in non-arteritic anterior ischemic optic neuropathy. Graefes Arch Clin Exp Ophthalmol. 2007;245: 288-292.

120. Born M. Natural philosophy of cause and chance. New York: Dover Publication; 1949.

121. Beare NAV, Riva CE, Taylor TE, et al. Changes in optic nerve head blood flow in children with cerebral malaria and acute papilloedema. J Neurol Neurosurg Psychiatry. 2006;77:1288-1290.
122. Hayreh SS. Optic disc edema in raised intracranial pressure. V. Pathogenesis. Arch Ophthalmol. 1977;95:1553-1565.

123. Medzhitov R. Origin and physiological roles of inflammation. Nature. 2008;454:428-435.

124. Shackelford RE, Kaufmann WK, Paules RS. Oxidative stress and cell cycle checkpoint function. Free Radic Biol Med. 2000;28: 1387-1404.

125. Battisti C, Formichi P, Caraioli E, et al. Cell response to oxidative stress induced apoptosis in patients with Leber's hereditary optic neuropathy. J Neurol Neurosurg Psychiatry. 2004;75: 1731-1736.

126. Chevrollier A, Guillet V, Loiseau D, et al. Hereditary optic neuropathies share a common mitochondrial coupling defect. Ann Neurol. 2008;63:794-798.

127. Hoegger MJ, Lieven CJ, Levin LA. Differential production of superoxide by neuronal mitochondria. BMC Neurosci. 2008;9:1-14.

128. Hudson G, Carelli V, Spruijt L. Clinical expression of Leber hereditary optic neuropathy is affected by the mitochondrial DNA-haplogroup background. Am J Hum Genet. 2007;81:228-233.

129. Newman NJ, Biousse V. Hereditary optic neuropathies. Eye. 2004; 18:1144-1160.

130. Yen MY, Wang Ag, Wei YH. Leber's hereditary optic neuropathy: a multifactorial disease. Pro Retin Eye Res. 2006;25:381-396.

131. Yu Wai Man CY, Chnnery PF, Griffiths PG. Optic neuropathies importance of spatial distribution of mitochondria as well as function. Med Hypotheses. 2005;65:1038-1042.

132. MedicineNet.com. Metabolic, in Webster's New World Medical Dictionary. http://www.medterms.com/script/main/art.asp?articlekey= 18074. Accessed May 10, 2009.

133. Chandalia M, Abate N. Metabolic complications of obesity: inflated or inflamed? J Diabetes Complications. 2007;21:128-136.

134. Das UN. Metabolic syndrome X: an inflammatory condition? Curr Hypertens Rep. 2004;6:66-73.

135. Green CR, Nicholson LF. Interrupting the inflammatory cycle in chronic diseases - do gap junctions provide the answer? Cell Biol Int. 2008;32:1578-1583.

136. Hotamisligil GS. Inflammation and metabolic disorders. Nature. 2006;444:860-867.

137. Leonard BE. Metabolic syndrome and schizophrenia: is inflammation the cause? Mod Trends Pharmacopsychiatry. 2009;26:1-11.

138. Nathanson D, Nystrom T. Hypoglycemic pharmacological treatment of type 2 diabetes: targeting the endothelium. Mol Cell Endocrinol. 2009;297:112-126.

139. Sacheck J. Pediatric obesity: an inflammatory condition? JPEN J Parenter Enter Nutr. 2008;32:633-637.

140. Warnberg J, Marcos A. Low-grade inflammation and the metabolic syndrome in children and adolescents. Curr Opin Lipidol. 2008;19: 11-15.

141. Wellen KE, Fucho R, Gregor MF, et al. Coordinated regulation of nutrient and inflammatory responses by STAMP2 is essential for metabolic homeostasis. Cell. 2007;129:537-548.

142. Zimmerman MB, Aeberli I. Dietary determinants of subclinical inflammation, dyslipidemia and components of the metabolic syndrome in overweight children: a review. Int J Obes (Lond). 2008;32: S11-S18.

143. Cameron AJ. Marked papilloedema in pulmonary emphysema. Br J Ophthalmol. 1933;17:167-169.

144. Peter L, Jacob M, Krolak-Salmon P, et al. Prevalence of papilloedema in patients with sleep apnoea syndrome: a prospective study. J Sleep Res. 2007;16:313-318.

145. Abdal H, Pizzimenti JJ, Purvis CC. The eye in sleep apnea syndrome. Sleep Med. 2006;7:97-99.

146. McNab AA. The eye and sleep apnea. Sleep Med Rev. 2007;11: 269-276.

147. Lavie L, Lavie P. Oxidative stress - the culprit of obstructive sleep apnea syndrome. In: Randerath WJ, Sanner BM, Somers VK, editors. Sleep apnea: current diagnosis and treatment, (progress in respiratory research, Vol 35). Basel, Switzerland: Karger; 2006: 97-104. 
148. Mojon DS, Hedges TR 3rd, Ehrenberg B, et al. Association between sleep apnea syndrome and nonarteritic anterior ischemic optic neuropathy. Arch Ophthalmol. 2002;120:601-605.

149. Palombi K, Renard E, Levy P, et al. Non-arteritic anterior ischemic optic neuropathy is nearly systematically associated with obstructive sleep apnoea. Br J Ophthalmol. 2006;90(7):879-882.

150. Purvin VA, Kawasaki A, Yee RD. Papilledema and obstructive sleep apnea syndrome. Arch Ophthalmol. 2000;118:1626-1630.

151. Behbehani R, Mathews MK, Sergott RC, Savino PJ. Nonarteritic anterior ischemic optic neuropathy in patients with sleep apnea while being treated with continuous positive airway pressure. Am J Ophthalmol. 2005;139:518-521.

152. Waller EA, Bendel RE, Kaplan J. Sleep disorders and the eye. Mayo Clin Proc. 2008;83:1251-1261.

153. Berger KI, Goldring RM, Rapoport DM. Obesity hypoventilation syndrome. Semin Respir Crit Care Med. 2009;30:249-251.

154. Powers MA. The obesity hypoventilation syndrome. Respir Care. 2008;53:1723-1730.

155. Berggren L, Fodstad H. Papilledema in the Pickwickian syndrome. Lakartidningen. 1974;71:2029. Swedish.

156. Bloomfield RL, Felts JH, Burkart JM, Cashwell FL. Optic disc edema in a Pickwickian man mimicking hypertensive crisis. J Clin Hypertens. 1987;3:27-30.

157. Reeve P, Harvey G, Seaton D. Papilloedema and respiratory failure. Br Med J (Clin Res Ed). 1985;291:331-332.

158. Rodriguez Vallejo J, Portera A, Descalazo F, et al. Pickwickian syndrome with papilledema. Rev Clin Esp. 1971;122:63-66 Spanish.

159. Newton DA, Bone I. Papilloedema and optic atrophy in chronic hypercapnia. Br J Dis Chest. 1979;73:399-404.

160. Redinger RN. The pathophysiology of obesity and its clinical manifestations. Gastroenterol Hepatol. 2007;3:856-863.

161. Coppack SW. Pro-inflammatory cytokines and adipose tissue. Proc Nutr Soc. 2001;60:349-356.

162. Bosch MM, Barthelemes D, Merz TM, et al. High incidence of optic disc swelling at very high altitudes. Arch Ophthalmol. 2008;126: 644-650.

163. Sharma RC. Ocular manifestations of high altitude. Indian $J$ Ophthalmol. 1981;29:261-262.

164. Bandyopadhyay S, Singh R, Gupta V, Gupta A. Anterior ischaemic optic neuropathy at high altitude. Indian J Ophthalmol. 2002;50: 324-325.

165. Kawasaki A, Purvin V. Recovery of postoperative visual loss following treatment of severe anaemia. Clin Experiment Ophthalmol. 2006;34: 497-499.

166. Ballen PH, Fox MJ, Weissman GS. Ischemic optic neuropathy secondary to intestinal hemorrohage. Ann Ophthalmol. 1985;17: 486-488.

167. Foroozan R. Unilateral pallid optic disc swelling and anemia associated with interferon alpha treatment. J Neuroophthalmol. 2004;24: 98-99.

168. Kacer B, Hattenbach LO, Horle S, et al. Central retinal vein occlusion and nonarteritic ischemic optic neuropathy in 2 patients with mild iron deficiency anemia. Ophthalmologica. 2001;215:128-131.

169. Slavin ML, Barondes MJ. Ischemic optic neuropathy in sickle cell disease. Am J Ophthalmol. 1988;105:212-213.

170. Avery R, Jabs DA, Wingard JR, et al. Optic disc edema after bone marrow transplantation. Possible role of cyclosporine toxicity. Ophthalmology. 1991;98:1294-1301.

171. Gupta SK, Brar VS, Keshavamurthy R, Chalam KV. Aplastic anemia induced disc edema and visual loss in pregnancy: a case report. Cases J. 2008; $1: 322$.

172. Mansour AM, Slati HI, Han DP, et al. Ocular findings in aplastic anemia. Ophthalmologica. 2000;214:399-402.

173. Lana-Peixoto MA, Barbosa A. Anterior ischaemic optic neuropathy in a child with AS haemoglobinopathy and migraine. Br J Ophthalmol. 1998;82:199-200.
174. Jaben SL, Glaser JS, Daily M. Ischemic optic neuropathy following general surgical procedures. J Clin Neuroophthalmol. 1983;3: 239-244.

175. Ahn BY, Choi KD, Choi YJ, et al. Isolated monocular visual loss as an initial manifestation of polycythemia vera. J Neurol Sci. 2007;258: $151-153$.

176. Mayer U. Involvement of the eye in polycythemia vera (Vaquez-Osler disease). Fortschr Med. 1983;101:1047-1049. German.

177. Tonz MS, Rigamonti V, Iliev ME. [Simultaneous, bilateral anterior ischemic optic neuropathy (AION) in polycythemia vera: a case report]. Klin Monatsbl Augenheilkd. 2008;225:504-506. German.

178. Killer HE, Huber A, Portman C, et al. Bilateral non-arteritic anterior ischemic optic neuropathy in a patient with autoimmune thrombocytopenia. Eur J Ophthalmol. 2000;10:180-182.

179. Black RL, Terry JE. Ocular manifestations of thrombotic thrombocytopenic purpura. J Am Optom Assoc. 1991;62:457-461.

180. Gallasch G. Pathogenesis of papilledema in polycythemia. Klin Monatsbl Augenheikld. 1983;182:94-95. German.

181. Helal J Jr, Malerbi FK, Melaragno Filho R. Bilateral central retinal vein occlusion associated with blood hyperviscosity syndrome - case report. Arq Bras Oftalmol. 2005;68:126-128. Portuguese.

182. Wang R, Zhu S, Chen Q. Hemorrheologic analyses of anterior ischemic optic neuropathy. Zhonghua Yan Ke Za Zhi. 1998;34:196-198. Chinese.

183. Wiek J, Krause M, Schade M, et al. Haemorheological parameters in patients with retinal artery occlusion and anterior ischaemic optic neuropathy. Br J Opthalmol. 1992;76:142-145.

184. Avisar R, Creter D, Schoenfeld D, et al. Hyperviscosity syndrome and eye involvement. Harefuah. 1990;118:696-699. Hebrew.

185. Wolf S, Schulte-Strake U, Bertram B, et al. Hemodilution therapy in patients with acute antioer ischemic optic neuropathy. Ophthalmologe. 1993;90:21-26. German.

186. Gaasterland DE, Barranger JA, Rapoport SI, et al. Long-term ocular effects of osmotic modification of the blood-brain barrier in monkeys. I. Clinical examinations; aqueous ascorbate and protein. Invest Ophthalmol Vis Sci. 1983;24:153-158.

187. Stefansson E, Pedersen DB, Jensen PK, et al. Optic nerve oxygenation. Pro Retin Eye Res. 2005;24:307-332.

188. Pedersen DB, Stefansson E, Kiilgaard JF, et al. Optic nerve $\mathrm{pH}$ and $\mathrm{PO}_{2}$ : the effects of carbonic anhydrase inhibition, and metabolic and respiratory acidosis. Acta Ophthalmol Scand. 2006;84: 475-480.

189. Cullinane DC, Jenkins JM, Reddy S, et al. Anterior ischemic optic neuropathy: a complication after systemic inflammatory response syndrome. J Trauma. 2000;48:381-386.

190. Chun DM, Levin DK. Ischemic optic neuropathy after hemorrhage from a cornual ectopic gestation. Am J Obstet Gynecol. 1997;177: $1550-1552$.

191. Silvaswamy L, Van Stavern GP. Ischemic optic neuropathy in a child. Pediatr Neurol. 2007;37:371-372.

192. Suzuki D, Ilsen PF. Hypovolemic ischemic optic neuropathy. Optometry. 2000;71:501-510.

193. Vallejo A, Lorente JA, Bas ML, Gonzalez Y. Blindness due to anterior ischemic optic neuropathy in a burn patient. J Trauma. 2002;53: 139-141.

194. Foroozan R, Buono LM, Savino PJ. Optic disc structure and shockinduced anterior ischemic optic neuropathy. Ophthalmology. 2003; 110:327-331.

195. Foroozan R. Shock-induced anterior ischaemic optic neuropathy after radical prostatectomy. Clin Experiment Ophthalmol. 2004;32: $438-439$

196. Shaked G, Gavriel A, Roy-Sharpira A. Anterior ischemic optic neuropathy after hemorrhagic shock. J Trauma. 1998;44: 923-925.

197. Bermejo-Alvarez MA, Carpintero M, Garcia-Carro G, et al. Ischemic optic neruopathy after lumbar spine surgery. Rev Esp Anestesiol Reanim. 2007;54:621-625. 
198. Shapira OM, Kimmel WA, Lindsey PS, Shahian DM. Anterior ischemic optic neuropathy after open heart operations. Ann Thorac Surg. 1996;61:660-666.

199. Brodsky MC, Wald KJ, Chen S, Weiter JJ. Protracted posttraumatic optic disc swelling. Ophthalmology. 1995;102:1628-1631.

200. Connolly SE, Gordon KB, Horton JC. Salvage of vision after hypotension-induced ischemic optic neuropathy. Am J Ophthalmol. 1994; 117:235-242.

201. Scalea TM. Does it matter how head-injured patients are resuscitated? In: Neurotrauma. New York: Thieme; 2005:3-7.

202. Sharma R, Desai S. Postpartum hemorrhage producing acute ischemic optic neuropathy. Asia Oceania J Obstet Gynaecol. 1993;19: 249-251.

203. Kim SK, Volpe NJ, Stoltz RA. Contemporaneous retinal and optic nerve infarcts, choroidal non-perfusion, and Hollenhorst plaque: are these all embolic events? J Neuroophthalmol. 2006;26:113-116.

204. Lieberman MF, Shahi A, Green WR. Embolic ischemic optic neuropathy. Am J Ophthalmol. 1978;86:206-210.

205. Portnoy SL, Beer PM, Packer AJ, Van Dyk HJ. Embolic anterior ischemic optic neuropathy. J Clin Neuroophthalmol. 1989;9 21-25.

206. Tomsak RL. Ischemic optic neuropathy associated with retinal embolism. Am J Ophthalmol. 1985;99:590-592.

207. Hayreh SS. Acute ischemic disorders of the optic nerve: pathogenesis, clinical manifestations and management. Ophthalmol Clin North Am 1996;9:407-442.

208. Kosmorsky G, Straga J, Knight C, et al. The role of transcranial Doppler in nonarteritic ischemic optic neuropathy. Am J Ophthalmol 1998;126:288-290

209. Kuhli-Hattenbach C, Scharrer I, Luchtenberg M, Hattenbach LO Selective thrombophilia screening of patients with nonarteritic anterior ischemic optic neuropathy. Graefes Arch Clin Exp Ophthalmol. 2009;247:485-490.

210. Nagy V, Steiber Z, Takacs L, et al. Thrombophilic screening for nonarteritic anterior ischemic optic neuropathy. Graefes Arch Clin Exp Ophthalmol. 2006;244:3-8.

211. Feldon SE. Anterior ischemic optic neuropathy: trouble waiting to happen. Ophthalmology. 1999;106:651-653.

212. Salomon O, Huna-Baron R, Kurtz S, et al. Analysis of prothrombotic and vascular risk factors in patients with nonarteritic anterior ischemic optic neuropathy. Ophthalmology. 1999;106:739-742.

213. Acheson JF, Sanders MD. Coagulation abnormalities in ischaemic optic neuropathy. Eye. 1994;8:89-92.

214. Randhawa S, Van Stavern GP. Sticky platelet syndrome and anterior ischaemic optic neuropathy. Clin Experiment Ophthalmol. 2007;35: 779-781.

215. Hayreh SS. Fundus changes in central retinal artery occlusion. Retina 2007;27:276-289.

216. Nasemann JE, Muller M, Pamer S. Systemic perfusion times in nonarteritic anterior ischemic optic neuropathy. Ophthalmologe. 1995;92:79-85. German.

217. Talea L. Optic ischemic neuropathy in mitral disease. Oftalmologia. 1991;35:39-41. Romanian.

218. Robinson RJ, Cecere R, Chiu RC. Binocular blindness following dynamic cardiomyoplasty. J Card Surg. 1996;11:75-78.

219. McCulley TJ, Lam BL, Feuer WJ. Incidence of nonarteritic anterior ischemic optic neuropathy associated with cataract extraction. Ophthalmology. 2001;108:1275-1278.

220. Moster ML. Visual loss after coronary bypass surgery. Surv Ophthalmol. 1998;42:453-457.

221. Sha'aban RI, Asfour WM. Visual loss after coronary artery bypass surgery. Saudi Med J. 2000;21:90-92.

222. Matsui M. Ophthalmological aspects of systemic vasculitis. Nippon Rinsho. 1994;52:2158-2163. Japanese.

223. Kattah JC, Chrousos GA, Katz PA, et al. Anterior ischemic optic neuropathy in Churg-Strauss syndrome. Neurology. 1994;44: 2200-2202.
224. Fowler TJ, Humpston DJ, Nussey AM, Small M. Behcet's syndrome with neurological manifestations in two sisters. $\mathrm{Br}$ Med J. 1968;2: 473-474.

225. Frigui M, Kechaou M, Jemal M, et al. Optic neuropathy in Behcet's disease: a series of 18 patients. Rev Med Interne. 2009;30:486-491. French.

226. Gallinaro C, Robinet-Combes A, Sale Y, et al. Neuropapillitis in Behcet's disease. A case. J Fr Ophtalmol. 1995;18:147-150. French

227. Kansu T, Kirkali P, Kansu E, Zileli T. Optic neuropathy in Behcet's Disease. J Clin Neuroophthalmol. 1989;9:277-280.

228. Nakamura T, Takahashi K, Kishi S. Optic nerve involvement in neuroBehcet's disease. Jpn J Ophthalmol. 2002;46:100-102.

229. Dick GF, Freeman G. Temporal arteritis. JAMA. 1940;114: 645-647.

230. Johnson RH, Harley RD, Horton BT. Arteritis of the temporal vessels associated with loss of vision. Am J Ophthalmol. 1943;26(2): 147-151.

231. Fujishiro M, Handa Y, Machino H, et al. Anterior ischemic optic neuropathy in a case of polyarteritis nodosa. Ryumachi. 1998;38: 831-835. Japanese.

232. Saraux H, Le Hoang P, Laroche L. Anterior and posterior acute ischemic optic neuropathy related to poly-arteritis nodosa. $\mathrm{J} \mathrm{Fr}$ Ophtalmol. 1982;5:55-61. French.

233. Howe L, D’Cruz D, Chopdar A, Hughes G. Anterior ischaemic optic neuropathy in Wegener's granulomatosis. Eur J Ophthalmol. 1995;5: 277-279.

234. Beri M, Klugman MR, Kohler JA, Hayreh SS. Anterior ischemic optic neuropathy. VII. Incidence of bilaterality and various influencing factors. Ophthalmology. 1987;94:1020-1028.

235. Eshaghian J. Controversies regarding giant cell (temporal, cranial) arteritis. Doc Ophthalmol. 1979;47:43-67.

236. Hayreh SS, Podhajsky PA, Zimmerman B. Occult giant cell arteritis: ocular manifestations. Am J Ophthalmol. 1998;125:521-526.

237. Liu GT, Glaser JS, Schatz NJ, Smith JL. Visual morbidity in giant cell arteritis. Clinical characteristics and prognosis for vision. Ophthalmology. 1994;101:1779-1785.

238. Meli B, Landau K, Gloor BP. The bane of giant cell arteritis from an ophthalmological viewpoint. Schweiz Med Wochenschr. 1996;126: 1821-1828. German.

239. Wagener HP, Hollenhorst RW. The ocular lesions of temporal arteritis. Trans Am Ophthalmol Soc. 1957-1958;55:249-269.

240. Ischemic Optic Neuropathy Decompression Trial Research Group. Optic nerve decompression surgery for nonarteritic anterior ischemic optic neuropathy (NAION) is not effective and may be harmful. JAMA. 1995;273:625-632.

241. Preechawat P, Bruce BB, Newman NJ, Biousse V. Anterior ischemic optic neuropathy in patients younger than 50 years. Am JOphthalmol. 2007;144:953-960.

242. Deramo VA, Sergott RC, Augsburger JJ, et al. Ischemic optic neuropathy as the first manifestation of elevated cholesterol levels in young patients. Ophthalmology. 2003;110:1041-1045.

243. Hayreh SS. Ischemic optic neuropathy. Int Ophthalmol. 1978;1: 9-18.

244. Sundaram MBM, Avram D, Cziffer A. Unilateral ischaemic optic neuropathy following systemic hypotension. J R Soc Med. 1986; 79:250.

245. Guyer DR, Miller NR, Auer CL, Fine SL. The risk of cerebrovascular and cardiovascular disease in patients with anterior ischemic optic neuropathy. Arch Ophthalmol. 1985;103:1136-1142.

246. Hayreh SS, Joos KM, Podhajsky PA, Long CR. Systemic diseases associated with nonarteritic anterior ischemic optic neuropathy. Am J Ophthalmol. 1994;118:766-780.

247. Ischemic Optic Neuropathy Decompression Trial Research Group. Characteristics of patients with nonarteritic anterior ischemic optic neuropathy eligible for the Ischemic Optic Neuropathy Decompression Trial. Arch Ophthalmol. 1996;114:1366-1374. 
248. Mathews MK. Nonarteritic anterior ischemic optic neuropathy. Curr Opin Ophthalmol. 2005;16:341-345.

249. Repka MX, Savino PJ, Schatz NJ, Sergott RC. Clinical profile and long-term implications of anterior ischemic optic neuropathy. $\mathrm{Am} \mathrm{J}$ Ophthalmol. 1983;96:478-483.

250. Hayreh SS. Ischaemic optic neuropathy. Indian J Ophthalmol. 2000; 48:171-194.

251. Unsold R. Anterior ischemic optic neuropathy: etiology, pathogenetic mechanisms and therapy. Ophthalmologe. 2008;105:967-982. German.

252. Tesser RA, Niendorf ER, Levin LA. The morphology of an infarct in nonarteritic anterior ischemic optic neuropathy. Ophthalmology. 2003;110:2031-2035.

253. Rupp-Montpetit K, Moody ML. Visual loss as a complication of nonophthalmic surgery: a review of the literature. Insight. 2005;30: $10-17$.

254. Janicki PK, Pai R, Kelly Wright J, et al. Ischemic optic neuropathy after liver transplantation. Anesthesiology. 2001;94:361-363.

255. Tempelhoff R. An optic nerve at risk and a prolonged surgery in the prone position: time to reconsider? Anesthesiology. 2008;108: 775-776.

256. Katz DM, Trobe JD, Cornblath WT, Kline LB. Ischemic optic neuropathy after lumbar spine surgery. Arch Ophthalmol. 1994;112: 925-931.

257. Sadaba LM, Garcia-Layana A, Maldonaldo MJ, Berian JM. Bilateral ischemic optic neuropathy after transurethral prostatic resection: a case report. BMC Ophthalmology. 2006;6:1-5.

258. Stevens WR, Glazer PA, Kelley SD, et al. Ophthalmic complications after spinal surgery. Spine. 1997;22:1319-1324.

259. Fung LW, Ganesan V. Arteriovenous malformations presenting with papilloedema. Dev Med Child Neurol. 2004;46:626-627.

260. Stiebel-Kalish H, Setton A, Nimii Y, et al. Cavernous sinus dural arteriorvenous malformations. Ophthalmology. 2002;109: 1685-1691.

261. Hayreh SS, Podjahsky P, Zimmerman MB. Role of nocturnal arterial hypotension in optic nerve head ischemic disorders. Ophthalmologica. 1999;213:76-96.

262. Hayreh SS. Role of nocturnal arterial hypotension in the development of ocular manifestations of systemic arterial hypertension. Curr Opin Ophthalmol. 1999;10:474-482.

263. Abraham M, Sakhuja N, Sinha S, Rastogi S. Unilateral vision loss after cervical spine surgery. J Neurosurg Anesthesiol. 2003;15: 319-322.

264. Sweeney PJ, Breuer AC, Selhorst JB, et al. Ischemic optic neuropathy: a complication of cardiopulmonary bypass surgery. Neurology. 1982;32:560-562.

265. Elliott WJ. Circadian variation in blood pressure: implications for the elderly patient. Am J Hypertens. 1999;12:43S-49S.

266. Hayreh SS, Zimmerman MB, Podhajsky P, Alward WL. Nocturnal arterial hypotension and its role in optic nerve head and ocular ischemic disorders. Am J Ophthalmol. 1994;117:603-624.

267. Landau K, Winterkorn JM, Mailloux LU, et al. 24-hour blood pressure monitoring in patients with anterior ischemic optic neuropathy. Arch Ophthalmol. 1996;114:570-575.

268. Aydin O, Memisoglu I, Ozturk M, Altintas O. Anterior ischemic optic neuropathy after unilateral radical neck dissection: case report and review. Auris Nasus Larynx. 2008;35:308-313.

269. Gilbert ME, Savino PJ, Sergott RC. Anterior ischaemic optic neuropathy after rotator cuff surgery. Br J Ophthalmol. 2006;90: 248-249.

270. Servilla KS, Groggel GC. Anterior ischemic optic neuropathy as a complication of hemodialysis. Am J Kidney Dis. 1986;8:61-63.

271. Basile C, Addabbo G, Montanaro A. Anterior ischemic optic neuropathy and dialysis: role of hypotension and anemia. J Nephrol. 2001;14:420-423.

272. Chang S, Masaryk TJ, Lee MS. Optic nerve edema: complication of peripheral hemodialysis shunt. Semin Ophthalmol. 2004;19:88-90.
273. Korzets A, Marashek I, Schwartz A, et al. Ischemic optic neuropathy in dialyzed patients: a previously unrecognized manifestation of calcific uremic arteriolopathy. Am J Kidney Dis. 2004;44: e93-e97.

274. Lapeyraque AL, Haddad E, Andre JL, et al. Sudden blindness caused by anterior ischemic optic neuropathy in 5 children on continuous peritoneal dialysis. Am J Kidney Dis. 2003;42:E3-E9.

275. Taban M, Taban M, Lee MS, et al. Prevalence of optic nerve edema in patients on peripheral hemodialysis. Ophthalmology. 2007;114: $1580-1583$.

276. Ellenberger C Jr. Ischemic optic neuropathy as a possible early complication of vascular hypertension. Am J Ophthalmol. 1979;88: 1045-1051.

277. Lin MC, Hsu FM, Sheu SJ. Nonarteritic ischemic optic neuropathy. J Chin Med Assoc. 2007;70:61-64.

278. Smith JL, Goldhammer Y. Hypertensive optic neuropathy. Trans Sect Ophthalmol Am Acad Ophthalmol Otolaryngol. 1975;79: $520-523$.

279. Tso MO, Jampol LM. Pathophysiology of hypertensive retinopathy. Ophthalmology. 1982;89:1132-1145.

280. Ahmetoglu A, Erdol H, Simsek A, et al. Effect of hypertension and candesartan on the blood flow velocity of the extraocular vessels in hypertensive patients. Eur J Ultrasound. 2003;16:177-182.

281. Beevers G, Lip GYH, O'Brien E. ABC of hypertension: the pathophysiology of hypertension. BMJ. 2001;322:912-916.

282. Dimitrova G, Kato S, Fukushima H, Yamashita H. Circulatory parameters in the retrobulbar central retinal artery and vein of patients with diabetes and medically treated systemic hypertension. Graefes Arch Clin Exp Ophthalmol. 2009;247:53-58.

283. Michelson G, Warntges S, Joana H, et al. Effect of NOS inhibition on retinal arterial and capillary circulation in early arterial hypertension. Retina. 2006;26:437-444.

284. Fry CL, Carter JE, Kanter MC, et al. Anterior ischemic optic neuropathy is not associated with carotid artery atherosclerosis. Stroke. 1993;24:539-542.

285. Van Gelder RN. Idiopathic no more: clues to the pathogenesis of Fuchs heterochromic iridocyclitis and glaucomatocyclitic crisis. $\mathrm{Am} \mathrm{J}$ Ophthalmol. 2008;145:834-8340.

286. Autoimmune Disease Research Foundation. Autoimmune disease common cause hypothesis. White paper. December 2005. http://www. cureautoimmunity.org/autoimmune-disease-common-causehypothesis/. Accessed May 18, 2009.

287. Jampol LM, Becker KG. White spot syndromes of the retina: a hypothesis based on the common genetic hypothesis of autoimmune/ inflammatory disease. Am J Ophthalmol. 2003;135:376-379.

288. Dutton JJ, Burde RM, Klingele TG. Autoimmune retrobulbar optic neuritis. Am J Ophthalmol. 1982;94:11-17.

289. Bielory L, Kupersmith MJ, Warren F, et al. Skin biopsies in the evaluation of atypical optic neuropathies. Ocul Immunol Inflamm. 1993;1:231-242.

290. Frohman L, Turbin R, Bielory L, et al. Autoimmune optic neuropathy with anticardiolipin antibody mimicking multiple sclerosis in a child. Am J Ophthalmol. 2003;136:358-360.

291. Kupersmith MJ, Burde RM, Warren FA, et al. Autoimmune optic neuropathy: evaluation and treatment. J Neurol Neurosurg Psychiatry. 1988;51:1381-1386.

292. Coppeto JR, Greco TP. Autoimmune ischemic optic neuropathy associated with positive rheumatoid factor and transient nephrosis. Ann Ophthalmol. 1992;24:434-438.

293. Unsold R. Neuropathies of the optic nerve in inflammatory systemic diseases and vasculitis. A frequently misdiagnosed early symptom. Ophthalmologe. 1994;91:251-262. German.

294. Dollfus H, Hafner R, Hofmann HM, et al. Chronic infantile neurological cutenous and articular/neonatal onset multisystem inflammatory disease syndrome: ocular manifestations in a recently recognized chronic inflammatory disease of childhood. Arch Ophthalmol. 2000;118: 1386-1392. 
295. Lee AG, Warren RW. Optic disc edema in neonatal onset multisystem inflammatory disease (NOMID). J Neuroophthalmol. 1999;19: 180-181.

296. Hirunwiwatkul P, Trobe JD. Optic neuropathy associated with periostitis in relapsing polychondritis. J Neuroophthalmol. 2007;27: 16-21.

297. Cinefro RJ, Frenkel M. Systemic lupus erythematosus presenting as optic neuritis. Ann Ophthalmol. 1978;10:559-563.

298. Eckstein A, Kotter I, Wilhelm H. Atypical optic neuritis in systemic lupus erythematosus (SLE). Klin Monatsbl Augenheilkd. 1995;207: 310-313. German.

299. Gass JD. Diseases of the optic nerve that may simulate macular disease. Trans Am Acad Ophthalmol Otolaryngol. 1977;83:763-770.

300. Lee AG, Brazis PW. Optic disc edema with a macular star and neuroretinitis. In: Clinical pathways in neuro-ophthalmology. New York: Thieme; 2003:63-72.

301. Brazis PW, Lee AG. Optic disk edema with a macular star. Mayo Clin Proc. 1996;71:1162-1166.

302. Hayreh SS. Optic disc vasculitis. Br J Ophthalmol. 1972;56: 652-670.

303. Oh KT, Oh DM, Hayreh SS. Optic disc vasculitis. Graefes Arch Clin Exp Ophthalmol. 2000;238:647-658.

304. Sogg RL. Optic disc vasculitis - a benign but prolonged form of disc edema. West J Med. 1974;120:235.

305. Nagai S, Izumi T. Pulmonary sarcoidosis: population differences and pathophysiology. South Med J. 1995;88:1001-1010.

306. Tozman EC. Sarcoidosis: clinical manifestations, epidemiology, therapy, and pathophysiology. Curr Opin Rheumatol. 1991;3: 155-159.

307. Graham EM, Ellis CJ, Sanders MD, McDonald WI. Optic neuropathy in sarcoidosis. J Neurol Neurosurg Psychiatry. 1986;49: 756-763.

308. Rush JA. Retrobulbar optic neuropathy in sarcoidosis. Ann Ophthalmol. 1980;12:390-394.

309. Frohman LP, Guirgis M, Turbin RE, Bielory L. Sarcoidosis of the anterior visual pathway: 24 new cases. J Neuroophthalmol. 2003;23: 190-197.

310. Koczman JJ, Rouleau J, Gaunt M, et al. Neuro-ophthalmic sarcoidosis: the University of Iowa experience. Semin Ophthalmol. 2008;23: 157-168.

311. Fahy S, Houlihan M, O’Keefe M, Nicholson AJ. Unilateral papilloedema in a 12 year old girl - a surprising diagnosis. Ir Med J. 1997;90:130.

312. Spalton DJ, Sanders MD. Fundus changes in histologically confirmed sarcoidosis. Br J Ophthalmol. 1981;65:348-358.

313. Baumgartner-Parzer SM, Waldhausl WK. The endothelium as a metabolic and endocrine organ: its relation with insulin resistance. Exp Clin Endocrinol Diabetes. 2001;109:S166-S179.

314. Brownlee M. The pathobiology of diabetic complications: a unifying mechanism. Diabetes. 2005;54:1615-1625.

315. Ekberg K, Johansson B. Effect of c-peptide on diabetic neuropathy in patients with type 1 diabetes. Exp Diabetes Res. 2008;2008: 457912.

316. Greene DA, Sima AA, Stevens MJ, et al. Complications: neuropathy pathologenetic considerations. Diabetes Care. 1992;15:1902-1925.

317. Katz B. Disk swelling in an adult diabetic patient. Surv Ophthalmol. 1990;35:158-163.

318. Barr CC, Glaser JS, Blankenship G. Acute disc swelling in juvenile diabetes. Clinical profile and natural history of 12 cases. Arch Ophthalmol. 1980;98:2185-2192.

319. Regillo CD, Brown GC, Savino PJ, et al. Diabetic papillopathy. Patient characteristics and fundus findings. Arch Ophthalmol. 1995;113: 889-895.

320. Vaphiades MS. The disk edema dilemma. Surv Ophthalmol. 2002;47: 183-188.

321. Zerren B, Nilay A, Sukru B. Diabetic papillopathy in type II diabetic patients. Retina. 2002;22:752-758.
322. Guy J, Qi X, Wang H, Hauswirth WW. Adenoviral gene therapy with catalase suppresses experimental optic neuritis. Arch Ophthalmol. 1999;117:1533-1539.

323. Felts PA, Woolston A, Fernando HB, et al. Inflammation and primary demyelination induced by the intraspinal injection of lipopolysaccharide. Brain. 2005;128:1649-1666.

324. Beck RW, Cleary PA. Optic neuritis treatment trial. One-year follow-up results. Arch Ophthalmol. 1993;111:773-775.

325. Optic Neuritis Study Group. Visual function 5 years after optic neuritis. Experience of the optic neuritis treatment trial. Arch Ophthalmol. 1997; 115:1545-1552.

326. Luke C, Dohmen C, Dietlein TS, et al. High-dose intravenous immunoglobulins for treatment of optic neuritis in Guillain-Barre syndrome. Klin Monatsbl Augenheilkd. 2007;224:932-934. German.

327. Jeffery AR, Buncic JR. Pediatric Devic's neuromyelitis optica. Pediatr Ophthalmol Strabismus. 1996;33:223-229.

328. McKee SH, McNaughton FL. Neuromyelitis optica: a report of two cases. Trans Am Ophthalmol Soc. 1937;35:125-135.

329. Smith CH. Optic Neuritis. In: Miller NR, Newman NJ, editors. Walsh and Hoyt's clinical neuro-ophthalmology. Philadelphia, PA: Lippincott Williams \& Wilkins; 2004:293-348.

330. Sweeney VP, Drance SM. Optic neuritis and compressive neuropathy associated with cat scratch disease. Can Med Assoc J. 1970;103: 1380-1381.

331. Vaphiades M, Golnik KC. Optic neuropathy from bacteria. Int Ophthalmol Clin. 2007;47:25-36.

332. Lesser RL, Kornmehl EW, Pachner AR, et al. Neuro-ophthalmologic manifestations of Lyme disease. Ophthalmology. 1990;97: 699-706.

333. Pendse S, Bilyk JR, Lee MS. The ticking time bomb. Surv Ophthalmol. 2006;51:274-279.

334. Martins MG, Matos KT, da Silva MV, de Abreu MT. Ocular manifestations in the acute phase of leptospirosis. Ocul Immunol Inflamm. 1998;6:75-79.

335. Lamb HD. A case of tuberculous papillitis with anatomic findings. Am J Ophthalmol. 1937;20:390-396.

336. Novelli VM, Marshall WC. Optic disc swelling and Mycoplasma pneumoniae. Pediatr Infect Dis. 1984;3:597.

337. Kouyoumdjian GA, Larking TP, Blackburn PJ, Mandava N. Optic disk edema as a presentation of propionibacterium acnes endophthalmitis. Am J Ophthalmol. 2001;132:259-261.

338. Weinstein JM, Lexow SS, Ho P, Spickards A. Acute syphilitic optic neuritis. Arch Ophthalmol. 1981;99:1392-1395.

339. Choi MY, Bae IH, Lee JH, Lee SJ. Aspergillosis presenting as an optic neuritis. Korean J Ophthalmol. 2002;16:119-123.

340. Beck RW, Sergott RC, Barr CC, Annesley WH. Optic disc edema in the presumed ocular histoplasmosis syndrome. Ophthalmology. 1984; 91:183-185.

341. Verma L, Agarwal T, Kulkarni et al. Optic nerve cysticercosis. Arch Ophthalmol. 2002;120:1408-1409.

342. Bird AC, Smith JL, Curvin VT. Nematode optic neuritis. Am J Ophthalmol. 1970;69:72-77.

343. Phillips CI, Mackenzie AD. Toxocara larval papillitis. Br Med J. 1973;1:154-155.

344. Beerlandt N, Dralands L, Vanginderdeuren R, et al. Ocular toxocariasis in a 36-year-old patient: a case report. Bull Soc Belge Ophtalmol. 1995;259:177-181.

345. Banta JT, Davis JL, Lam BL. Presumed toxoplasmosic anterior optic neuropathy. Ocul Immunol Inflamm. 2002;10:201-211.

346. Eckert GU, Melamed J, Menegaz B. Optic nerve changes in ocular toxoplasmosis. Eye. 2007;21:746-751.

347. Shenoy R, Al Hinai A. Presumed ocular toxoplasmosis presenting as papillitis. Indian J Ophthalmol. 2003;51:357-359.

348. Lalitha P, Rathinam S, Banushree K, et al. Ocular involvement associated with an epidemic outbreak of chikungunya virus infection. Am J Ophthalmol. 2007;144:552-556. 
349. Mittal A, Mittal S, Bharati MJ, et al. Optic neuritis associated with chikungunya virus infection in south India. Arch Ophthalmol. 2007; 125:1381-1386.

350. Beral L, Merle H, David T. Ocular complications of dengue fever. Ophthalmology. 2008;115:1100-1101.

351. Miranda de Sousa A, Puccioni-Sohler M, Dias Borges A, et al. Post-dengue neuromyelitis optica: case report of a Japanese-descendent Brazilian child. J Infect Chemother. 2006;12:396-398.

352. Vaispapir V, Blum A, Soboh S, Ashkenazi H. West Nile virus meningoencephalitis with optic neuritis. Arch Intern Med. 2002;162: 606-607.

353. Fodor M, Nagy V, Berta A, et al. Hepatitis C virus presumably associated bilateral consecutive anterior ischemic optic neuropathy. Eur J Ophthalmol. 2008;18:313-315.

354. Brack MJ, Cleland PG, Owen RI, Allen ED. Anterior ischemic optic neuropathy in the acquired immune deficiency syndrome. $\mathrm{Br} \mathrm{Med} J$ (Clin Res Ed). 1987;295:696-697.

355. Srivastava SP, Nema HV. Optic neuritis in measles. Br J Ophthalmol. 1963;47:180-181.

356. Achiron LR. Postinfectious hepatitis B optic neuritis. Optom Vis Sci. 1994;71:53-56.

357. Sugita K, Ando M, Minamitani K, et al. Magnetic resonance imaging in a case of mumps postinfectious encephalitis with asymptomatic optic neuritis. Eur J Pediatr. 1991;150:773-775.

358. Gross JG, Sadun AA, Wiley CA, Freeman WR. Severe visual loss related to isolated peripapillary retinal and optic nerve head cytomegalovirus infection. Am J Ophthalmol. 1989;108:691-698.

359. Karpe G, Wising P. Retinal changes with acute reduction of vision as initial symptoms of infectious mononucleosis. Acta Ophthalmol. 1948;26:19-23.

360. Parry TGW, Laszlo GC. Herpes zoster ophthalmicus - two rare manifestations. Br J Ophthalmol. 1943;27:465-467.

361. Saenz-Frances F, Calvo-Gonzalez C, Jiminez-Santos M, et al. Herpetic optic neuritis associated with herpetic keratitis. Eur J Ophthalmol. 2007; 17:638-641.

362. Stergiou PK, Konstantinou IM, Karagianni TN, et al. Optic neuritis caused by varicella infection in an immunocompetent patient. Pediatr Neurol. 2007;37:138-139.

363. Golnik KC, Newman SA. Anterior ischemic optic neuropathy associated with macrocystic anemia. J Clin Neuroophthalmol. 1990; 10:244-247.

364. Kesler A, Pianka P. Toxic optic neuropathy. Curr Neurol Neurosci Rep. 2003;3:410-414.

365. Neumann-Andersen G. Two ultraviolet radiation-induced episodes of optic neuritis in a patient with antinuclear antibody. Rheumatology (Oxford). 1999;38:1296-1297.

366. Kreissig I. Use of the scleral applicator for I 125 in the treatment of choroidal melanoma (long-term results). Cesk Oftalmol. 1994;50: 135-144. Czech.

367. Parsons JT, Bova JF, Fitzgerald CR, et al. Radiation optic neuropathy after megavoltage external-beam irradiation: analysis of time-dose factors. Int J Radiat Oncol Biol Phys. 1994;30:755-763.

368. Eryilmaz T, Attila H, Batioglu F, Gunalp I. Amiodarone-related optic neuropathy. Jpn J Ophthalmol. 2000;44:565-568.

369. Uebermuth CA, Gerke E. First unilateral, later bilateral optic neuropathy. Amiodarone as the cause? Ophthalmologe. 2002;99: 470-473. German.

370. Cunningham AV, Smith KH. Anterior ischemic optic neuropathy associated with viagra. J Neuroophthalmol. 2001;21:22-25.

371. Egan R, Pomeranz H. Sildenafil (Viagra) associated anterior ischemic optic neuropathy. Arch Ophthalmol. 2000;118:291-292.

372. Pomeranz HD, Smith KH, Hart WM Jr, Egan RA. Sildenafil-associated nonarteritic anterior ischemic optic neuropathy. Ophthalmology. 2002;109:584-587.

373. Fledelius HC. Unilateral papilloedema after hepatitis B vaccination in a migraine patient. A case report including forensic aspects. Acta Ophthalmol Scand. 1999;77:722-724.
374. Stevenson VL, Acheson JF, Ball J, Plant GT. Optic neuritis following measles/rubella vaccination in two 13-year-old children. $\mathrm{Br} J$ Ophthalmol. 1996;80:1110-1111.

375. Cangemi FE, Bergen RL. Optic atrophy following swine flu vaccination. Ann Ophthalmol. 1980;12:857-863.

376. Goldstein NP, Rucker CW, Woltman HW. Neuritis occurring after insect stings. JAMA. 1960;173:1727-1730.

377. Song HS, Wray SH. Bee sting optic neuritis. A case report with visual evoked potentials. J Clin Neuroophthalmol. 1991;11:45-49.

378. Maltzman JS, Lee AG, Miller NR. Optic neuropathy occurring after bee and wasp sting. Ophthalmology. 2000;107:193-195.

379. Kerty E, Vigander K, Flage T, Brinch L. Ocular findings in allogeneic stem cell transplantation without total body irradiation. Ophthalmology. 1999;106:1334-1338.

380. Krumsiek J, Kruger C, Wurster U, Patzold U. Tobacco-alcohol amblyopia. Clinical course in 33 patients. Fortschr Neurol Psychiatr. 1985;53:88-93.

381. Rizzo JF 3rd, Lessell S. Optic neuritis and ischemic optic neuropathy: overlapping clinical profiles. Arch Ophthalmol. 1991;109: 1668-1672.

382. Behbehani R, Sergott RC, Savino PJ. Tobacco-alcohol amblyopia: a maculopathy? Br J Ophthalmol. 2005;89:1543-1544.

383. Wood CA, Buller F. Poisoning by wood alcohol. JAMA. 1904;43: 972-977.

384. Kerrison JB. Optic neuropathies caused by toxins and adverse drug reactions. Ophthalmol Clin North Am. 2004;17:481-488.

385. Martinelli V, Marzoli SB. Non-demyelinating optic neuropathy: clinical entities. Neurol Sci. 2001;22:555-559.

386. Freeman AG. Optic neuropathy and chronic cyanide intoxication: a review. J R Soc Med. 1988;81:103-106.

387. Kohn AN. Ocular toxicity of styrene. Am J Ophthalmol. 1978;85: 569-570.

388. Lloyd MJ, Fraunfelder FW. Drug-induced optic neuropathies. Drugs Today (Barc). 2007;43:827-836

389. Kahana LM. Toxic ocular effects of ethambutol. CMAJ. 1987;137: 213-216.

390. Li J, Tripathi RC, Tripathi BJ. Drug-induced ocular disorders. Drug Saf. 2008;31:127-141

391. Macaluso DC, Shults WT, Fraunfelder FT. Features of amiodaroneinduced optic neuropathy. Am J Ophthalmol. 1999;127:610-612.

392. Purvin V, Kawasaki A, Borruat FX. Optic neuropathy in patients using amiodarone. Arch Ophthalmol. 2006;124:696-701.

393. Laties AM. Vision disorders and phosphodiesterase type 5 inhibitors: a review of the evidence to date. Drug Saf. 2009;32:1-18.

394. Okuma H, Kawamura Y, Ohnuki Y, Takagi S. Optic neuritis caused by interferon-beta administration. Inter Med. 2008;47:1759.

395. Moradian S, Ahmadieh H. Early onset optic neuritis following measles-rubella vaccination. J Ophthalmic Vis Res. 2008;3: 118-122.

396. Burkhard C, Choi M, Wilhelm H. [Optic neuritis as a complication in preventive tetanus-diptheria-poliomyelitis vaccination: a case report]. Klin Monatsbl Augenheilkd. 2001;218:51-54. German.

397. Berger RR, Brook S. Cobra bite: ophthalmic manifestations. Harefuah. 1993;125:265-266, 327-328. Hebrew.

398. Menon V, Tandon R, Sharma T, Gupta A. Optic neuritis following snake bite. Indian J Ophthalmol. 1997;45:236-237.

399. Schwersenski J, Beatty DW. Unusual features in a case of snakebite, presumably due to a Cape cobra (Naja nigricollis). S Afr Med J. 1982; 619:597-598.

400. Wabbels B, Demmler A, Seitz J, et al. Unilateral adult malignant optic nerve glioma. Graefes Arch Clin Exp Ophthalmol. 2004;242: 741-748.

401. Wright JE, McDonald WI, Call NB. Management of optic nerve gliomas. Br J Ophthalmol. 1980;64:545-552.

402. Asproudis IC, Nikas AN, Psilas KG. Paraneoplastic optic neuropathy in a patient with a non-small cell lung carcinoma: a case report. Eur J Ophthalmol. 2005;15:420-423. 
403. Tsai CC, Ho HC, Ka DSC, Hsu WM. Optic neuritis: a rare manifestation of nasopharyngeal carcinoma. Eye. 2002;16: 501-503.

404. Price KM, Cummings TJ, Etter JR, Woodward JA. Ectopic brain in the orbit presenting as disc edema in an adult. Orbit. 2009;28: 74-77.

405. Gass JD, Braunstein RA. Sessile and exophytic capillary angiomas of the juxtapapillary retina and optic nerve head. Arch Ophthalmol. 1980;98:1790-1797.

406. Prenner JL, Sharma A, Ibarra MS, et al. Prolonged premonitory optic disc signs in anterior ischemic optic neuropathy. J Neuroophthalmol. 2002;22:110-112.

407. Iliff WJ, Green WR. Orbital lymphangiomas. Ophthalmology. 1979;86:914-929.

408. Hajji Z, Charif Chefchaouni M, Chaoui Z, et al. Diagnostic difficulties in pigmented tumor of the optic nerve head. A case report. $J \mathrm{Fr}$ Ophtalmol. 2005;28:614-617. French.

409. Liano H, Garcia-Alex C, Lousa M, et al. Bilateral optic nerve meningioma. Case Report. Eur Neurol. 1982;21:102-106.

410. Sarkies NJ. Optic nerve sheath meningioma: diagnostic features and therapeutic alternatives. Eye. 1987;1:597-602.

411. Sibony PA, Krauss HR, Kennerdell JS, et al. Optic nerve sheath meningiomas. Clinical manifestations. Ophthalmology. 1984;91: 1313-1326.

412. Wright JE. Primary optic nerve meningiomas: clinical presentation and management. Trans Sect Ophthalmol Am Acad Ophthalmol Otolaryngol. 1977;83:617-625

413. Wright JE, Call NB, Liaricos S. Primary optic nerve meningiomas. Br J Ophthalmol. 1980;64:553-558.

414. Kattah JC, Chrousos GC, Roberts J, et al. Metastatic prostate cancer to the optic canal. Ophthalmology. 1993;100:1711-1715.

415. Hertle RW, Robb RM. Pinealoblastoma metastatic to the optic nerve. J Clin Neuroophthalmol. 1990;10:95-99.

416. Little HL, Chambers JW, Walsh FB. Unilateral intracranial optic nerve involvement: neurosurgical significance. Arch Ophthalmol. 1965;73: 331-337.

417. Purvin V, Van Dyk HJ. Primary reticulum cell sarcoma of the brain presenting as steroid-responsive optic neuropathy. J Clin Neuroophthalmol. 1984;4:15-23.

418. Miller NR, Green WR. Arachnoid cysts involving a portion of the intraorbital optic nerve. Arch Ophthalmol. 1975;93:1117-1121.

419. Saari M, Mustonen E, Palva A, et al. Arachnoid cyst of the intraorbital portion of the optic nerve with unilateral disc oedema and transient shallowing of the anterior chamber. A case report. Acta Ophthalmol (Copenh). 1977;55:959-964.

420. Gurha N, Sood A, Dhar J, Gupta S. Optic nerve cysticercosis in the optic canal. Acta Ophthalmol Scand. 1999;77:107-109.

421. Lodato G, Affronti A, Mangiavillano C. Acute ischemia of the optic nerve after retrobulbar injection. J Fr Ophtalmol. 1986;9:431-433. French.

422. Martin-Gousset D, Romanet P, Giroud M, et al. Spontaneous hematoma of the intra-orbital optic nerve. J Fr Ophtalmol. 1983;6: 917-920. French.

423. Munteanu G, Munteanu M. Anterior ischemic optic neuropathy secondary to retrobulbar hematoma. Oftalmologia. 2000;52(3):49-52. Romanian.

424. Kennerdell JS, Dresner SC. The nonspecific orbital inflammatory syndromes. Surv Ophthalmol. 1984;29:93-103.

425. Purvin V, Kawasaki A, Jacobson DM. Optic perineuritis: clinical and radiographic features. Arch Ophthalmol. 2001;119:1299-1306.

426. Bettman JW Jr, Daroff RB, Sanders MD, Hoyt WF. Edema of the optic disc in hyperthyroidism without exophthalmos. A fluorescein angiographic study of its resolution. Am J Ophthalmol. 1968;66: 714-719.

427. Agarwal MR, Wagner P, Bedros AA. Unilateral optic nerve edema as the initial sign of recurrence of acute lymphoblastic leukemia. J Pediatr. 2006;148(5):703.
428. Behbehani RS, Vacarezza N, Sergott RC, et al. Isolated optic nerve lymphoma diagnosed by optic nerve biopsy. Am J Ophthalmol. 2005; 139:1128-1130.

429. Bernardczyk-Meller J, Stefanska K. Local involvement of the optic nerve by acute lymphoblastic leukemia. Klin Oczna. 2005;107: 521-524. Polish.

430. Facsko A, Nemeth J. Unilateral infiltration of the optic papilla in chronic lymphatic leukemia. Klin Monatsbl Augenheilkd. 1988;192: 37-39. German.

431. Shibasaki H, Hayasaka S, Noda S, et al. Radiotherapy resolves leukemic involvement of the optic nerves. Ann Ophthalmol. 1992;24: 395-397.

432. Yamamoto N, Kiyosawa M, Kawasaki T, et al. Successfully treated optic nerve infiltration with adult T-cell lymphoma. J Neuroophthalmol. 1994; 14:81-83.

433. Smith JL, Byrne SF, Cambron CR. Syphiloma/gumma of the optic nerve and human immunodeficiency virus seropositivity. J Clin Neuroophthalmol. 1990;10:175-184.

434. Beck AD, Newman NJ, Grossniklaus HE, et al. Optic nerve enlargement and chronic visual loss. Surv Ophthalmol. 1994;38:555-566.

435. Katz B. Disc edema, transient obscurations of vision, and a temporal fossa mass. Surv Ophthalmol. 1991;36:133-139.

436. Lustgarten JS, Mindel JS, Yablonski ME, Friedman AH. An unusual presentation of isolated optic nerve sarcoidosis. JClin Neuroophthalmol. 1983;3:13-18.

437. Mackie RW. Unusual cerebral tuberculoma. Surg Neurol. 1979;11: 7-8.

438. Mack HG, Jakobiec FA. Isolated metastases to the retina or optic nerve. Int Ophthalmol Clin. 1997;37:251-260.

439. Shields JA, Demirci H, Mashayekhi A, Shields CL. Melanocytoma of the optic disc in 115 cases: the 2004 Samuel Johnson memorial lecture, Part 1. Ophthalmology. 2004;111:1739-1746.

440. Erzurum SA, Jampol LM, Territo C, O’Grady R. Primary malignant melanoma of the optic nerve simulating a melanocytoma. Arch Ophthalmol. 1992;110:684-686.

441. Shields JA, Shields CL, Singh AD. Metastatic neoplasms in the optic disc: the 1999 Bjerrum Lecture: part 2. Arch Ophthalmol. 2000;118: 217-224.

442. Backhouse O, Simmons I, Frank A, Cassels-Brown A. Optic nerve breast metastasis mimicking meningioma. Aust $N \mathrm{Z} \mathrm{J}$ Ophthalmol. 1998; 26:247-249.

443. Arsava EM, Cikrikci BI, Mocan G, et al. Postoperative progressive visual loss. Surv Ophthalmol. 2004;49:509-512.

444. Cantillo R, Jain J, Singhakowinta A, Vaitkevicius VK. Blindness as initial manifestation of meningeal carcinomatosis in breast cancer. Cancer. 1979;44:755-757.

445. Moreau R, Boudin G, Auquier L, Le Henaff. Diffuse carcinomatosis of the nervous system with cancerous polyradiculoneuritis and blindness caused by infiltration of the optic nerves. Bull Mem Soc Med Hop Paris. 1952;68:705-710. French.

446. Pillay N, Gilbert JJ, Ebers GC, Brown JD. Internuclear ophthalmoplegia and "optic neuritis": paraneoplastic effects of bronchial carcinoma. Neurology. 1984;34:788-791.

447. Chawla HS, Goodwin JA, Ticho BH, Fiest RM. Orbital and sinus inflammation with secondary optic neuropathy. Ann Ophthalmol. 1991; 23:231-233.

448. Yu-Wai-Man P, Crompton DE, Graham JY, et al. Optic perineuritis as a rare initial presentation of sarcoidosis. Clin Experiment Ophthalmol. 2007;35:682-684.

449. Jacob M, Kodjikian L, Ponceau B, Grange JD. Can optic perineuritis be triggered by Mycobacterium tuberculosis? J Fr Ophtalmol. 2006;29:e7. French.

450. Gordon LK. Diagnostic dilemmas in orbital inflammatory disease. Ocul Immunol Inflamm. 2003;11:3-15.

451. Dutton JJ, Anderson RL. Idiopathic inflammatory perioptic neuritis simulating optic nerve sheath meningioma. Am J Ophthalmol. 1985; 100:424-430. 
452. Glatt HJ. Optic nerve dysfunction in thyroid eye disease: a clinician's perspective. Radiology. 1996;200:26-27.

453. Nakase Y, Higashide T, Yshikawa K, Inoue Y. Color doppler imaging of orbital blood flow in dysthyroid ophthalmopathy. In: Thijssen JM, Fledelius HC Tane S, editors. Ultrasonography in ophthalmology, vol 14 in documenta ophthalmologica proceeding series. Dordrecht, the Netherlands: Kluwer; 1995:216-224.

454. Trobe JD. Optic nerve involvement in dysthryroidism. Ophthalmology. 1981;88:488-492.

455. Hvarfner C, Larsson J. Is optic nerve head swelling of prognostic value in central retinal vein occlusion? Graefes Arch Clin Exp Ophthalmol. 2003;241:463-467.

456. Giuffre G, Randazzo-Papa G, Palumbo C. Central retinal vein occlusion in young people. Doc Ophthalmol. 1992;80:127-132.

457. Galluzzi P, Cerase A, Hadjistilianou T, et al. Retinoblastoma: abnormal gadolinium enhancement of anterior segment of eyes at MR imaging with clinical and histopathological correlation. Radiology. 2003;228: 683-690.

458. Honavar SG, Singh AD, Shields CL, et al. Postenucleation adjuvant therapy in high-risk retinoblastoma. Arch Ophthalmol. 2002;120: 923-931.

459. Schouten-van Meeteren AY, van der Valk P, van der Linden HC, et al. Histopathologic features of retinoblastoma and its relation with in vitro drug resistance measured by means of the MTT assay. Cancer. 2001;92:2933-2940.

460. Schueler AO, Hosten N, Bechrakis NE, et al. High resolution magnetic resonance imaging of retinoblastoma. Br J Ophthalmol. 2003;87: 330-335.

461. Brown GC, Shields JA. Mechanisms of optic disc swelling with diffuse choroidal melanomas: clinicopathologic correlations. Br JOphthalmol. 1982;66:77-82.

462. Volpe NJ. Compressive and infiltrative optic neuropathies. In: Walsh and Hoyt's Clinical Neuro-Ophthalmology. Philadelphia, PA: Lippincott Williams \& Wilkins; 2004:385-430.

463. Barnes C, Sanchez-Dalmau BF, Vela D, Alarcon S. Papilledema as an indicator of POEMS syndrome. Arch Soc Esp Oftalmol. 2008;81: 709-712. Spanish.

464. Bolling JP, Brazis PW. Optic disk swelling with peripheral neuropathy, organomegaly, endocrinopathy, monoclonal gammopathy, and skin changes (POEMS syndrome). Am J Ophthalmol. 1990;109: 503-510.

465. Bourdette DN, Rosenberg NL. Infiltrative orbitopathy, optic disk edema, and POEMS. Neurology. 1984;34:532-533.

466. Schakal A, Cordonnier M, Soupart A. POEMS syndrome and papilledema. Bull Soc Belge Ophtalmol. 1992;243:1-10. French.

467. Nenning H, Meier P, Penk A, Kossling S. Mycotic retrobulbar neuritis. Klin Monatsbl Augenheilkd. 1994;204:244-247. German.

468. Nerkelun S, Kellermann S, Nenning H. Acute blindness caused by fungal infection in chronic myeloid leukemia. Klin Monatsbl Augenheilkd. 1997;211:272-274. German.

469. Hayreh SS, Revie IH, Edwards J. Vasogenic origin of visual field defects and optic nerve changes in glaucoma. Br J Ophthalmol. 1970; $54: 461-472$.

470. Morgan WH, Yu DY, Balaratnasingham C. The role of cerebrospinal fluid pressure in glaucoma pathophysiology: the dark side of the optic disc. J Glaucoma. 2008;17:408-413.

471. Leydhecker W, Akiyama K, Neumann HG. Intraocular pressure in normal human eyes. Klin Monatsbl Augenheilkd. 1958;133:662-670. German.

472. Torbey MT, Geocadin RG, Razumovsky AY, et al. Utility of CSF pressure monitoring to identify idiopathic intracranial hypertension without papilledema in patients with chronic daily headache. Cephalalgia. 2004;24:495-502.

473. Armaly MF, Araki M. Optic nerve circulation and ocular pressure. Invest Ophthalmol. 1975;14:724-731.

474. Ernest JT. Optic disc blood flow. Trans Ophthalmol Soc U K. 1976;96: 348-351.
475. Minckler DS, Bunt AH, Johanson GW. Orthograde and retrograde axoplasmic transport during acute ocular hypertension in the monkey. Invest Ophthalmol Vis Sci. 1977;16:426-441.

476. Minckler DS, Bunt AH. Axoplasmic transport in ocular hypotony and papilledema in the monkey. Arch Ophthalmol. 1977;95:1430-1436.

477. Minckler DS, Tso MO, Zimmerman LE. A light microscopic, autoradiographic study of axoplasmic transport in the optic nerve head during ocular hypotony, increased intraocular pressure, and papilledema. Am J Ophthalmol. 1976;82:741-757.

478. Tuite GF, Chong WK, Evanson J, et al. The effectiveness of papilledema as an indicator of raised intracranial pressure in children with craniosynostosis. Neurosurgery. 1996;38:272-278.

479. Jinkins JR. "Papilledema": neuroradiologic evaluation of optic disk protrusion with dynamic orbital CT. AJR Am J Roentgenol. 1987;149: 793-802.

480. Selhorst JB, Gudeman GK, Butterworth JF 4th, et al. Papilledema after acute head injury. Neurosurgery. 1985;16:357-363.

481. Biousse V, Rucker JUC, Vignal C, et al. Anemia and papilledema. Am J Ophthalmol. 2003;135:437-446.

482. Chari C, Rao NS. Benign intracranial hypertension - its unusual manifestations. Headache. 1991;31:599-600.

483. Kirkham TH, Sanders MD, Sapp GA. Unilateral papilloedema in benign intracranial hypertension. Can J Ophthalmol. 1973;8: 533-538.

484. Monteiro ML, Hoyt WF, Imes RK, Narahara M. [Unilateral papilledema in pseudotumor cerebri]. Arq Neuropsiquiatr. 1985;43: 154-159. Portuguese.

485. Rene R, Aguilar M, Arruga J, Vila F. Pseudotumor cerebri and unilateral papillary edema. Presentation of a case. Neurologia. 1986; 1:257-259. Spanish.

486. To KW, Warren FA. Unilateral papilledema in pseudotumor cerebri. Arch Ophthalmol. 1990;108:644-645.

487. Jantzen JP. Prevention and treatment of intracranial hypertension. Best Pract Res Clin Anaesthesiol. 2007;21:517-538.

488. Stephensen H, Tisell M, Wikkelso C. Intracranial pressure during wakefulness and sleep in 55 adult patients with chronic hydrocephalus. Neurosurgery. 2006;59:326-332.

489. Kalenak JW, Kosmorsky GS, Rockwood EJ. Nonarteritic anterior ischemic optic neuropathy and intraocular pressure. Arch Ophthalmol. 1991;109:660-661.

490. Knox DL, Eagle RC Jr, Green WR. Optic nerve hydropic axonal degeneration and blocked retrograde axoplasmic transport: histopathologic features in human high-pressure secondary glaucoma. Arch Ophthalmol. 2007;125:347-353.

491. Pillunat LE, Anderson DR, Knighton RW, et al. Autoregulation of human optic nerve head circulation in response to increased intraocular pressure. Exp Eye Res. 1997;64:737-744.

492. James CB, Smith SE. The effect of posture on the intraocular pressure and pulsatile ocular blood flow in patients with non-arteritic anterior ischaemic optic neuropathy. Eye. 1991;5:309-314.

493. Stambough JL, Dolan D, Werner R, Godfrey E. Ophthalmologic complications associated with prone positioning in spine surgery. J Am Acad Orthop Surg. 2007;15:156-165.

494. Sanborn GE, Friberg TR, Allen R. Optic nerve dysfunction during gravity inversion: visual field abnormalities. Arch Ophthalmol. 1987; 105:774-776.

495. Schuman JS, Massicotte EC, Connolly S, et al. Increased intraocular pressure and visual field defects in high resistance wind instrument players. Ophthalmology. 2000;107:127-133.

496. Polk JD, Rugaber C, Kohn G, et al. Central retinal artery occlusion by proxy: a cause for sudden blindness in an airline passenger. Aviat Space Environ Med. 2002;73:385-357.

497. Dieckert JP, O'Connor PS, Schacklett DE, et al. Air travel and intraocular gas. Ophthalmology. 1986;93:642-645.

498. Fang IM, Huang JS. Central retinal artery occlusion caused by expansion of intraocular gas at high altitude. Am J Ophthalmol. 2002; 134:603-605. 
499. Hayreh SS. Anterior ischemic optic neuropathy. IV. Occurrence after cataract extraction. Arch Ophthalmol. 1980;98:1410-1416.

500. Garvin JC, Weber PA. Intermediate post cataract extraction ischemic optic neuropathy associated with an intraocular lens implant. $J \mathrm{Am}$ Intraocul Implant Soc. 1982;8:144-147.

501. Spedick MJ, Tomsak RL. Ischemic optic neuropathy following secondary intraocular lens implantation. J Clin Neuroophthalmol. 1984:4:255-257.

502. Lee MS, Rizzo JF 3rd, Lessell S. Neuro-ophthalmologic complications of cataract surgery. Semin Ophthalmol. 2002;17:149-152.

503. McCulley TJ, Lam BL, Feuer WJ. A comparison of risk factors for postoperative and spontaneous nonarteritic anterior ischemic optic neuropathy. J Neuroophthalmol. 2005;15:22-24.

504. McCulley TJ, Lam BL, Feuer WJ. Nonarteritic anterior ischemic optic neuropathy and surgery of the anterior segment: temporal relationship analysis. Am J Ophthalmol. 2003;136(6):1171-1172.

505. Nguyen LT, Taravella MJ, Pelak VS. Determining whether delayed nonarteritic ischemic optic neuropathy associated with cataract extraction is a true entity. J Cataract Refract Surg. 2006;31: 2105-2219.

506. Irak I, Katz BJ, Zabriskie NA, Zimmerman PL. Posner-Schlossman syndrome and nonarteritic anterior ischemic optic neuropathy. J Neuroophthalmol. 2003;23:264-267.

507. Kim R, Van Stavern G, Juzych M. Nonarteritic ischemic optic neuropathy associated with acute glaucoma secondary to PosnerSchlossman syndrome. Arch Ophthalmol. 2003;121:127-128.

508. Tham VM, Cunningham E Jr. Anterior ischaemic optic neuropathy in a patient with HLA-B27 associated anterior uveitis and ankylosing spondylitis. Br J Ophthalmol. 2001;85:756.

509. Nahum Y, Newman H, Kurtz S, Rachmiel R. Nonarteritic anterior ischemic optic neuropathy in a patient with primary acute angle-closure glaucoma. Can J Ophthalmol. 2008;43:723-724.

510. Slavin ML, Margulis M. Anterior ischemic optic neuropathy following acute angle-closure glaucoma. Arch Ophthalmol. 2001; 119:1215.

511. Yip LW, Yong VKY, Hoh ST, Wong HT. Optical coherence tomography of optic disc swelling in acute primary angle-closure glaucoma. Arch Ophthalmol. 2005;123:567-569.

512. Weiss HS, Rubinfeld RS, Anderschat JF. LASIK-associated visual field loss in a glaucoma suspect. Arch Ophthalmol. 2001;119: 774-775.

513. Bradley JC, McCartney DL, Craenen GA. Continuous intraocular pressure recordings during lamellar microkeratotomy of enucleated human eyes. J Cataract Refract Surg. 2007;33:869-872.

514. Lee AG, Kohnen T, Ebner R, et al. Optic neuropathy associated with laser in situ keratomileusis. J Cataract Refract Surg. 2000;26: $1581-1584$

515. Viola F, Morescalchi F, Gandolfo E, Staurenghi G. Ocular hypotony secondary to spontaneously ruptured sclera in choroidal coloboma. Arch Ophthalmol. 2004;122:1549-1551.

516. Altan T, Temel A, Bavbek T, Kazokoglu H. Hypotonic maculopathy after trabeculectomy with postoperative use of 5-fluorouracil. Ophthalmologica. 1994;208:318-320.

517. Costa VP, Wilson RP, Moster MR, et al. Hypotony maculopathy following the use of topical mitomycin $\mathrm{C}$ in glaucoma filtration surgery. Ophthalmic Surg. 1993;24:389-394.

518. Brandonisio TM, Newman TL. Hypotonous maculopathy and normal visual acuity secondary to post-traumatic cyclodialysis cleft Optometry. 2002;73:620-625.

519. Cerio-Ramsden CD, Munoz-Negrete FJ, Rebolleda G. Post-traumatic cyclodialysis cleft treated with transscleral diode laser. Arch Soc Esp Oftalmol. 2009;84:47-50. Spanish.

520. Patte M, Bonicel P, Bacin F. Treatment of post-traumatic cyclodialysis by direct cyclopexy. $J$ Fr Ophtalmol. 2001;24:282-285. French.

521. Roe R, Branco BC, Cunningham ET Jr. Hypotony maculopathy in a patient with HLA-B27-associated uveitis. Ocul Immunol Inflamm. 2008;16:107-108.
522. Schubert HD. Postsurgical hypotony: relationship to fistulization, inflammation, chorioretinal lesions, and the vitreous. Surv Ophthalmol. 1996;41:97-125.

523. Boghen D, Sebag M, Michaud J. Paraneoplastic optic neuritis and encephalomyelitis. Report of a case. Arch Neurol. 1988;45: 353-356.

524. Balcer LJ. Optic neuritis. N Engl J Med. 2006;354:1273-1280.

525. Hayreh SS. Anterior ischaemic optic neuropathy. Differentiation of arteritic from non-arteritic type and its management. Eye. 1990;4: $25-41$.

526. Warner JEA, Lessell S, Rizzo JF, Newman NJ. Does optic disc appearance distinguish ischemic optic neuropathy from optic neuritis? Arch Ophthalmol. 1997;115:1408-1410.

527. Rath EZ, Rehany U, Linn S, Rumelt S. Correlation between optic disc atrophy and aetiology: anterior ischaemic optic neuropathy vs optic neuritis. Eye. 2003;17:1019-1024.

528. Gerling J, Janknecht P, Hansen LL, Kommerell G. Diameter of the optic nerve in idiopathic optic neuritis and in anterior ischemic optic neuropathy. Int Ophthalmol. 1997;21:131-135.

529. Levin LA, Rizzo JF, Lessell S. Neural network differentiation of optic neuritis and anterior ischaemic optic neuropathy. $\mathrm{Br} J$ Ophthalmol. 1996;80:835-839.

530. Shults WT. Ischemic optic neuropathy. Still the ophthalmologist's dilemma. Ophthalmology. 1984;91:1338-1341.

531. Bhatti MT. Optic neuropathy from viruses and spirochetes. Int Ophthalmol Clin. 2007;47:37-66.

532. Sadun AA, Currie JN, Lessell S. Transient visual obscurations with elevated optic discs. Ann Neurol. 1984;16:489-494.

533. Almog Y, Goldstein M. Visual outcome in eyes with asymptomatic optic disc edema. J Neuroophthalmol. 2003;23:204-207.

534. Gordon RN, Burde RM, Slamovits T. Asymptomatic optic disc edema. J Neuroophthalmol. 1997;17:29-32.

535. Hayreh SS, Zimmerman MB. Incipient nonarteritic anterior ischemic optic neuropathy. Ophthalmology. 2007;114:1763-1772.

536. Husted RC, Shock JP. Acute presumed histoplasmosis of the optic nerve head. Br J Ophthalmol. 1975;59:409-412.

537. Browning DJ, Fraser CM. Ocular conditions associated with peripapillary subretinal neovascularization, their relative frequencies, and associated outcomes. Ophthalmology. 2005;112:1054-1061.

538. Gass JD, Braunstein RA. Further observations concerning the diffuse unilateral subacute neuroretinitis syndrome. Arch Ophthalmol. 1983; 101:1689-1397.

539. Matsumoto BT, Adelberg DA, Del Priore LV. Transretinal membrane formation in diffuse unilateral subacute neuroretinitis. Retina. 1995;15: 146-149.

540. Myint K, Sahay R, Mon S, et al. "Worm in the eye": the rationale for treatment of DUSN in south India. Br J Ophthalmol. 2006;90: $1125-1127$.

541. Besada E, Woods A, Caputo M. An uncommon presentation of Bartonella-associated neuroretinitis. Optom Vis Sci. 2002;79: 479-488.

542. Kucukerdonmez C, Akova YA, Yilmaz G. Ocular toxoplasmosis presenting as neuroretinitis: report of two cases. Ocul Immunol Inflamm. 2002;10:229-234.

543. Wade NK, Levi L, Jones MR, et al. Optic disk edema associated with peripapillary serous retinal detachment: an early sign of systemic Bartonella henselae infection. Am J Ophthalmol. 2000;130: 327-334.

544. Foster BS, March GA, Lucarelli MJ, et al. Optic nerve avulsion. Arch Ophthalmol. 1997;115:623-630.

545. Friedman NJ, Kaiser PK. Neuro-ophthalmology. In: Essentials of Ophthalmology. Philadelphia, PA: Elsevier; 2007:47-86.

546. Sawhney R, Kochhar S, Gupta R, et al. Traumatic optic nerve avulsion: role of ultrasonography. Eye. 2003;17:667-670.

547. Mottow LS, Jakobiec FA. Idiopathic inflammatory orbital pseudotumor in childhood. I. Clinical characteristics. Arch Ophthalmol. 1978;96: 1410-1417. 
548. Rootman J, Nugent R. The classification and management of acute orbital pseudotumors. Ophthalmology. 1982;89:1040-1048.

549. Kelman SF. Neuro-ophthalmological Diseases. In: Lee DA, Higginbotham EJ, editors. Clinical guide to comprehensive ophthalmology. New York: Thieme; 1999:491-534.

550. Rosenberg ML, O'Connor P, Carter J. Idiopathic unilateral disc edema. The big blind spot syndrome. J Clin Neuroophthalmol. 1984;4: 181-184.

551. Bhatti MT, Holt JL, Slavin M. An eye for an eye; a tooth for a tooth. Surv Ophthalmol. 2005;50:207-214.

552. Jampol LM, Becker KG. White spot syndromes of the retina: a hypothesis based on the common genetic hypothesis of autoimmune/inflammatory disease. Am J Ophthalmol. 2003;135:376-379.

553. Eilam S. The swollen optic disc with an emphasis on the pediatric patient. J Behav Optom. 2003;14:31-38.

554. McManaway JW 3rd, Bonsall DJ. Management of common pediatric neuro-ophthalmology problems. In: Wright KE, Spiegel $\mathrm{PH}$, Thompson PH, editors. Handbook of pediatric neuro-ophthalmology. New York: Springer; 2006:400-434.

555. Rosenberg MA, Savino PJ, Glaser JS. A clinical analysis of pseudopapilledema. I. Population, laterality, acuity, refractive error, ophthalmoscopic characteristics, and coincident disease. Arch Ophthalmol. 1979;97:65-70.

556. Brodsky MC. Congenital anomalies of the optic disc. In: Miller NR, Newman NJ, editors. Walsh and Hoyt's clinical neuro-ophthalmology. Philadelphia, PA: Lippincott Williams \& Wilkins; 2007:151-196.

557. Kurz-Levin MM, Landau K. A comparison of imaging techniques for diagnosing drusen of the optic nerve head. Arch Ophthalmol. 1999; 117:1045-1049.

558. Bhatt UK. Bilateral optic disc swelling; is a CT scan necessary? Emerg Med J. 2005;22:827-830.

559. Lam BL, Morais CG Jr, Pasol J. Drusen of the optic disc. Curr Neurol Neurosci Rep. 2008;8:404-408.

560. Spencer WH. Drusen of the optic disk and aberrant axoplasmic transport. The XXXIV Edward Jackson memorial lecture. Am J Ophthalmol. 1978;85:1-12.

561. Hepler RS. Letter to the editor. Arch Ophthalmol. 1979;97:1543.

562. Spencer TS, Katz BJ, Weber SW, Digre KB. Progression from anomalous optic discs to visible optic disc drusen. J Neuroophthalmol. 2004;24:297-298.

563. Hordines HM. Optic nerve head drusen causing disc hemorrhage and disc edema. Clin Eye Vis Care. 1999;11:109-114.

564. Liew SC, Mitchell P. Anterior ischaemic optic neuropathy in a patient with optic disc drusen. Aust N Z J Ophthalmol. 1999;27:157-160.

565. Munteanu M, Lehaci C. Acute anterior ischemic optic neuropathy in association with optic nerve drusen. Oftalmologia. 2004;48:16-19. Romanian.

566. Purvin V, King R, Kawasaki A, Yee R. Anterior ischemic optic neuropathy in eyes with optic disc drusen. Arch Ophthalmol. 2004;122: $48-53$.

567. Smith EG. Unilateral papilledema: its significance and pathologic physiology. Arch Ophthalmol. 1939;21:856-873.

568. Hattenhauer MG, Leavitt JA, Hodge DO, et al. Incidence of nonarteritic anterior ischemic optic neuropathy. Am J Ophthalmol. 1997;123: 103-107.

569. Johnson LN, Arnold AC. Incidence of nonarteritic and arteritic anterior ischemic optic neuropathy: population-based study in the state of Missouri and Los Angeles County California. J Neuroophthalmol. 1994;14:38-44.

570. Lim SA, Wong WL, Fu F, et al. The incidence of neuro-ophthalmic diseases in Singapore: a prospective study in public hospitals. Ophthalmic Epidemiol. 2009;16:65-73.

571. Hayreh SS, Zimmerman MB. Nonarteritic anterior ischemic optic neuropathy: refractive error and its relationship to cup/disc ratio. Ophthalmology. 2008;115:2275-2281.

572. Kahana E, Alter M, Feldman S. Optic neuritis in relation to multiple sclerosis. J Neurol. 1976;213:87-95.
573. Kinnunen E. The incidence of optic neuritis and its prognosis for multiple sclerosis. Acta Neurol Scand. 1983;68:371-377.

574. Rodriguez M, Siva A, Cross SA, et al. Optic neuritis: a populationbased study in Olmstead County, Minnesota. Neurology. 1995;45: 244-250.

575. Wikstrom J. The epidemiology of optic neuritis in Finland. Acta Neurol Scand. 1975;52:196-206.

576. Kennedy C, Carroll FD. Optic neuritis in children. AMA Arch Ophthalmol. 1960;63:747-755.

577. Morales DS, Siatkowski RM, Howard CW, Warman R. Optic neuritis in children. J Pediatr Ophthalmol Strabismus. 2000;37: 254-259.

578. Yaqub S, von Hanno T, Stokke A, et al. Acute visual loss in an eightyear-old girl. Tidsskr Nor Laegeforen. 2004;124:189-191. Norwegian.

579. Cakmakli G, Kurne A, Guven A, et al. Childhood optic neuritis: the pediatric neurologist's perspective. Eur J Paediatr Neurol. 2009;13: $452-457$.

580. Chutorian AM, Winterkorn JM, Geffner M. Anterior ischemic optic neuropathy in children: case reports and review of the literature. Pediatr Neurol. 2002;26:358-364.

581. Thomas WJ, Sahney S, Siegel LM. Acute visual loss in a child with autosomal recessive polycystic kidney disease: case report and review of the literature. JAAPOS. 2003;7:217-220.

582. Bradley WG, Whitty WM. Acute optic neuritis: its clinical features and their relation to prognosis for recovery of vision. $J$ Neurol Neurosurg Psychiatry. 1967;30:531-538.

583. Brass SD, Zivadinov R, Bakshi R. Acute demyelinating optic neuritis: a review. Front Biosci. 2008;13:2376-2390.

584. Janaky M, Fulop Z, Palffy A, et al. Non-arteritic ischaemic optic neuropathy (NAION) in patients under 50 years of age. Acta Ophthalmol Scand. 2005;83:499-503.

585. Vighetto A, Krolak-Salmon P. Inflammatory optic neuropathies. Rev Prat. 2001;51:2206-2209. French.

586. Kirkman MA, Korsten A, Leonhardt M, et al. Quality of life in patients with Leber hereditary optic neuropathy. Invest Ophthalmol Vis Sci. 2009;50:3112-3115.

587. Stammen J, Unsold R, Arendt G, et al. Etiology and pathogenetic mechanisms of optic disc swelling with visual loss: an interdisciplinary prospective pilot study of 102 cases. Ophthalmologica. 1999;213: 40-47.

588. Collingnon-Robe NJ, Feke GT, Rizzo JF 3rd. Optic nerve head circulation in nonarteritic anterior ischemic optic neuropathy and optic neuritis. Ophthalmology. 2004;111:1663-1672.

589. Contreras I, Rebolleda G, Noval S. Munoz-Negrete FJ. Optic disc evaluation by optical coherence tomography in nonarteritic anterior ischemic optic neuropathy. Invest Ophthalmol Vis Sci. 2007;48: 4087-4092.

590. Hayreh SS, Zimmerman B. Visual field abnormalities in nonarteritic anterior ischemic optic neuropathy: their pattern and prevalence at initial examination. Arch Ophthalmol. 2005;123:1554-1562.

591. Hayreh SS, Zimmerman MB. Nonarteritic anterior ischemic optic neuropathy: natural history of visual outcome. Ophthalmology. 2008; 115:298-305.

592. Monteiro ML. Anterior ischemic optic neuropathy: a comparison of the optic disc area of patients with the arteritic and non-arteritic forms of the disease and that of normal controls. Arq Bras Oftalmol. 2006;69:805-810.

593. Saito H, Tomidokoro A, Tomita G, et al. Optic disc and peripapillary morphology in unilateral nonarteritic anterior ischemic optic neuropathy and age- and refraction-matched normals. Ophthalmology. 2008;115:1585-1590.

594. Cullen JF. Occult temporal arteritis: a common cause of blindness in old age. Br J Ophthalmol. 1967;51:513-525.

595. Lana-Peixoto MA. The arteritic type of anterior ischemic optic neuropathy. Study of 25 cases. Arq Neuropsiquiatr. 1994;52:343-353. Portuguese. 
596. Ellenberger C Jr. Acute optic neuropathy in older patients. Arch Neurol. 1973;28:182-185.

597. Biousse V. The optic neuropathies. Rev Neurol (Paris). 2005;161: 519-530. French.

598. Fontal MR, Kerrison JB, Garcia R, Oria V. Ischemic optic neuropathy. Semin Neurol. 2007;17:221-232.

599. Griffin JF, Wray SH. Acquired color vision defects in retrobulbar neuritis. Am J Ophthalmol. 1978;86:193-201.

600. Nikoskelainen E, Falck B. Do visual evoked potentials give relevant information to the neuro-ophthalmological examination in optic nerve lesions? Acta Neurol Scand. 1982;66:42-57.

601. Katz B. The dyschromatopsia of optic neuritis: a descriptive analysis of data from the optic neuritis treatment trial. Trans Am Ophthalmol Soc. 1995;93:685-708.

602. Mullen KT, Plant GT. Colour and luminance vision in human optic neuritis. Brain. 1986;109:1-13.

603. Schneck ME, Haegerstrom-Portnoy G. Color vision defect type and spatial vision in the optic neuritis treatment trial. Invest Ophthalmol Vis Sci. 1997;38:2278-2289.

604. Kirkham TH, Coupland SG. Multiple regression analysis of diagnostic predictors in optic nerve disease. Can J Neurol Sci. 1981; 8:67-72.

605. Boldt HC, Byrne SF, DiBernardo C. Echographic evaluation of optic disc drusen. J Clin Neuroophthalmol. 1991;11:85-91.

606. Doro D. Optic neuropathies: diagnostic role of standardized echography. Metab Pediatr Syst Ophthalmol. 1990;13:67-71.

607. Friedman AH, Beckermann B, Gold DH, et al. Drusen of the optic disk. Surv Ophthalmol. 1977;21:375-390.

608. Noel LP, Clarke WN, MacInnes BJ. Detection of drusen of the optic disc in children by B-scan ultrasonography. Can J Ophthalmol. 1983; 18:266-268.

609. Rochels R, Neuhann T. B scan sonography in drusen of the optic disc. Ophthalmologica. 1979;179:330-335. German.

610. Schargus M, Gramer E. Optic disc drusen. Ophthalmologe. 2008;105: 693-710. German.

611. Schroeder W. A-scan-ultrasonography in unilateral optic nerve lesions. Klin Monatsbl Augenheilkd. 1976;169:30-38. German.

612. Kottow M. Differential diagnosis of blurred optic disks by fluorescein angiography. Klin Monatsbl Augenheilkd. 1980;177:696-705. German.

613. Anmarkrud N. The value of fluorescein fundus angiography in evaluating optic disc oedema. Acta Ophthalmol (Copenh). 1977;55: 605-615.

614. Valmaggia C, Speiser P, Bischoff P, Neiderberger H. Indocyanine green versus fluorescein angiography in the differential diagnosis of arteritic and nonarteritic anterior ischemic optic neuropathy. Retina. 1999;19:131-134.

615. Arnold AC, Badr MA, Hepler RS. Fluorescein angiography in nonischemic optic disc edema. Arch Ophthalmol. 1996;114: 293-298.

616. Karaali K, Senol U, Aydin H, et al. Optic neuritis: evaluation with orbital Doppler sonography. Radiology. 2003;226:355-358.

617. Haynes RJ, Manivannan A, Walker S, et al. Imaging of optic nerve head drusen with the scanning laser ophthalmoscope. Br J Ophthalmol. 1997;81:654-657.

618. Johnson LN, Diehl ML, Hamm CW, et al. Differentiating optic disc edema from optic nerve head drusen on optical coherence tomography. Arch Ophthalmol. 2009;127:45-49.

619. Banks MC, Robe-Collignon NJ, Rizzo JF 3rd, Pasquale LR. Scanning laser polarimetry of edematous and atrophic optic nerve heads. Arch Ophthalmol. 2003;121:484-490.

620. Kaufman DI, Lorance RW, Woods M, Wray SH. The pattern electroretinogram. A long-term study in acute optic neuropathy. Neurology. 1988;38:1767-1774.

621. Bobak P, Friedman R, Brigell M, et al. Visual evoked potentials to multiple temporal frequencies. Use in the differential diagnosis of optic neuropathy. Arch Ophthalmol. 1988;106:936-940.
622. Traversi C, Bianciardi G, Tasciotti A, et al. Fractal analysis of fluoroangiographic patterns in anterior ischaemic optic neuropathy and optic neuritis: a pilot study. Clin Experiment Ophthalmol. 2008;36: 323-328.

623. Ho SF, Dhar-Munshi S. Nonarteritic anterior ischaemic optic neuropathy. Curr Opin Ophthalmol. 2008;19:461-467.

624. Zaveri MS, Conger A, Salter A, et al. Retinal imaging by laser polarimetry and optical coherence tomography evidence of axonal degeneration in multiple sclerosis. Arch Neurol. 2008;65:924-928.

625. Allen ED, Byrd SE, Darling CF, et al. The clinical and radiological evaluation of primary brain neoplasms in children, Part II: radiological evaluation. J Natl Med Assoc. 1993;85:546-553.

626. Deck MD, Henschke C, Lee BC, et al. Computed tomography versus magnetic resonance imaging of the brain. A collaborative interinstitutional study. Clin Imaging. 1989;13:2-15.

627. Earnest F 4th, Baker HL Jr, Kispert DB, Laws ER Jr. Magnetic resonance imaging vs computed tomography: advantages and disadvantages. Clin Neurosurg. 1985;32:540-573.

628. Maya MM, Heier LA, Orbital CT. Current use in the MR era. Neuroimaging Clin NAm. 1998;8:651-683.

629. Hopper KD, Sherman JL, Boal DK, Eggli KD. CT and MR imaging of the pediatric orbit. Radiographics. 1992;12:485-503.

630. Curtin HD. Pseudotumor. Radiol Clin North Am. 1987;25:583-599.

631. Duvoisin B, Zanella FE, Sievers KW. Imaging of the normal and pathological orbit. Eur Radiol. 1998;8:175-188.

632. Gyldensted C, Lester J, Fledelius H. Computed tomography of orbital lesions. A radiological study of 144 cases. Neuroradiology. 1977;13:141-150.

633. Kaufman LM, Villablanca JP, Mafee MF. Diagnostic imaging of cystic lesions in the child's orbit. Radiol Clin North Am. 1998;36: 1149-1163, xi.

634. Wenig BM, Mafee MF, Ghosh L. Fibro-osseous, osseous, and cartilaginous lesions of the orbit and paraorbital region. Correlative clinicopathologic and radiographic features, including the diagnostic role of CT and MR imaging. Radiol Clin North Am. 1998;36: 1241-1259, xii.

635. Ben Simon GJ, Annunziata CC, Fink J, et al. Rethinking orbital imaging: establishing guidelines for interpreting orbital imaging studies and evaluating their predictive value in patients with orbital tumors. Ophthalmology. 2005;112:2196-2207.

636. Heran F, Schaison-Cusin M, Williams M, Piekarski JD. Imaging of neuro-ophthalmological emergencies. $J$ Neuroradiol. 2004;31: 291-300.

637. McCrary JA 3rd, Demer JL, Friedman DI, Mawad MM. Computed tomography and magnetic resonance imaging in the diagnosis of inflammatory disease of the optic nerve. Surv Ophthalmol. 1987;31: 352-355.

638. Wiegand W. Neutron spin tomography of the optic nerve in retrobulbar neuritis and optic nerve atrophy: demonstration of inflammation and demyelination. Ophthalmologica. 1988;197:193-1201. German.

639. Wiegand $\mathrm{W}$. The optic nerve pathology in magnetic resonance imaging. Metab Pediatr Syst Ophthalmol. 1990;13:60-66.

640. Kakisu Y, Adachi-Usami E, Kojima S, Hirayama K. Magnetic resonance imaging (MRI) in the diagnosis of optic neuritis and neuropathy. Nippon Ganka Gakkai Zasshi. 1989;93:281-286. Japanese.

641. Kinnunen E, Larsen A, Ketonen L, et al. Evaluation of central nervous system involvement in uncomplicated optic neuritis after prolonged follow-up. Acta Neurol Scand. 1987;76:147-151.

642. Miller DH, Ormerod IE, McDonald WI, et al. The early risk of multiple sclerosis after optic neuritis. J Neurol Neurosurg Psychiatry. 1988;51: $1569-1571$.

643. Ormerod IE, McDonald WI, du Boulay GH, et al. Disseminated lesions at presentation in patients with optic neuritis. $J$ Neurol Neurosurg Psychiatry. 1986;49:124-127.

644. Deschamps R, Gout O, Fontaine B, et al. Acute optic neuritis: clinical and MRI prognotic factors. Study of fifty patients. Rev Neurol (Paris). 2002;158:446-452. French. 
645. Dunker S, Wiegand W. Prognostic value of magnetic resonance imaging in monosymptomatic optic neuritis. Ophthalmology. 1996; 103:1768-1773.

646. Ghezzi A, Martinelli V, Rodegher M, et al. The prognosis of idiopathic optic neuritis. Neurol Sci. 2000;21:S865-S869.

647. Hickman SJ, Toosy AT, Miszkiel KA, et al. Visual recovery following acute optic neuritis - a clinical, electrophysiological and magnetic resonance imaging study. J Neurol. 2004;251:996-1005.

648. Kupersmith MJ, Alban T, Zeiffer B, Lefton D. Contrast-enhanced MRI in acute optic neuritis: relationship to visual performance. Brain. 2002;125:812-822.

649. Fay Am, Kane SA, Kazim M, et al. Magnetic resonance imaging of optic perineuritis. J Neuroophthalmol. 1997;17:247-249.

650. McCaffery S, Simon EM, Fischbein NJ, et al. Three-dimensional high-resolution magnetic resonance imaging of ocular and orbital malignancies. Arch Ophthalmol. 2002;120:747-754.

651. Kaufman DI. Acute optic neuritis. Curr Treat Options Neurol. 1999;1: 44-48.

652. Trobe JD, Sieving PC, Guire KE, Fendrick AM. The impact of the optic neuritis treatment trial on the practices of ophthalmologists and neurologists. Ophthalmology. 1999;106:2047-2053.

653. Burde RM. Optic disk risk factors for nonarteritic ischemic anterior ischemic optic neuropathy. Am J Ophthalmol. 1993;116:759-764.

654. Beck RW, Savino PJ, Repka MX, et al. Optic disc structure in anterior ischemic optic neuropathy. Ophthalmology. 1984;91:1334-1337.

655. Beck RW, Servais GE, Hayreh SS. Anterior ischemic optic neuropathy. IX. Cup-to-disc ratio and its role in pathogenesis. Ophthalmology. 1987;94:1503-1508.

656. Doro S, Lessell S. Cup-disc ratio and ischemic optic neuropathy. Arch Ophthalmol. 1985;103:1143-1144.

657. Feit RH, Tomsak RL, Ellenberger C Jr. Structural factors in the pathogenesis of ischemic optic neuropathy. Am J Ophthalmol. 1984; 98:105-108.

658. Feldon SE. Reply to letter to the editor. Ophthalmology. 1999;106: 2234-2235.

659. Stedmans.com. Idiopathic, in Stedman's Online Medical Dictionary. Source location: http://www.stedmans.com/section.cfm/45. Available at: http://www.stedmans.com/. Accessed June 24, 2009.

660. Lin YC, Yen MY, Hsu WM, et al. Low conversion rate to multiple sclerosis in idiopathic optic neuritis in Taiwan. Jpn J Ophthalmol. 2006;50:170-175.

661. Luneau K, Newman NJ, Biousse V. Ischemic optic neuropathies. Neurologist. 2008;14:341-354.

662. Hayreh SS, Zimmerman MB. Optic disc edema in non-arteritic anterior ischemic optic neuropathy. Graefes Arch Clin Exp Ophthalmol. 2007;247:1107-1121.

663. Hepler RS. Management of optic neuritis. Surv Ophthalmol. 1976;20: 350-357.

664. Purvin V. Optic neuritis. Curr Opin Ophthalmol. 1998;9:3-9.

665. Beck RW, Savino PJ, Schatz NJ, et al. Anterior ischaemic optic neuropathy: recurrent episodes in the same eye. Br J Ophthalmol. 1983;67:705-709.

666. Guy J, Sherwood M, Day AL. Surgical treatment of progressive visual loss in traumatic optic neuropathy. Report of two cases. J Neurosurg. 1989;70:799-801.

667. Ischemic Optic Neuropathy Decompression Trial Research Group. Ischemic Optic Neuropathy Decompression Trial: twenty-four month update. Arch Ophthalmol. 2000;118:793-797.

668. Kupersmith MJ, Frohman L, Sanderson M, et al. Aspirin reduces the incidence of second eye NAION: a retrospective study. J Neuroophthalmol. 1997; 17:250-253.

669. Pomeranz HD. Non-arteritic anterior ischemic optic neuropathy and thromophilia: is there an association? J Lab Clin Med. 2004;143: 141-142.

670. Butler FK Jr, Hagan C, Murphy-Lavoie H. Hyperbaric oxygen therapy and the eye. Undersea Hyperb Med. 2008;35:333-387.
671. Finger PT. Anti-VEGF bevacizumab (Avastin) for radiation optic neuropathy. Am J Ophthalmol. 2007;143:335-338.

672. Shields CL, Demirci H, Marr BP, et al. Intravitreal triamcinolone for acute radiation papillopathy. Retina. 2006;26:537-544.

673. Sohn BJ, Chun BY, Kwon JY. The effect of intravitreal triamcinolone acetonide injection for acute nonarteritic anterior ischemic optic neuropathy. Korean J Ophthalmol. 2009;23:59-61.

674. Karadeniz-Bilgili MY, Ekmekci Y, Koksal A, et al. Effects of hypertension and antihypertensive treatment on retrobulbar circulation detected on Doppler sonography. J Ultrasound Med. 2004;23: 13-17.

675. Dick A, Okada A, Forrester JV. Practical manual of intraocular inflammation. London, UK: Informa Healthcare; 2008.

676. Speicher CE. The right test: a physician's guide to laboratory medicine. Philadelphia, PA: WB Saunders Co; 1998.

677. Vaphiades MS. Disk edema and cranial MRI optic nerve enhancement: how long is too long? Surv Ophthalmol. 2001;46:56-58.

678. Brigden ML. Clinical utility of the erythrocyte sedimentation rate. Am Fam Physician. 1999;60:1443-1450.

679. Sox HC Jr, Liang MH. The erythrocyte sedimentation rate. Guidelines for rational use. Ann Intern Med. 1986;104:515-523.

680. Hayreh SS, Podhajsky PA, Raman R, Zimmerman B. Giant cell arteritis: validity and reliability of various diagnostic criteria. Am J Ophthalmol. 1997;123:392-395.

681. Beck RW, Cleary PA, Backlund JC. The course of visual recovery after optic neuritis. Experience of the Optic Neuritis Treatment Trial. Ophthalmology. 1994;101:1771-1778.

682. Lim SA, Goh KY, Tow S, et al. Optic neuritis in Singapore. Singapore Med J. 2008;49:667-671.

683. Chang YC, Wu WC, Tsai RK. Prognosis of Taiwanese patients with isolated optic neuritis after intravenous methylprednisolone pulse therapy. J Formos Med Assoc. 2007;106:656-663.

684. Kriss A, Francis DA, Cuendet F, et al. Recovery after optic neuritis in childhood. J Neurol Neurosurg Psychiatry. 1988;51:1253-1258.

685. Visudhiphan P, Chiemchanya S, Santadusit S. Optic neuritis in children: recurrence and subsequent development of multiple sclerosis. Pediatr Neurol. 1995;13:293-295.

686. Sawle GV, James CB, Russell RW. The natural history of non-arteritic anterior ischaemic optic neuropathy. J Neurol Neurosurg Psychiatry. 1990;53:830-833.

687. Desai N, Patel MR, Prisant LM, Thomas DA. Nonarteritic ischemic optic neuropathy. J Clin Hypertens (Greenwich). 2005;7:130-133.

688. Menon V, Arya AN, Sharma P, Chhabra VK. An aetiological profile of optic atrophy. Acta Ophthalmol (Copenh). 1992;70:725-729.

689. Boghen DR, Glaser JS. Ischaemic optic neuropathy. The clinical profile and history. Brain. 1975;98:689-708.

690. Cerovski B, Saric B. Risk factors in nonarteritic anterior ischemic optic neuropathy. Acta Med Iugosl. 1990;44:533-540.

691. Radius RL, Anderson DR. Fast axonal transport in early experimental disc edema. Invest Ophthalmol Vis Sci. 1980;19:158-168.

692. Bejma J, Ramires P, Ji LL. Free radical generation and oxidative stress with ageing and exercise: differential effects in the myocardium and liver. Acta Physiol Scand. 2000;169:343-351.

693. Martins Chaves M, Rocha-Viera E, Pereira dos Reis A, et al. Increase of reactive oxygen (ROS) and nitrogen (RNS) species generated by phagocyting granulocytes related to age. Mech Ageing Dev. 2000;119: $1-8$.

694. Miquel J. Nutrition and ageing. Public Health Nutr. 2001;4: 1385-1388.

695. Terman A. Catabolic insufficiency and aging. Ann NY Acad Sci. 2006; 1067:27-36.

696. Osborne NN, Chidlow G, Layton CJ, et al. Optic nerve and neuroprotection strategies. Eye. 2004;18:1075-1084.

697. MacLaren RE. Regeneration and transplantation of the optic nerve: developing a clinical strategy. Br J Ophthalmol. 1998;82: 577-583. 
698. Dori I, Zacharaki T. Apoptotis cell death in the mammalian central nervous system during development and in pathological conditions. J Hellen Vet Med Soc. 2008;59:29-39.

699. Miller NR. Optic nerve protection, regeneration, and repair in the $21 \mathrm{st}$ century: LVII Edward Jackson Memorial Lecture. Am J Ophthalmol. 2001;132:811-818

700. Zhu B, Moore GB, Zwimpfer TJ, et al. Axonal cytoskeleton changes in experimental optic neuritis. Brain Res. 1999;824:204-217.

701. Maxwell WL, Domleo A, McColl G, et al. Post-acute alterations in the axonal cytoskeleton after traumatic axonal injury. J Neurotrauma. 2003;20:151-168.

702. Zhai Q, Wang J, Kim A, et al. Involvement of the ubiquitin-proteasome system in the early stages of Wallerian degeneration. Neuron. 2003; 39:217-225.
703. Quigley HA, Iglesia DS. Stem cells to replace the optic nerve. Eye. 2004;18:1085-1088.

704. Harvey AR, Hu Y, Leaver SG, et al. Gene therapy and transplantation in CNS repair: the visual system. Pro Retin Eye Res. 2006;25: 449-489.

705. Qi X, Hauswirth WW, Guy J. Dual gene therapy with extracellular superoxide dismutase and catalase attenuates experimental optic neuritis. Mol Vis. 2007;13:1-11.

706. Qi X, Sun L, Hauswirth WW, et al. Use of mitochondrial antioxidant defenses for rescue of cells with a Leber hereditary optic neuropathycausing mutation. Arch Ophthalmol. 2007;125:268-272.

\section{Clinical Optometry}

\section{Publish your work in this journal}

Clinical Optometry is an international, peer-reviewed, open access journa publishing original research, basic science, clinical and epidemiologica studies, reviews and evaluations on clinical optometry. All aspects of patient care are addressed within the journal as well as the practice of optometry including economic and business analyses. Basic and clinical research

\section{Dovepress}

papers are published that cover all aspects of optics, refraction and its application to the theory and practice of optometry. The manuscript management system is completely online and includes a very quick and fair peer-review system, which is all easy to use. Visit http://www.dovepress. com/testimonials.php to read real quotes from published authors. 